\begin{tabular}{|c|c|c|}
\hline (ATINER) & $\begin{array}{l}\text { The Athens Journal of } \\
\text { Business \& Economics }\end{array}$ & (ATINER) \\
\hline \multicolumn{3}{|c|}{ Volume 6, Issue 3, July 2020} \\
\hline \multicolumn{3}{|c|}{ Front Pages } \\
\hline \multicolumn{3}{|c|}{$\begin{array}{l}\text { FLORINA SALAGHE, DIMITRA PAPADOVASILAKI, } \\
\text { FEDERICO GUERRERO E JAMES SUNDALI }\end{array}$} \\
\hline \multicolumn{3}{|c|}{$\begin{array}{l}E D U A R D O V . L O E P Z \\
\text { How to Survive with Various Sets of Ethical Values }\end{array}$} \\
\hline \multicolumn{3}{|c|}{$\begin{array}{l}\text { THOMAS DICKSON NDAMSA, GLADYS NJANG } \mathcal{E} \\
\text { FRANCIS MENJO BAYE }\end{array}$} \\
\hline $\begin{array}{l}\text { MICHAEL } \\
\text { Managing } \\
\text { Monetary } \\
\end{array}$ & $\begin{array}{l}\text { N OGUNMUYIWA } \\
\text { flation Problem in Nigeria using th } \\
\text { ach }\end{array}$ & \\
\hline
\end{tabular}




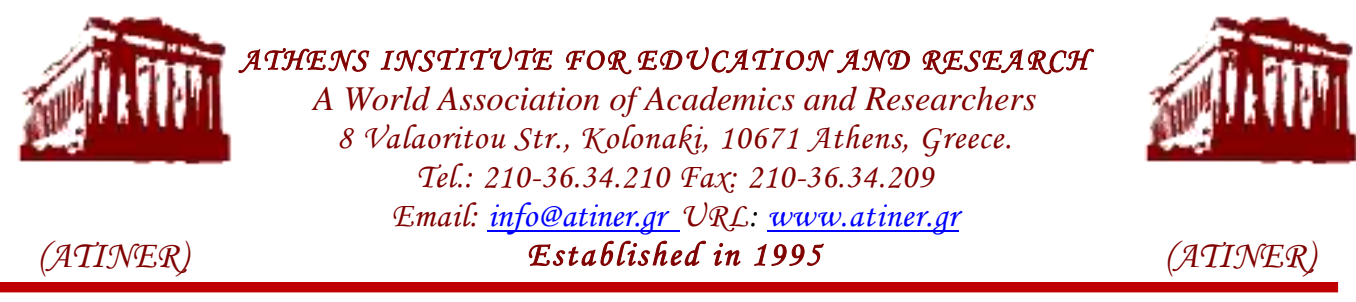

\section{Mission}

ATINER is an Athens-based World Association of Academics and Researchers based in Athens. ATINER is an independent and non-profit Association with a Mission to become a forum where Academics and Researchers from all over the world can meet in Athens, exchange ideas on their research and discuss future developments in their disciplines, as well as engage with professionals from other fields. Athens was chosen because of its long history of academic gatherings, which go back thousands of years to Plato's Academy and Aristotle's Lyceum. Both these historic places are within walking distance from ATINER's downtown offices. Since antiquity, Athens was an open city. In the words of Pericles, Athens"... is open to the world, we never expel a foreigner from learning or seeing". ("Pericles' Funeral Oration", in Thucydides, The History of the Peloponnesian War). It is ATINER's mission to revive the glory of Ancient Athens by inviting the World Academic Community to the city, to learn from each other in an environment of freedom and respect for other people's opinions and beliefs. After all, the free expression of one's opinion formed the basis for the development of democracy, and Athens was its cradle. As it turned out, the Golden Age of Athens was in fact, the Golden Age of the Western Civilization. Education and (Re)searching for the 'truth' are the pillars of any free (democratic) society. This is the reason why Education and Research are the two core words in ATINER's name. 
The Athens Journal of Business \& Economics

ISSN NUMBER: 2241-794X- DOI: 10.30958/ajbe

Volume 6, Issue 3, July 2020

Download the entire issue ( $\underline{\mathrm{PDF}})$

Front Pages

i-viii

Temptation and Retirement Accounts: A Story of Time

173 Inconsistency and Bounded Rationality

Florina Salaghe, Dimitra Papadovasilaki, Federico Guerrero

$\mathcal{E}$ James Sundali

$\underline{\text { How to Survive with Various Sets of Ethical Values }}$

199

Eduardo V. López

Social Welfare Consequences of the Radius of

Employment Decency

Thomas Dickson Ndamsa, Gladys Njang $\mathcal{E}$

Francis Menjo Baye

Managing the Inflation Problem in Nigeria using the

Fisco-Monetary Approach

Michael Segun Ogunmuyiwa 


\section{Athens Journal of Business \& Economics Editorial and Reviewers' Board}

\section{Editors}

- Dr. Christos Sakellariou, Associate Professor of Economics, Nanyang Technological University, Singapore \& Vice President of Administration and Finance, Athens Institute for Education and Research (ATINER).

- Dr. Gregory T. Papanikos, Honorary Professor, University of Stirling, UK \& President of ATINER.

- Dr. Peter Yannopoulos, Professor, Brock University, Canada \& Vice President of Global Communications, ATINER.

- Dr. Julia Underwood, Professor, Azusa Pacific University, USA \& Academic Member, ATINER.

- Dr. Nektarios Tzempelikos, Senior Lecturer in Marketing, Anglia Ruskin University, UK.

\section{Editorial Board}

- Dr. Panagiotis Petratos, Vice President of ICT, ATINER \& Professor, Department of Computer Information Systems, California State University (Stanislaus), USA.

- Dr. Michael P. Malloy, Director, Business \& Law Research Division, ATINER \& Distinguished Professor of Law, University of the Pacific, USA.

- Dr. Peter Koveos, Head, Accounting \& Finance Research Unit, ATINER \& Professor of Finance, Syracuse University, USA.

- Dr. Sharon Claire Bolton, Head, Management Research Unit, ATINER \& Professor, The Management School, University of Stirling, Scotland.

- Dr. Cleopatra Veloutsou, Head, Marketing Research Unit, ATINER \& Professor of Brand Management, University of Glasgow.

- Dr. John Thanopoulos, Professor of International Business (IB), and Dean, Business and Economics, IST

College \& Emeritus Professor, University of Piraeus, Greece.

- Dr. Elyas Elyasiani, Professor Finance and Economics, Fox School of Business and Management, Temple University, USA.

- Dr. Eduardo Segarra, Academic Member, ATINER \& Professor, Department of Agricultural \& Applied Economics, Texas Tech University, USA.

- Dr. Samuel Seaman, Academic Member, ATINER \& Professor of Decision Sciences, Graziadio School of Business and Management, Pepperdine University, USA.

- Dr. Hercules Haralambides, Academic Member, ATINER \& Professor of Maritime Economics and Logistics, Department of Econometrics, Erasmus University Rotterdam, The Netherlands.

- Dr. Steven Dellaportas, Academic Member, ATINER \& Professor of Accounting, RMIT (Royal Melbourne Institute of Technology) University, Australia.

- Dr. George V. Priovolos, Professor, Iona College, USA.

- Dr. George Saridakis, Director of Doctoral Programmes, Kingston Business School, Kingston University \&

Professor of Small Business and Entrepreneurship, Kingston Hill, Kingston Upon Thames, UK.

- Dr. Liliana Costa, Tutor, Department of Communication and Art, University of Aveiro, Portugal.

- Dr. Gilles Chemla, Academic Member, ATINER \& Professor, Imperial College Business School, UK.

- Dr. Nathalie Homlong, Associate Professor, University College Volda, Norway.

- Dr. Tatyana Boikova, Associate Professor, Business Administration Department, Baltic International Academy, Latvia.

- Dr. Zubin Sethna, Associate Professor of Entrepreneurial Marketing, Regent's University London, UK.

- General Managing Editor of all ATINER's Publications: Ms. Afrodete Papanikou

- ICT Managing Editor of all ATINER's Publications: Mr. Kostas Spyropoulos

- Managing Editor of this Journal: Ms Fani Balaska (bio)

\section{Reviewers' Board}

Click Here 


\section{President's Message}

All ATINER's publications including its e-journals are open access without any costs (submission, processing, publishing, open access paid by authors, open access paid by readers etc.) and is independent of presentations at any of the many small events (conferences, symposiums, forums, colloquiums, courses, roundtable discussions) organized by ATINER throughout the year and entail significant costs of participating. The intellectual property rights of the submitting papers remain with the author. Before you submit, please make sure your paper meets the basic academic standards, which includes proper English. Some articles will be selected from the numerous papers that have been presented at the various annual international academic conferences organized by the different divisions and units of the Athens Institute for Education and Research. The plethora of papers presented every year will enable the editorial board of each journal to select the best, and in so doing produce a top-quality academic journal. In addition to papers presented, ATINER will encourage the independent submission of papers to be evaluated for publication.

The current issue is the third of the sixth volume of the Athens Journal of Business \& Economics (AJBE), published by the Business \& Law Division and the Economics Unit of ATINER. 


\section{Athens Institute for Education and Research}

\section{A World Association of Academics and Researchers}

\section{5 ${ }^{\text {th }}$ Annual International Symposium on Economic Theory, Policy and Applications 29-30 June \& 1-2 July 2020, Athens, Greece}

The Economics Unit of ATINER, will hold its $14^{\text {th }}$ Annual International Symposium on Economic Theory, Policy and Applications, 29-30 June \& 1-2 July 2020, Athens, Greece sponsored by the Athens Journal of Business \& Economics. The aim of the conference is to bring together academics and researchers of all areas of economics and other related disciplines. You may participate as panel organizer, presenter of one paper, chair a session or observer. Please submit a proposal using the form available (https:// www.atiner.gr/2020/FORM-ECO.doc).

\section{Academic Members Responsible for the Conference}

- Dr. Gregory T. Papanikos, President, ATINER \& Honorary Professor, University of Stirling, UK.

- Dr. Chris Sakellariou, Head, Economics Unit \& Associate Professor of Economics, Nanvang Technological University, Singapore.

\section{Important Dates}

- Abstract Submission: 15 June 2020

- Acceptance of Abstract: 4 Weeks after Submission

- Submission of Paper: 1 June 2020

\section{Social and Educational Program}

The Social Program Emphasizes the Educational Aspect of the Academic Meetings of Atiner.

- Greek Night Entertainment (This is the official dinner of the conference)

- Athens Sightseeing: Old and New-An Educational Urban Walk

- Social Dinner

- Mycenae Visit

- Exploration of the Aegean Islands

- Delphi Visit

- Ancient Corinth and Cape Sounion

\section{Conference Fees}

Conference fees vary from $400 €$ to $2000 €$

Details can be found at: https://www.atiner.gr/2019fees 


\section{Athens Institute for Education and Research}

A World Association of Academics and Researchers

\section{$8^{\text {th }}$ Annual International Conference on Business, Law \& Economics 3-6 May 2021, Athens, Greece}

The Business, Economics and Law Division (BLRD) of ATINER is organizing its $8^{\text {th }}$ Annual International Conference on Business, Law \& Economics, 3-6 May 2021, Athens, Greece, sponsored by the Athens Journal of Business \& Economics and the Athens Journal of Law. In the past, the six units of BLRD have organized more than 50 annual international conferences on accounting, finance, management, marketing, law and economics. This annual international conference offers an opportunity for cross disciplinary presentations on all aspects of business, law and economics. This annual international conference offers an opportunity for cross disciplinary presentations on all aspects of business, law and economics. Please submit an abstract (email only) to: atiner@atiner.gr, using the abstract submission form (https://www.atiner.gr/2021/FORM-BLE.doc)

\section{Important Dates}

- Abstract Submission: 5 October 2020

- Acceptance of Abstract: 4 Weeks after Submission

- Submission of Paper: 5 April 2021

\section{Academic Member Responsible for the Conference}

- Dr. Gregory T. Papanikos, President, ATINER.

- Dr. Michael P. Malloy, Director, Business, Economics and Law Division, ATINER \& Distinguished Professor \& Scholar, University of the Pacific, USA.

- Dr. David A. Frenkel, LL.D., Head, Law Research Unit, ATINER \& Emeritus Professor, Law Area, Guilford Glazer Faculty of Business and Management, Ben-Gurion University of the Negev, Beer-Sheva, Israel.

\section{Social and Educational Program}

The Social Program Emphasizes the Educational Aspect of the Academic Meetings of Atiner.

- Greek Night Entertainment (This is the official dinner of the conference)

- Athens Sightseeing: Old and New-An Educational Urban Walk

- Social Dinner

- Mycenae Visit

- Exploration of the Aegean Islands

- Delphi Visit

- Ancient Corinth and Cape Sounion

More information can be found here: https://www.atiner.gr/social-program

\section{Conference Fees}

Conference fees vary from $400 €$ to $2000 €$

Details can be found at: https://www.atiner.gr/2019fees 





\title{
Temptation and Retirement Accounts: A Story of Time Inconsistency and Bounded Rationality
}

\author{
By Florina Salaghe*, Dimitra Papadovasilaki ${ }^{ \pm}$, Federico Guerrero* \\ \& James Sundali
}

\begin{abstract}
Research shows that American workers tend to under-save for retirement. Some studies attribute the under-saving to a lack of self-control and time inconsistent saving plans, while others use the bounded rationality of retirement account holders as an alternative explanation. In this paper we ran a laboratory experiment using subjects residing in the U.S., to further explore the relationship between under-saving for retirement and investment decisions, in the context of an asset allocation game. A theoretical framework that can account for both time inconsistent (investment) behavior and boundedly rational (investment) choices is given by the "absent-minded driver's (AMD) paradox" decision-making game of Piccione and Rubinstein (1997). The main idea of the AMD paradox is that (investment) plans that were optimal at the planning stage may no longer be optimal at decision time even if no new information and/or no change in preferences occurs. The contribution of this paper is twofold. First, our paper is the first to apply the AMD paradox to the study of asset allocation decisions in the laboratory. Second, we find that temptation and potentially boundedly rational choices seem to affect a significant number of subjects by inducing them to abandon their optimal investment plans in favor of luring potential returns offered by riskier assets. (JEL D14, D15, G11, C91)
\end{abstract}

Keywords: Absent-Mindedness, Asset Allocations, Imperfect Recall, Retirement Saving, Time Inconsistency, Temptation.

\section{Introduction}

Demographic shifts and an aging population, have led to increased social problems such as a diminishing base to fund social security payments. One of the solutions that policy makers have implemented in the U.S. is the privatization of Social Security and the shifting of the responsibility of retirement asset accumulation from the government to the individual level. However, mounting evidence suggests individuals have a difficult time accumulating enough funds in their retirement accounts, even though financial planning services are widely available and affordable, and tax incentives are in place to encourage retirement savings.

\footnotetext{
*Assistant Professor, Department of International Business and Economics, Benedictine University, USA.

${ }^{ \pm}$Assistant Professor, Department of Economics Business and Finance, Lake Forest College, USA.

*Associate Professor, Department Economics, University of Nevada, USA.

'Professor, Department of Managerial Sciences, University of Nevada, USA.
} 
The literature attempting to explain inadequate levels of asset accumulation in individual retirement accounts has primarily focused on the issue of undersaving. While under-saving is certainly a critical issue, in this paper we focus on the mistakes people make regarding asset allocation between safe and risky choices. Specifically, we concentrate on the role of distractions and the inability of investors to stay on a prudent investment path in the face of risky temptations.

Drawing inspiration from the "absent-minded driver's (AMD) paradox" introduced by Piccione and Rubinstein in 1997, this paper seeks to address the lack of a theoretical framework to explain the type of time inconsistent behavior that is observed when it comes to retirement savings. The AMD model is a single player game that studies the possibility that temptation may induce rational individuals to deviate from previously chosen optimal plans. The model provides a game-theoretic foundation to study time inconsistent behavior in asset allocation decisions. Models of time inconsistent behavior help explain the insufficient saving levels in individual retirement accounts but have not been applied to explain the inconsistent asset allocation decisions.

Our paper should be of interest to a few different audiences. First, theoreticcians and scholars interested in the development of the consequences of the AMD model under pure strategies should find our experiment intriguing. Second, our paper should be of interest to behavioral scientists studying strategies to overcome time-inconsistent asset allocation decisions in saving for retirement. Third, the paper makes a methodological suggestion for the study of intertemporal decisions in the laboratory and in that regard, should also be of interest to experimental economists and psychologists specialized in the study of inter-temporal decision-making.

\section{Literature Review}

The burden of saving for retirement in the U.S. is shifting from a social responsibility (Social Security) to an individual responsibility. Employers in the private sector are switching from Defined Benefit Pension plans to Defined Contribution plans to shift the investment risk to their employees (Morrissey 2016). The outcome of this shift is a general decline in the participation of employees in retirement plans, especially in the new millennium. According to Morrissey (2016), the share of families pariticipating in retirement plans has dropped from $28 \%$ in 2001 to $21 \%$ in 2013, while about half of the American workers are not given access to a retirement plan by their employers (Benartzi and Thaler 2013). Except for a relatively dated academic study (Scholz et al. 2006, using HRS (Health and Retirement Survey) primary data for the years 1992 and 1993), most of the recent studies show that Americans reach retirement age with inadequate levels of savings in their individual retirement accounts (Gale et al. 2012, Rhee 2013).

Evidence that Americans are under-saving for retirement is not limited to survey data on retirement accounts. There is indirect evidence from studies of 
consumption patterns that suggest a similar result. In an early contribution, Hamermesh (1984) found that consumption falls sharply as households move into retirement. This finding was later complemented by Bernheim et al. (2001) who found that the consumption drop is sharper for households with less generous pensions and social security benefits. Furthermore, unless one assumes that American consumers are perfect inter-temporal optimizers, it is difficult to claim that this is a simple reflection of underlying preferences. Bernheim (1995) writes: "If saving reflects rational, far sighted optimization, then low saving is simply an expression of preferences. If, however, households are short-sighted, boundedly rational, dynamically inconsistent, impulsive, or prone to regret, then the adequacy of saving is a well-posed and important empirical issue".

The literature on optimal consumption, labor effort, investment and retirement decisions is rich and well-developed (Fahri and Panageas 2007, Choi et al. 2008, Dybvig and Liu 2010, Barucci and Marazzina 2012). Barucci and Marazzina (2012) is perhaps the contribution most closely connected with the issue of underfunded individual retirement accounts at the time of retirement. In incomplete market setups in which the risky asset does not act as a hedge (i.e., the returns of the risky asset are positively correlated with labor income changes), Barucci and Marazzina (2012: 5589) have shown that labor effort and the share of the risky asset in the portfolio both decline whereas consumption goes up, as opportunities to cover against risk decline. In other words, in contexts where hedging and insurance opportunities are restricted, "agents act in a myopic way and consume a lot".

The standard tradition of economics assumes that individuals face no problems solving their inter-temporal optimization problems. While that is a natural starting point to advance our understanding of the inter-relationships between consumption, portfolio investment and retirement decisions, there are serious reasons to start considering the problems introduced by limited rationality. As Carroll (2001: 41) bluntly puts it, "One problem is the spectacular contrast between the sophisticated mathematical apparatus required to solve the optimal consumption problem and the mathematical imbecility of most consumers". Additionally, the evidence from both survey data (see Lusardi and Mitchell 2007, for example) and from the laboratory (Brown et al. 2009, for example) suggest that bounded rationality is indeed a large obstacle preventing individuals from adopting the optimal strategies implied by inter-temporal optimization models.

Munnell et al. (2016) investigate whether households save enough over their lifetime to maintain their pre-retirement standard of living, while trying to eliminate the restrictive behavioral assumptions of previous studies. Their findings suggest that studies that concluded that under-saving is not an issue are based on behavioral assumptions "that may not reflect real world activity or on a snapshot of consumption levels that are unsustainable in the long run". They conclude that future retirees will be less prepared than past retirees and that more than half of the households will under-save for retirement. Munnell et al. (2014) also predict that in the coming decades a large segment of retirees will live below the poverty line. Johnson et al. (2017) find that when individuals who were 
born between 1976 and 1985 become 70 years old, their inflation-adjusted average annual household earnings will be less than $75 \%$ of the average wages earned from ages 50 to 54 .

Another under-saving explanation is that a significant fraction of Americans are not "financially literate". Lusardi and Mitchell (2007) show that a non-trivial percentage of Americans is unable to calculate percentages, compound interest, or division of funds. For those individuals, it is clearly far-fetched to assume that they can solve for the optimal saving policies implied in the standard models of rational consumer behavior with a buffer stock motive and habit formation (Carroll et al. 2000). Thus, part of under saving can be explained by the lack of financial literacy and the positive association with the difficulty of solving for the optimal savings rate and choosing optimal investment strategies.

The literature explaining under-saving for retirement has focused on the role played by two main behavioral assumptions: present bias (i.e., a preference for immediacy) and bounded rationality. The literature on present bias is abundant and includes models of hyperbolic discounting and quasi-hyperbolic discounting (so-called delta-beta models) a la Laibson (1997), as well as dual-self models stressing self-control (or lack thereof). The literature on the effects of bounded rationality on under-saving is also extensive. Previous experimental literature, finding evidence of under-saving and attributing it to different forms of bounded rationality, includes but it is not limited to: Hey and Dardanoni (1988), Fehr and Zych (1998), Kotlikoff (2001), Ballinger et al. (2003), Ballinger et al. (2007) and Sass and Mercado (2015).

Planning and its role in individuals' savings, investment and wealth accumulation is a crucial piece of the puzzle in understanding why households do not develop adequate savings plans. Ameriks et al. (2003) find that financial planning is positively related to wealth for households that otherwise have very similar demographic characteristics. However, we often observe a discrepancy between planning and acting, not only when it comes to financial matters but almost all other domains such as dieting and exercise. Many psychologists and economists alike "blame" it on issues of self-control and will power that stand in the way of plans turning into actions. According to Benartzi and Thaler (2013: 1152) "self-control is easier to accept if delayed rather than immediate". Instead, individuals deviate from their plans because of temptation. Being impatient and having myopic views on future consumption, individuals prefer present indulgence and disregard the carefully thought out planning by financial experts or themselves. Further, Benartzi and Thaler (2007) suggest that individuals spend less than one hour determining how much their savings' rate should be. Ameriks et al. (2007) find that self-control is related to wealth accumulation, especially liquid wealth, and age, while Benartzi and Thaler (1999), suggest that the way investors think about their future decisions, such as retirement plans, depends on how the relative risk and return data are presented to them, displaying myopic loss aversion.

Sass and Mercado (2015) find that workers themselves recognize their limited discipline managing even daily finances, let alone future ones. Americans, 
regardless of their age or income level, are found to be shortsighted when it comes to addressing future financial issues. Sass and Mercado (2015) estimate that financial satisfaction is influenced more by current financial problems as opposed to distant ones. Current financial problems include difficulty in covering expenses, heavy current debt burdens, unemployment, and inability to access $\$ 2000$. Distant financial problems included no medical insurance, no life insurance, no retirement plan, no college savings, and underwater mortgages. All current financial problems were found to be statistically significant predictors in reducing one's financial satisfaction, while among distant problems only not saving for college and not having medical insurance were found to have a negative and statistically significant impact on financial satisfaction. Having neither Defined Benefit nor Defined Contribution, did not seem to matter to financial satisfaction, even to those belonging to age groups that were approaching retirement. However, labor market developments such as deterioration in employment conditions, declining real wages, and increased income inequality, contributed to a short-term emphasis on consumption spending for a large fraction of the US labor force. Retirement plans seemed to be important only to those that belonged in the top income decile, suggesting that low income individuals might experience even worse economic conditions in the future and a deepening of the income inequality among retirees.

Clearly there are numerous behavioral problems that contribute to the lack of adequate financial assets in retirement. While no single theory can provide a comprehensive framework for all these problems, we believe the AMD model is rich enough to accommodate many explanations. The AMD model incorporates several of the concepts previously discussed: there is bounded rationality because the individual suffers from absent-mindedness and imperfect recall; temptation in that the object of desire (i.e. the risky asset providing high returns) becomes tempting only to the future self (the decision-maker), but not to the planner (the present self). Thus, we choose the AMD model to explain inadequate levels of funds in individuals' retirement accounts. In contrast to the existing literature on bounded rationality, the limits on rationality, in our study, are connected to the investment component of the saving for retirement process, and not with under-saving per se. That is, we do not focus on the amount saved but on how the funds for retirement are invested, to ensure an adequate level of consumption during retirement years. We next provide a review of the absent-minded driver's paradox.

\section{The Absent-Minded Driver's Paradox}

In their paper, "On the Interpretation of Decision Problems with Imperfect Recall”, Piccione and Rubinstein (1997) offer a theoretical framework where time inconsistent decisions are optimal in a one person, two selves, one shot decision-making game. The simple one-person game introduced by Piccione and Rubinstein (1997) is summarized by Figure 1 below. The paradox of the 
absent-minded driver stems from two different ways of reasoning that lead to two conflicting equilibria between the two stages of the game: the planning stage, when the driver is sitting at the bar planning his midnight trip home; and the action stage, when he is driving down the highway. According to Piccione and Rubinstein (1997), one way of reasoning about the problem leads the driver to stick to the plan and continue to drive down the highway when reaching an intersection. Piccione and Rubinstein (1997: 8) write: "having chosen an optimal strategy, one does not have to verify its optimality at the time of execution unless there is a change in information or in preferences". The second way of reasoning, "which calls at each instance to maximize expected payoffs given the relevant beliefs" leads to taking the exit when reaching the intersection.

Imagine an absent-minded driver sitting in a bar planning his trip home. He knows that to get home he needs to take the highway and correctly identify and take the exit that leads home. However, if he takes the wrong exit, he ends up in a bad neighborhood and cannot return to the highway to get home. While sitting at the bar, the driver knows that he is absent-minded and will not be able to correctly identify the exit when he reaches it, so he decides his optimal strategy is to continue driving until the end of the highway and spend the night at the motel. However, when he leaves the bar to drive to the motel, although there is no change in preferences and no new information, the driver forms beliefs regarding where he is on the highway and decides to take the risk of exiting the highway rather than continuing on to the motel.

Figure 1. Absentminded Driver Decision Game

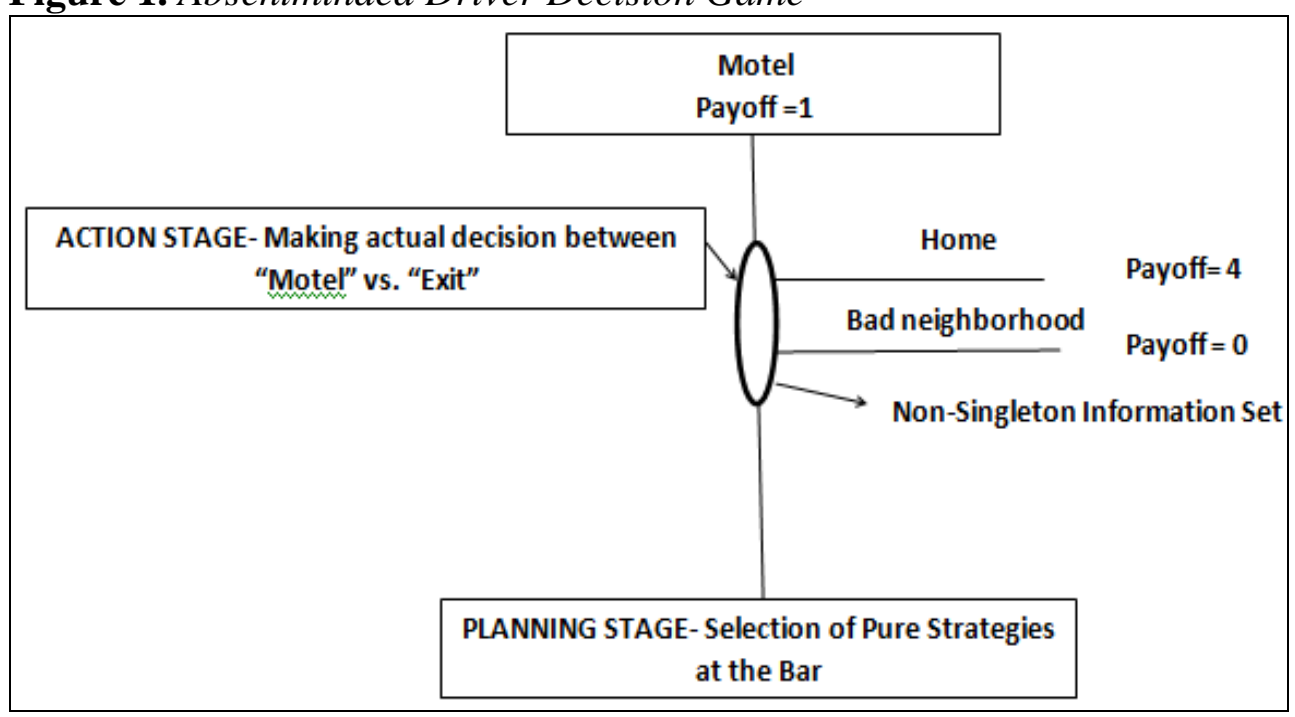

Source: Authors.

The paradox of the absent-minded driver stems from two different ways of reasoning that lead to two conflicting equilibria between the two stages of the game: the planning stage, when the driver is sitting at the bar planning his midnight trip home; and the action stage, when he is driving down the highway. According to Piccione and Rubinstein (1997), one way of reasoning about the 
problem leads the driver to stick to the plan and continue to drive down the highway when reaching an intersection. Piccione and Rubinstein (1997: 8) write: "having chosen an optimal strategy, one does not have to verify its optimality at the time of execution unless there is a change in information or in preferences". The second way of reasoning, "which calls at each instance to maximize expected payoffs given the relevant beliefs" leads to taking the exit when reaching the intersection.

In the first way of reasoning the equilibrium of the game consists of planning on going to the motel while at the bar and sticking to this strategy when the critical junction is reached on the highway. However, based on the second way of reasoning the driver forms beliefs about where he is on the highway and should take them into account when choosing whether to take the exit. Piccione and Rubinstein (1997) prove mathematically that unless the driver believes he is at the bad exit with certainty, he should choose to exit and maximize his expected payoff (accounting for his beliefs regarding the critical junction). Thus, one equilibrium dictates sticking to the original plan and driving to the motel while the second suggests it is optimal to deviate from the plan during the action stage (i.e., taking the exit). At this point, one should also note that in order to obtain the PR equilibrium, the type of thinking at the planning stage has to be deterministic, of the type "either or" ("should I plan to stay on the road or to exit"?) and of a clear normative nature ("what should I do for my own good?"), whereas the type of thinking at decision time becomes probabilistic and lacks a strong normative component.

\section{The Absent-Minded Investor's Game}

Adapting the absent-minded driver's game to an absent-minded investor's game, we used a road to retirement analogy as presented in Figure 2 below. In this game an investor chooses an investment strategy in two different stages: the planning and the action stage. In the first stage the investor can choose either a safe asset (payoff of 1) or a risky asset (payoff of 0 or 4) whose payoff is determined by chance. After choosing a strategy in the planning stage, the player then proceeds down the "investment highway" until he reaches the action stage (highway exit) where he again chooses between the safe or risky asset. The structure of the investor's game is identical to the absent-minded driver's game.

The intuition behind the investor's game is the following. In the presence of absent-mindedness, that can come from either imperfect recall or bounded rationality, optimal strategies can change between the planning and the action stage without the arrival of new information and/or a change in preferences. Belief formation plays an essential part in finding the optimal strategy which led to the analogy of an uncertain investor. An investor may be uncertain about where she is in the financial cycle or, whether a new company stock is truly a "rock star" (will continue to display above average returns) or a "one hit wonder" (the stock price will plummet at some point in the near future and the 
company will go bankrupt) ${ }^{1}$. Since there is no way of knowing ex ante, investors base their decisions on beliefs they form with regards to where they are in the financial cycle or the real type of the company they are investing in. Regardless of the true type, they get tempted by the potential high returns that they don't want to miss out on, regardless of what a closer analysis might reveal.

Figure 2. Absentminded Investor Decision Game

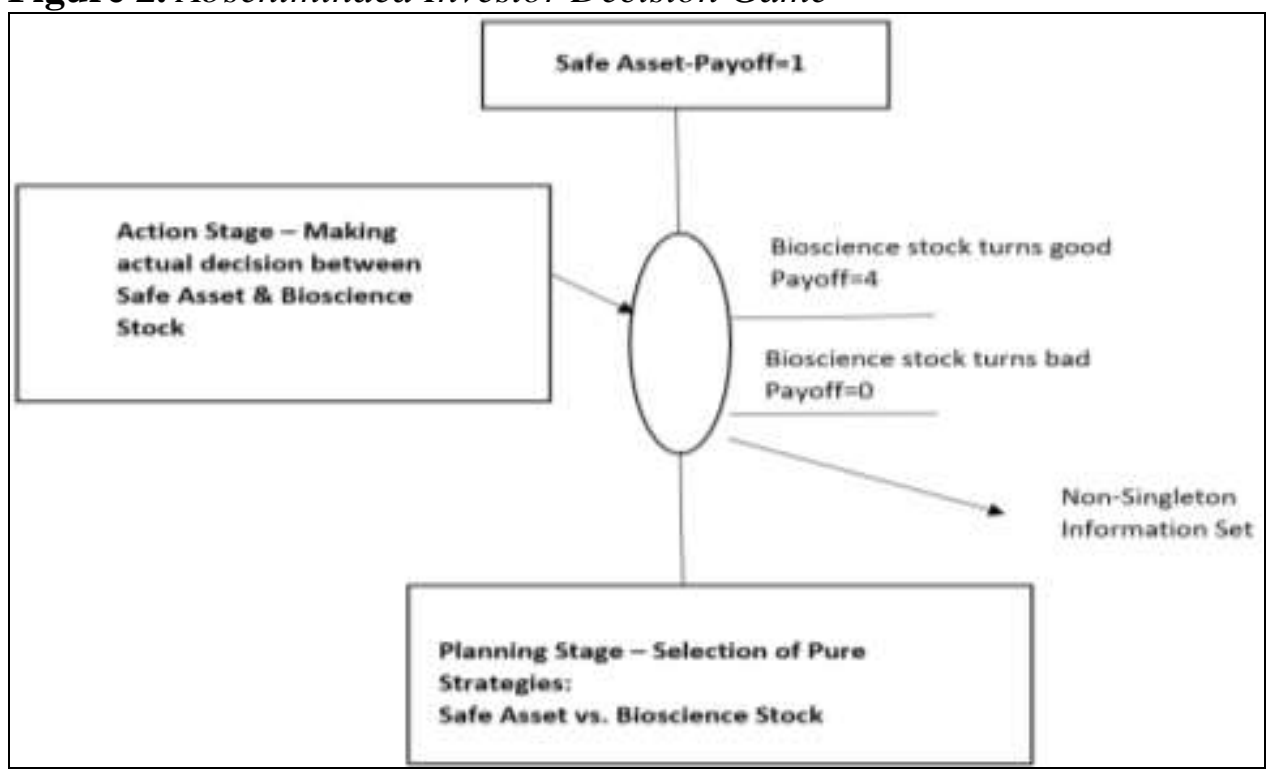

Source: Authors.

Just as in the AMD game, the investor's game has two possible equilibria: 1. Choosing to invest in the safe asset in the planning stage and not deviating during the action stage (we refer to this equilibrium as the traditional economic theory equilibrium); 2. Planning to invest in the safe asset but choosing to switch to the risky asset in the action stage (we call this equilibrium the PR equilibrium). ${ }^{2}$

\section{Pilot Studies 1-5}

The investment game is framed as a one-shot "retirement" asset allocation task between two assets. The safe asset is a balanced index of stocks and bonds that provides a guaranteed return of 1 unit. The risky asset is a Bioscience company stock that has a 50/50 chance of returning 0 or 4 units.

The implementation of the experiment turned out to be quite challenging methodologically since it is not a standard game for which procedures are wellknown. The two features of the experiment that were particularly troublesome included correctly framing the experiment as an asset allocation retirement task

\footnotetext{
${ }^{1}$ As an example, the reader might think of the dot-com bubble from the late 1990's when some companies were truly innovative and survived the financial crisis, such as Amazon, while others disappeared when the bubble burst, such as Pets.com.

${ }^{2} \mathrm{~A}$ more detailed explanation of the experiment is provided in the Appendix 1.
} 
and creating a true state of uncertainty at the action stage. Next, we briefly describe the results of five pilot studies conducted to test and refine the parameters of the experiment.

Subjects for the pilot studies were recruited through an advertisement sent out in the campus mail to all University of Nevada, Reno staff employees (approximately 1400), as well as through posting on SONA, an online software for human subject recruitment within the campus. The advertisement stated that a subject could earn between $\$ 5.00$ and $\$ 21.00$ depending on their performance for participating in a one-hour experiment on finance/economic decision making.

The Pilot Studies all had the same basic setup in which subjects were asked to make investment choices in the planning and action stages as shown in Figure 2 above. In Pilots Studies 1-3 we observed that a large number of subjects did not choose the optimal (pure) strategy at the planning stage (the choice of the safe asset) when the question about their plans concerning the asset to invest in was formulated as a positive statement ("What asset do you plan to choose...?"). Therefore, in Pilots 4 and 5 we reformulated the question as a normative one: "What asset should you plan to choose...?" Results from pilot studies 4 and 5 showed that the normative nature of the question enforced the selection of the pure dominant strategy at the planning stage. We believe this is a very important lesson in financial planning: when saving for retirement people need to be reminded about their long-term goal and the normative implications of their plans.

A critical component of the game is to deliver the subjects to the action stage in a state of uncertainty. To implement such uncertainty, after the action stage, and keeping a highway to retirement analogy, the subjects were given the task of counting exit signs in a video game, flashing at relatively fast speeds, as a way of identifying the "good" and "bad" exits (associated with a high and low payoff respectively).The purpose of this task was to induce absentmindedness similar to the driver from the bar in the AMD paradox. Pilot studies four and five were conducted to calibrate the speed of the flashing exit signs to induce absent-mindedness in the decision-making process. Our intent was to make the flashing exit signs impossible to count without discouraging the participants from trying. This is the equivalent of the driver not being able to distinguish with certainty the good from the bad exit, while driving down the highway. After Pilot Study 5, we identified the correct calibration for the speed of the flashing signs and were ready to proceed with a full experiment which we describe next.

\section{Experiment on the Absent-Minded Investor's Game}

\section{Experimental Procedures}

The experiment took place at Lake Forest College, a liberal arts college in Illinois, U.S. Subjects were recruited through an advertisement sent out on campus email to all Lake Forest College staff employees and some students. The experiment was conducted in a computer lab in the Lake Forest College library. 
Upon arrival, each subject received a copy of the human subject consent form and task instructions. The experiment began with the reading aloud of the consent form. After consent was obtained, each subject received a $\$ 5.00$ showup fee. Since the recruitment advertisement stated that subjects would receive a minimum compensation of $\$ 5.00$, the show-up fee was given to fulfill this promise. Subjects were then told that any further compensation in the experiment was contingent on their performance in an asset allocation task. Then, each subject filled the financial portion of DOSPERT that is used to measure relative risk attitudes.

The experiment continued with the reading aloud of the instructions ${ }^{1}$. During this process, subjects were given many opportunities to ask questions. The Principal Investigator navigated all the subjects through the experimental task simultaneously and thus all subjects completed the experimental task at a similar pace. The total duration of the experiment was about 45 minutes.

After the experimental task was completed, each subject filled out a short questionnaire regarding demographic and other questions, and a receipt documenting their earnings. Subjects then walked to the back of the room where they were paid individually and anonymously in cash for their performance, thanked, and dismissed from the laboratory.

\section{The Experimental Task}

The experimental instructions explained that subjects would engage in a one-shot "retirement" asset allocation task between a safe and a risky asset. The safe asset paid 1 experimental dollar and the risky asset paid 4 experimental dollars. Subjects were then told that the experimental dollars would be converted into real dollars at the end of the experiment. For example, a payoff of 4 experimental dollars would be associated with four times more earnings compared to a payoff of 1 experimental dollar. The actual conversion rate was revealed after the asset allocation game was over and for each experimental dollar subjects received \$4-real dollars (conversion rate of 1 to 4 ). The decision of revealing the conversion rate after the experimental game had concluded was meant to ensure that players had relative, not absolute payoffs in mind during the game. This way, the implications of the experiment can be generalized and do not apply solely to the comparison of 4-real dollars to 16-real dollars.

The instructions indicated that participants should frame their decision as an analogy between an absent-minded investor who is saving for retirement and is not sure whether risky assets will turn out to be good or bad, and an absent-minded driver who is driving on the highway and isn't sure which exit to take to get home. Instructions stated the following: "The safe option for the driver is to take the highway and drive all the way to the end where she can spend the night at a motel. The driver can get to the motel with certainty as there are no exits that she needs to take. Similarly, the investor can choose the safe road to retirement and invest her retirement savings in the safe asset. The

\footnotetext{
${ }^{1}$ A copy of the instructions is provided in the Appendix 1.
} 
risky option for the driver is to take an exit, knowing that she can't get back on the highway if it is the wrong one. If she takes the wrong exit she ends up in a bad neighborhood (associated with a payoff of zero), while if she takes the exit and it turns out to be the correct one, she ends up home (associated with the highest payoff). The analogous of taking the exit for the investor is to invest in the risky stock, not knowing whether it will have a high or low payoff." Subjects were told that the experimental task had two stages, a planning stage and an action stage. In the planning stage subjects had to answer the question shown in Figure 3 below.

Figure 3. User Interface for the Planning Stage

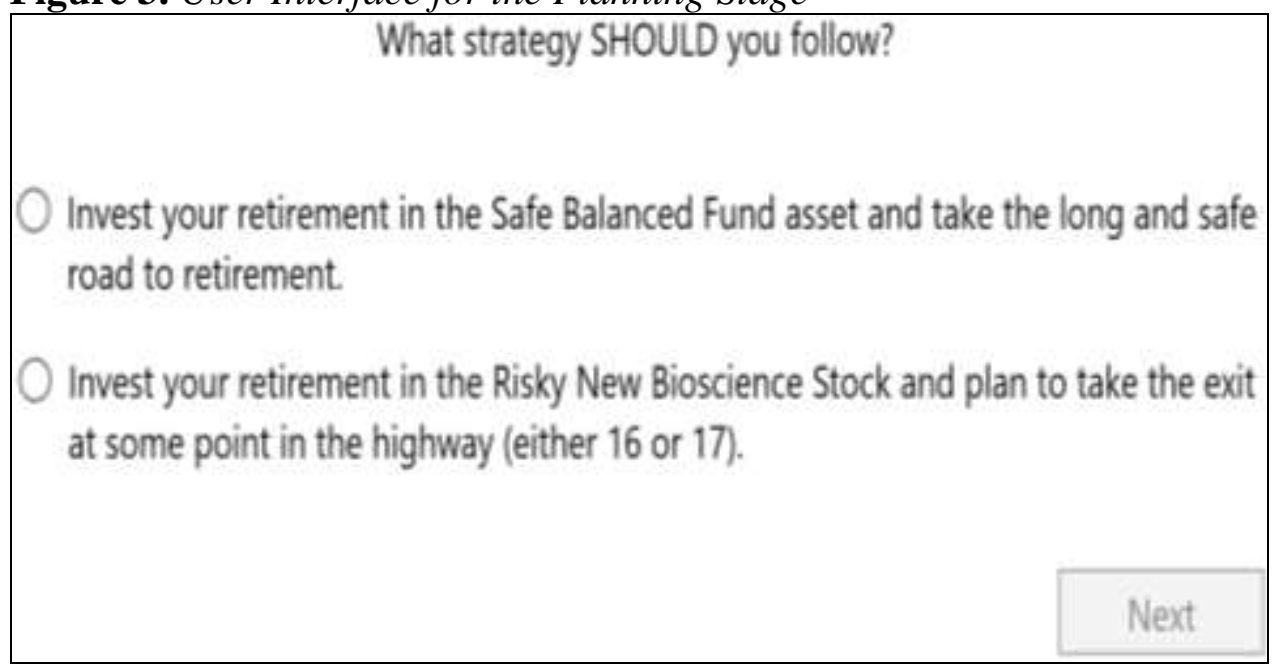

Source: Authors.

The question in the planning stage was formulated as a normative question, using the word "should." As discussed earlier, the results from Pilot Study 3 indicate that framing the question in a normative way helped subjects realize that the first stage was referring to a plan and not an action.

After subjects reported what strategy they should follow, they clicked the "Next" button. The following screen prompted them to answer, "Why did you choose this strategy?" After answering, subjects clicked "Next" and the image presented in Figure 3 appeared.

The highway shown in Figure 4 was used as an analogy between the absent-minded investor saving for retirement and the absent-minded driver that might get distracted while driving on the highway. Subjects were told that flashing exit signs would pop up on their computer screen to replicate their fictional movement along the retirement road. Their task would be to try to count the rapidly flashing Exit signs in order to identify which exit they were at. Correctly identifying the exit is akin to knowing whether the risky asset is good or bad.

Subjects were told again that it is impossible to know in advance whether the risky asset will turn out to be good or bad, and the only way to figure this out would be to try and count the rapidly flashing exit signs. Figure 5 above 
shows the flashing exit signs as presented to the participants.

Figure 4. User Interface for Road to

Retirement Analogy

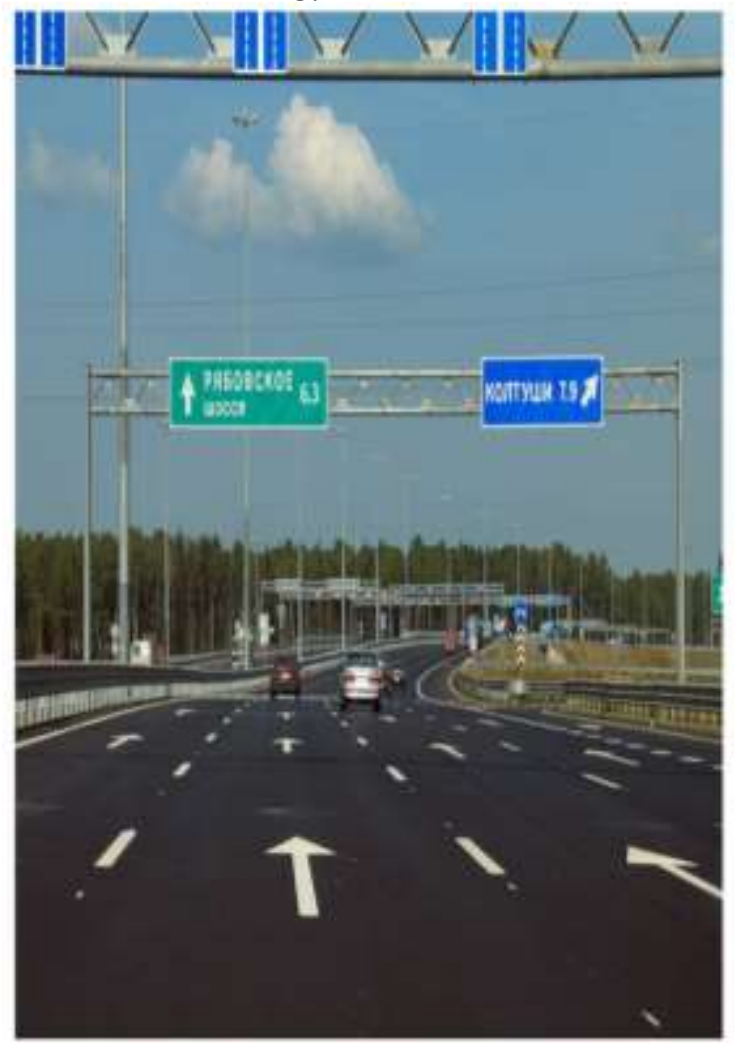

Source: Authors.
Figure 5. User Interface for Counting Flashing Exit Signs

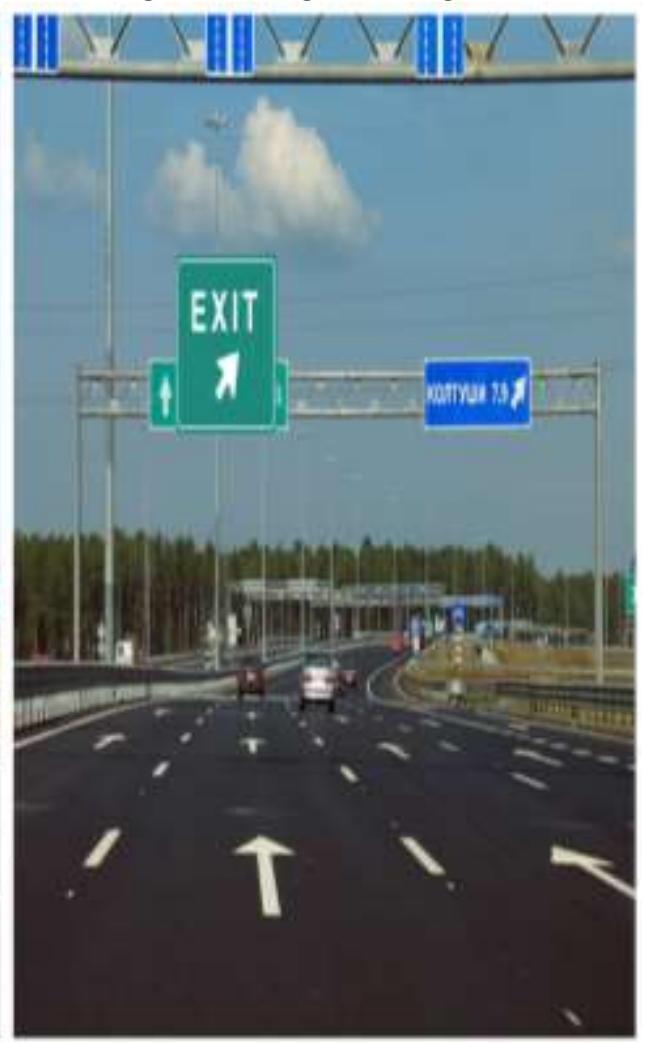

Source: Authors.

Subjects were then given the opportunity to practice "counting exits" in an uncompensated round. After the exit signs flashed on the screens, subjects were asked, "Which exit do you think you are at?" Subjects answered and received feedback as of whether they were correct or wrong.

Subjects then continued to the "action stage" of the experiment after being told that, "the highway has a critical region comprising of Exit 16 and Exit 17. After counting the flashing exits you will arrive at the critical region. There you will have to decide if you want to continue on the highway or take an Exit. If you decide to continue on the highway, you take no risk and you will get a payoff of 1 experimental dollar, corresponding to investing in the safe asset. In other words, imagine as if you decided to invest your retirement in the balanced index of Treasury bonds and stocks of large American companies. If you decide to take the Exit then you will either get a payoff of zero experimental dollars, which is akin to having picked the wrong bioscience stock, or you will get a payoff of 4 experimental dollars, which is akin to having guessed correctly and picked the right bioscience stock."

Chance determined whether subjects saw 16 or 17 flashing exit signs, i.e., whether the new bioscience stock would provide the good or the bad payoff. To 
introduce chance in the experiment we used a coin toss. All subjects were provided with a coin that they had to toss and enter the outcome on their screen, as shown in Figure 6 below. The software was programmed such that clicking "Heads" was the bad exit and "Tails" was the good exit.

Figure 6. User Interface for Entering the Coin Toss Outcome

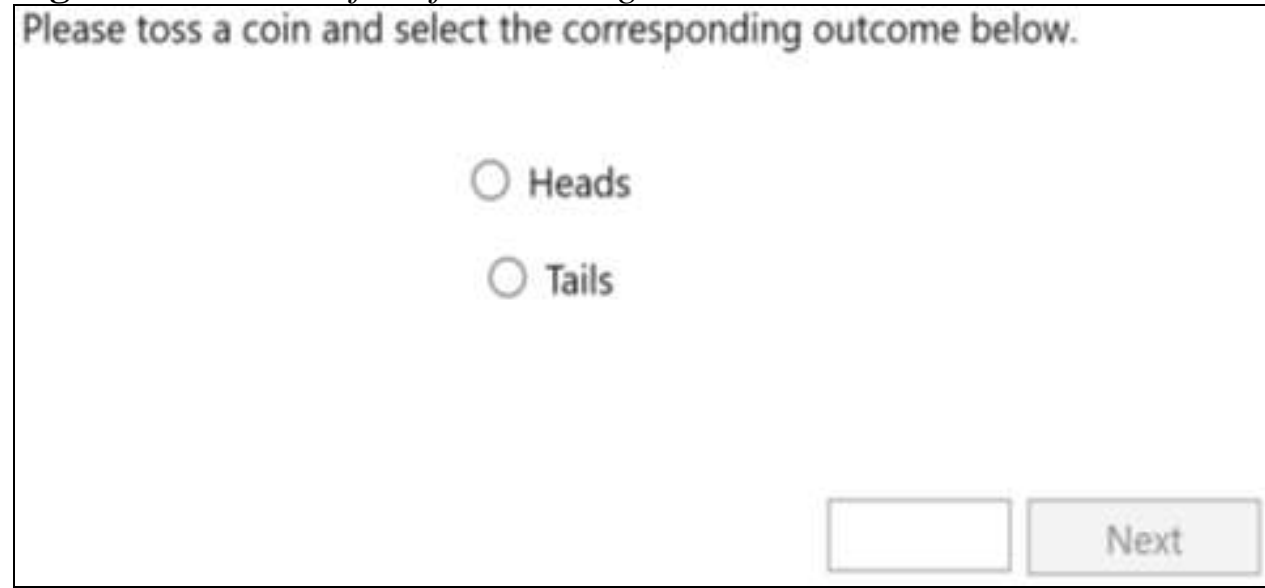

Source: Authors.

Subjects were then told that the action stage would begin next. Subjects had to count the flashing exits that popped on their screens in the next 30 seconds. The speed of the flashing signs was 0.1 seconds, and each flashing sign popped up every 0.05 seconds. The relatively high speed of the flashing exit signs was meant to ensure the impossibility of identifying the correct exit with certainty through counting, while at the same time not constituting a deterrent for subjects to at least try counting. The flashing speeds were determined by trial and error in the pilot studies. Specifically, in Pilot 1 signs were set to flash at a speed of 0.13 seconds, which, as we were to discover, turned out to be too slow, convincing subjects that identifying the "good" risky asset is not only possible, but very doable, thus denying the logic intrinsic in the Piccione and Rubinstein (1997) decision-making game. For this reason, in pilot studies 2 and 3, we speed up the rate of the flashing exit signs at 0.075 seconds. The speed turned out to be excessively fast, making the task of counting flashing exit signs humanly impossible, discouraging subjects from even trying to count the signs. Accordingly, the speed of the regular-sized flashing exit signs was set at 0.10 seconds, which is between the 0.13 seconds of pilot 1 and the 0.075 of pilot 2 and 3 .

After all flashing exits popped up, subjects had to decide whether they would exit, or not. Before deciding, subjects had to answer the question shown in Figure 7 below. 
Figure 7. User Interface for Belief Assessment at the Action Stage

\begin{tabular}{|l|l|}
\hline \multicolumn{1}{|c|}{ Questions on Beliefs about HERE (PAPER-based) } \\
\hline $\begin{array}{l}\text { Question: What's your best guess that you have counted the flashing exit signs } \\
\text { correctly and that you know where you are on the highway? Options: }\end{array}$ \\
\hline 1. & Probability of having counted correctly $=1$ (or $100 \%)$ \\
\hline 2. & Probability of having counted correctly $=0.9($ or $90 \%)$ \\
\hline 3. & Probability of having counted correctly $=0.8($ or $80 \%)$ \\
\hline 4. & Probability of having counted correctly $=0.7$ (or $70 \%)$ \\
\hline 5. & Probability of having counted correctly $=0.6($ or $60 \%)$ \\
\hline 6. & Probability of having counted correctly $=0.5($ or $50 \%)$ \\
\hline 7. & Probability of having counted correctly $=0.4($ or $40 \%)$ \\
\hline 8. & Probability of having counted correctly $=0.3($ or $30 \%)$ \\
\hline 9. & Probability of having counted correctly $=0.2($ or $20 \%)$ \\
\hline 10. Probability of having counted correctly $=0.1($ or $10 \%)$ \\
\hline 11. Probability of having counted correctly $=0$ (or $0 \%)$ \\
\hline
\end{tabular}

Source: Authors.

Subjects were then given the formula to calculate the expected value of "exiting the road", given their guess about having counted the flashing signs correctly, as:

Prob (correct count) $* 4+$ Prob (incorrect count) $* 0=X$.

Following, subjects compared the alternatives of staying on the road and receiving a certain payoff of 1 experimental dollar, with exiting the road and receiving the calculated expected value. Subjects made their decision in the action stage by answering the question shown in Figure 8 below.

Figure 8. User Interface for Choosing a

Strategy in the Action Stage

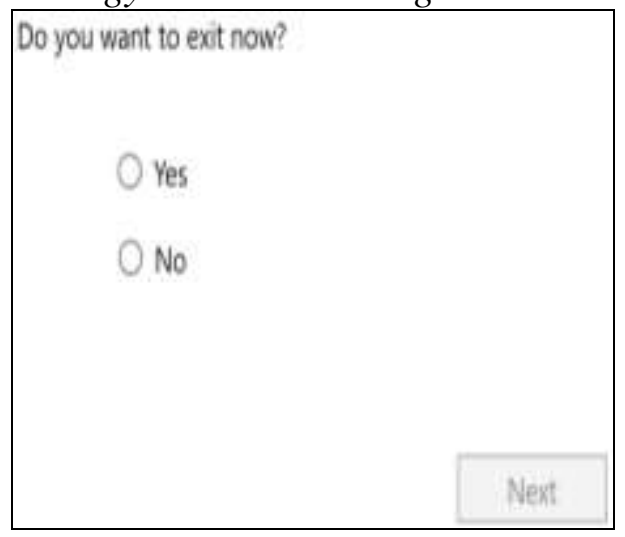

Source: Authors.
Figure 9. User Interface Belief

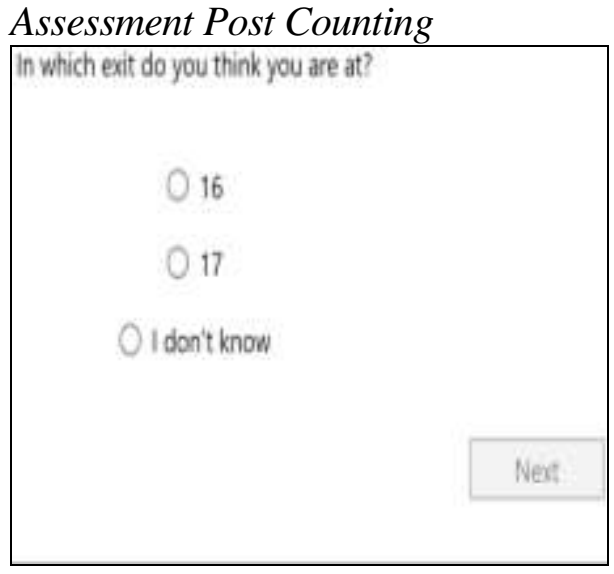

After subjects chose Yes or No they clicked the "Next" button, and they were 
prompted on to the next screen, where they had to explain why they chose whether to exit or not. After that, subjects reported which exit they thought they were at, as shown in Figure 9 above.

The last screen subjects saw was the outcome of their choice and the associated payoff. For example, a subject who got "Tails" in the coin toss exercise and decided to exit in the action stage, would see the message shown in Figure 10 below.

Figure 10. User Interface for Revealing the Game Outcome

\begin{tabular}{l} 
Your final outcome is $\$ 4$. Please fill the paper receipt in front of you with this outcome. \\
After that, press next to fill the final survey. Failure to do so will result in $\$ 0$ \\
compensation. \\
Next \\
\hline
\end{tabular}

Source: Authors.

\section{Experiment Results}

Twenty-seven subjects participated in the experiment. The subject pool is $48 \%$ females, and $52 \%$ males. Most of the participants were college students. The average age of the participants is 21.7 years old, with $78 \%$ in the $18-22$ age bracket, $20 \%$ in the $23-25$ bracket, and $2 \%$ above 25 years old. In terms of investment experience, $52 \%$ reported having some, and $48 \%$ reported no investment experience. Also, $52 \%$ of the subjects claimed to have experienced a traumatic event, which might affect their subsequent risk attitudes.

In our single shot game, there are two possible equilibria as in the absentminded driver paradox: one equilibrium that stems from traditional economic theory and suggests that once an optimal strategy has been chosen it should not be revised if there is no change in preferences and no new information (traditional economic theory equilibrium); and another that accounts for belief formation and postulates that one should always maximize expected payoffs (PR equilibrium). Playing according to traditional economic theory is equivalent to planning on investing in the safe asset and choosing the safe asset in the action stage. Playing according to the reasoning introduced by Piccione and Rubinstein (1997) is equivalent to planning on investing in the safe asset but choosing the risky asset in the action stage. Thus, we group participants based on the strategy they play in the two stages of the game as: "safe-safe" with players that plan to invest in the safe asset and choose the safe asset in the action stage (equivalent to playing the traditional economic theory equilibrium); the "safe-risky" category with players that plan to invest in the safe asset but end up deviating from their original plan in the action stage by choosing to invest in the risky asset (equivalent to playing the PR equilibrium); the "other" category with players that either planned and invested in the risky asset or planned to invest in the 
risky and then chose the safe option in the action stage.

As shown in Table 1 below, $88.89 \%$ (24 out of 27) of the participants played either the "safe-safe" or the "safe-risky" equilibria, while $11.11 \%$ played the "other" strategies. Out of the total participants, $60 \%$ seemed to have constant preferences and followed the "safe-safe" strategy, while 30\% followed the "saferisky" strategy. The gender distribution among participants who played each of the 3 strategies is also shown in Table 1 below.

Table 1. Strategy and Gender Distribution

\begin{tabular}{|l|c|c|c|}
\hline & \multicolumn{2}{|c|}{ Gender } & \\
\hline Strategy & Male & Female & Total \\
\hline Safe-safe & 8 & 8 & 16 \\
\hline Safe-risky & 4 & 4 & 8 \\
\hline Other & 2 & 1 & 3 \\
\hline Total & 14 & 13 & 27 \\
\hline
\end{tabular}

Source: Authors.

As shown in Table 1 there are no gender effects in following different strategies. The same number of males and females play either the "safe-safe" or the "safe-risky" strategy.

Figure 11 below compares the income distribution by strategy. The "other" group is composed solely of middle-class participants, while the "safe-safe" and the "safe-risky" contain all three income groups (with subjects who grew up in lower middle class, middle class, and upper middle class). Specifically, the "saferisky" group has a slightly higher percentage of participants having grown up in the upper middle class, and slightly less participants in the middle class, compared to the "safe-safe" group.

Figure 11. Income Group by Strategy Played

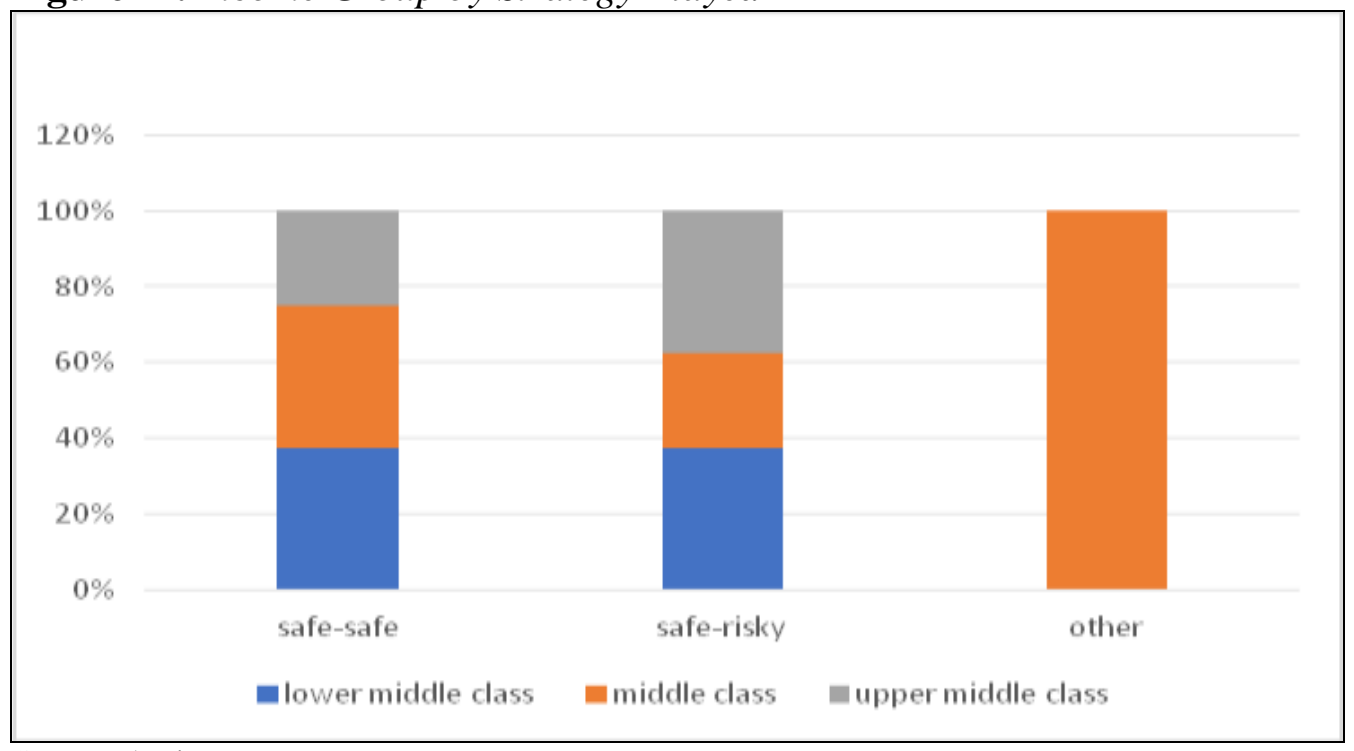

Source: Authors. 
A potential explanation for the income distribution across the different strategy groups is that richer families can afford to take more risk and thus, are more susceptible to temptation compared to families from lower income categories who exhibit more self-control and discipline. Indeed, individuals in the upper middle class display higher scores on the DOSPERT scale of risk seeking attitudes, providing some support to the aforementioned interpretation.

The experimental results suggest risk seeking attitudes are not likely to be the reason subjects change their initial retirement allocations to riskier assets, since the DOSPERT survey shows that only 3 out of the 27 participants were risk seeking, while the rest were risk averse. All subjects playing the "safe-risky" equilibrium are risk averse. One would perhaps expect that because these subjects are risk averse, they would follow the traditional economic theory and stick to the safe asset, but that can only be true in the absence of temptation. The fact that risk averse individuals deviate from their original (optimal) plans suggests that either temptation or bounded rationality, or both, might play a role in the decision making process.

Combining the previous observations, results suggest that temptation and absentmindedness may be causing participants to deviate at the action stage. Furthermore, participants with milder levels of risk aversion are the ones who mostly tend to deviate from their optimal plans. Given the small number of subjects in each category, these interpretations are highly conjectural and subject to potential revision by further research using significantly larger samples.

The results from our experiment indicate that most players choose the optimal strategy in the planning stage and do not deviate in the action stage, further reinforcing the idea that a large component of the under-funding of retirement accounts has to do with unsuccessful investment choices. In other words, we believe that an important issue, so far ignored by the literature, might be that individuals mismanage their savings by falling prey to temptation or distractions and thereby making poor investment decisions. Of course, we keep in mind the limitations of our study, and mainly the fact that this is a one-shot game that doesn't exactly replicate real life situations where individuals are faced with repeated decisions regarding their asset allocations using savings from their retirement account. However, there is some related evidence that individuals display bounded rationality in repeated asset allocation games as well. In a repeated asset allocation game, Papadovasilaki et al. (2018) show that investors have the tendency to change their portfolio allocation too often, even when provided with the underlying characteristics of the distribution of returns.

Our study also gives an insight into the role played by overconfidence in explaining time inconsistent behavior. To measure overconfidence, we used players' beliefs that they can correctly count the flashing exit signs, conditional on their (prior) experience playing video games. Since the task of counting rapidly flashing exit signs should be easier for those who are experienced video gamers, if a player had little experience playing video games but was fairly confident in their ability to count, we consider them overconfident. As previously explained, the speed of the flashing exit signs was chosen such that accurately counting would 
be impossible, without discouraging players from trying. Using results from our five pilot studies, we found a positive association between experience playing video games and a player's ability to count flashing exit signs on a computer screen (the near misses and accurate counts of the exit signs were higher for those who frequently played video games).

Figure 12 below supports our hypothesis regarding the relationship between overconfidence and time inconsistent decisions. Given the relatively small sample of our data, we grouped players into two categories based on their self-reported performance in playing video games: terrible and good. The first group includes those who consider themselves terrible or mediocre at playing video games, while the second contains those who ranked themselves as good or very good when it comes to playing video games. Figure 12 reveals that there is a higher percentage of players who rank themselves terrible or mediocre at video games, in the "saferisky" and "other" categories. Furthermore, players' confidence in their counting ability is relatively higher in these subgroups, compared to the same subgroup (players who have terrible or mediocre video game experience) in the "safesafe" category. Also, within each category, players' belief that they can accurately count the flashing exit signs is higher for those with terrible or mediocre perceptions, compared to those with good or very good perceptions. Although further investigation is needed, our results are in line with previous literature and are an indication that overconfidence is associated with time inconsistency and overtrading. For example, Barber and Odean (2001: 289) find that overconfident investors trade too much which lowers their expected utility: "models that assume that market participants are overconfident yield one central prediction: overconfident investors will trade too much." Although we find no gender differences, which with our sample size could be the effect of pure randomness, we introduced a new context for measuring overconfidence and its effect on the asset allocation of retirement savings, using the absent-minded investor framework.

Figure 12. Overconfidence and Time Inconsistent Decisions

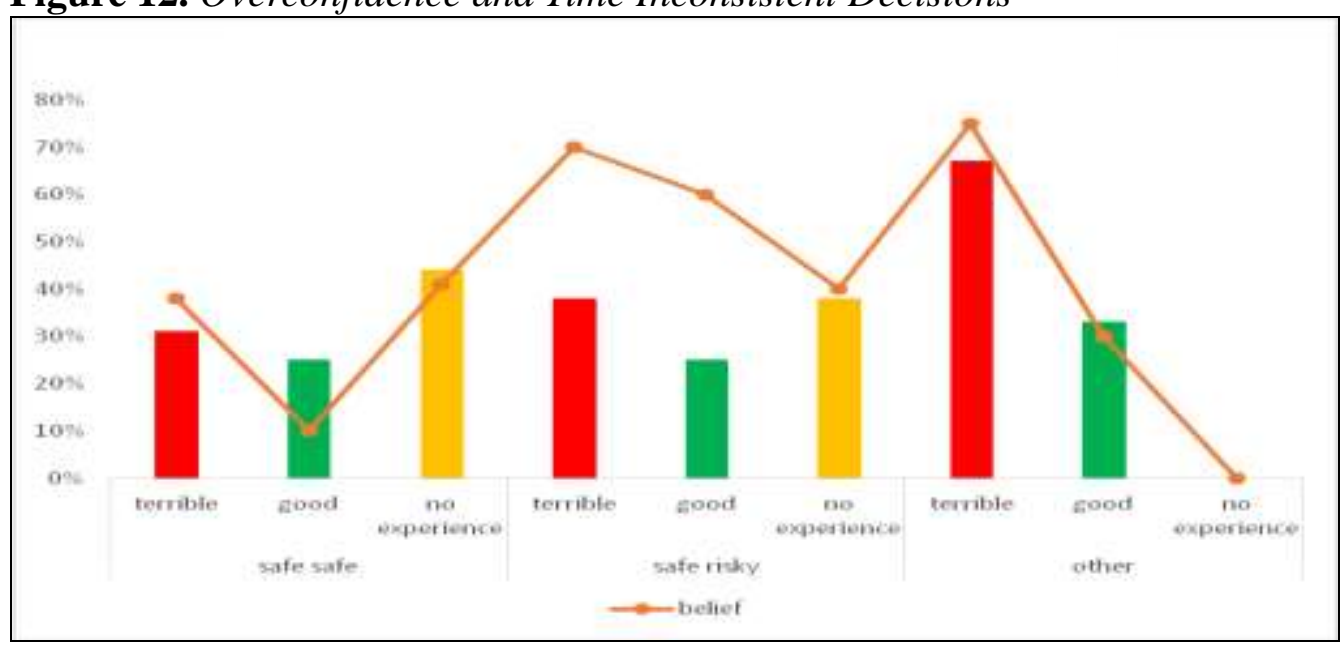

Source: Authors.

The fact that overconfidence induces subjects to deviate, and makes them 
more susceptible to risk, is further reinforced by the subjects' free responses on the question as of why they decide to invest in the risky asset in the action stage. From the 8 subjects following the "safe risky" strategy, 6 claim to be very confident that they counted correctly, despite the fact that the speed of the flashing signs renders it impossible.

Although no strong conclusions can be drawn given our limited sample size and further partitioning into groups, our study gives some important insights about the role that temptation plays when it comes to asset allocation of retirement savings. Furthermore, it can be the starting point of a deeper investigation concerning the effect of overconfidence on falling prey to temptation in the context of asset allocation using the absentminded investor framework.

\section{Conclusion and Future Work}

The experiment we ran, helped us discover under what set of parameters (flashing Exit signs speeds) do subjects divide into two well-populated sets, which replicate the two equilibria of the absent-minded driver paradox in a laboratory set-up. Roughly one third of subjects played the "safe-risky" time inconsistent equilibrium (PR equilibrium), and the other two thirds played the more standard, time consistent equilibrium (traditional economic theory equilibrium). Thus, our main contribution was to translate the game theoretic approach of Piccione and Rubinstein (1997) into an investment game by making an analogy between an absent-minded driver and an absent-minded investor. Just like the driver cannot distinguish the exit that leads home on the highway from the one that leads into a bad neighborhood, the investor cannot distinguish between good and bad risky assets because she doesn't know where she is in the financial cycle. To our knowledge, this is the first laboratory study that attempts to apply the absentminded driver paradox to an asset allocation game in the laboratory.

The second contribution of this study is to reveal the importance of a normative approach in the planning stage. Not only it helped participants distinguish between the two stages of the asset allocation game, but it also taught us an important lesson in financial planning: the significance of a normative approach in inducing participants to think of their long-term retirement goals.

Finally, our experiment offers an insight into the role played by temptation and overconfidence in an asset allocation game, using retirement savings. Although specific to the way we framed our experiment, results show there is a positive association between overconfidence and time inconsistent decisions, between the planning and action stage of an asset allocation game using retirement savings.

We plan to continue our research in the following steps. First, we plan to stay within the boundaries of the present non-repeated game and explore the consequences of a few important modifications to the current setup. The first exploration has to do with varying the type of saving plans and decisions subjects 
are confronted with. Subjects may behave differently if for example they are told that they are saving for college rather than retirement. Re-running the experiment with different saving conditions may shed light on the different degrees of time inconsistent asset allocations as the nature of the saving plans is altered. Another interesting and important manipulation involves replacing individual decisionmaking with a simulated "household-level" decision-making game, since in practice plans and decisions involving retirement saving are not made by single individuals, but by multiple person households. Prior literature has found that in the presence of social learning, saving decisions more closely resemble decisions based on models of rational behavior (Brown et al. 2009). These findings suggest another natural extension, allowing a household to learn from the decisions of the most successful households. Learning would involve a repeated game setup, to which we turn in the second stage of our research agenda.

Second, we plan to focus on the implications of the repeated decisionmaking game, extending the one period game to a multi-period repeated one in which subjects can plan for their retirement only once, but are given the option of making their asset allocations multiple times. The reasoning behind this implementation is that in reality one has the option to change the contribution in their benefit plans at any time. Our purpose is to understand the mechanisms that explains why individuals get short sighted when it comes to investing, in favor of satisfying shorter term needs. We propose to start with individual decision-making and then turn the setup into simulated household-level decision making with and without social learning conditions.

A third avenue includes investigating belief formation and the existence of behavioral strategies by eliciting beliefs from participants, at different stages of the game. To start with, we want to see whether participants change their beliefs regarding the probability that the risky asset is "good" or "bad" when they play repeatedly. Since in our current setup chance is the sole determinant of the risky asset being associated with a high or low payoff, playing repeatedly shouldn't affect player's beliefs in any way. We speculate that players will be affected by cognitive biases which will lead them to change strategies and beliefs between consecutive rounds. Specifically, we want to investigate whether participants are affected by the hot hand belief, the belief in positive autocorrelation of independent events, or gambler's fallacy, the belief in negative autocorrelation of independent events, as found in studies such as Salaghe et al. (2016).

\section{References}

Ameriks J, Caplin A, Leahy J (2003) Wealth accumulation and the propensity to plan. The Quarterly Journal of Economics 118: 1007-1047.

Ameriks J, Caplin A, Leahy J, Tyler T (2007) Measuring self-control problems. American Economic Review 97(3): 966-972.

Ballinger TP, Palumbo MG, and Wilcox NT (2003) Precautionary saving and social learning across generations: an experiment. The Economic Journal 113(490): 

920-947.

Ballinger P, Hudson E, Karkoviata L, Wilcox NT (2007) Saving performance and cognitive abilities. University of Houston manuscript.

Barber BM, Odean T (2001) Boys will be boys: Gender, overconfidence, and common stock investment. The quarterly journal of economics 116: 261-292.

Barucci E, and Marazzina D (2012) Optimal investment, stochastic labor income and retirement. Alied Mathematics and Computation 218(9): 5588-5604.

Benartzi S, Thaler RH (1999) Risk aversion or myopia? Choices in repeated gambles and retirement investments. Management science 45(3): 364-381.

Benartzi S, and Thaler R (2007) Heuristics and biases in retirement savings behavior. Journal of Economic perspectives 21(3): 81-104.

Benartzi S, Thaler RH (2013) Behavioral economics and the retirement savings crisis. Science 339: 1152-1153.

Bernheim D (1995) Do households areciate their financial vulnerabilities? An analysis of actions, perceptions, and public policy. Tax policy and economic growth 3: 1113.

Bernheim BD, Skinner J, and Weinberg S (2001) What accounts for the variation in retirement wealth among US households? American Economic Review 91: 832857.

Brown AL, Chua ZE, Camerer CF (2009) Learning and visceral temptation in dynamic saving experiments. The Quarterly Journal of Economics 124(1): 197231.

Carroll CD, Overland J, Weil DN (2000) Saving and growth with habit formation. American Economic Review 90: 341-355.

Carroll CD (2001) A theory of the consumption function, with and without liquidity constraints. Journal of Economic perspectives 15(3): 23-45.

Choi KJ, Shim G, Shin YH (2008) Optimal portfolio, consumption-leisure and retirement choice problem with CES utility. Mathematical Finance 18(3): 445472.

Dybvig PH, Liu H (2010) Lifetime consumption and investment: retirement and constrained borrowing. Journal of Economic Theory 145(3): 885-907.

Farhi E, Panageas S (2007) Saving and investing for early retirement: A theoretical analysis. Journal of Financial Economics 83(1): 87-121.

Fehr E, Zych PK (1998) Do addicts behave rationally? Scandinavian Journal of Economics 100(3): 643-661.

Gale WG, Harris BH, Levine R (2012) Raising household saving: Does financial education work. Soc Sec Bull 72(2): 39-48.

Hamermesh DS (1984) Life-cycle effects on consumption and retirement. Journal of Labor Economics 2(3): 353-370.

Hey JD, Dardanoni V (1988) Optimal consumption under uncertainty: An experimental investigation. The Economic Journal 98(390):105-116.

Johnson RW, Smith KE, Cosic D, Wang CX (2017) Retirement Prospects for the Millennials: What is the Early Prognosis? CRR WP 17.

Kotlikoff LJ (2001) Essays on Saving, Bequests, Altruism, and Life-Cycle Planning. MIT Press.

Laibson D (1997) Golden eggs and hyperbolic discounting. The Quarterly Journal of Economics 112(2): 443-478.

Lusardi A, Mitchelli OS (2007) Financial literacy and retirement preparedness: Evidence and implications for financial education. Business economics 42(1): 3544. 
Morrissey M (2016) The state of American retirement: How 401 (k) s have failed most American workers. Economic Policy Institute 3.

Munnell AH, Hou W, Webb A (2014) NRRI update shows half still falling short. Center for Retirement Research at Boston College 14-20.

Munnell AH, Rutlege MS, Webb A (2016) Are retirees falling short? Reconciling the conflicting evidence. In OS Mitchell, RC Shea (eds) Reimagining Pensions: The next 40 years, 11-36. Oxford: Oxford University Press.

Papadovasilaki D, Guerrero F, Sundali J (2018) The effect of early and salient investment experiences on subsequent asset allocations-An experimental study. Journal of Behavioral and Experimental Finance 19: 1-19.

Piccione M, Rubinstein A (1997) On the interpretation of decision problems with imperfect recall. Games and Economic Behavior 20: 3-24.

Rhee N (2013) The Retirement Crisis: Is It Worse Than We Think? National Institute on Retirement Security.

Salaghe F, Sundali J, Nichols M W, and Guerrero F (2016) An Empirical Investigation of Wagering Behavior in a Large Sample of Slot Machine Gamblers. Bay Area Behavioral and Experimental Economics Workshop.

Sass SA, and Ramos-Mercado JD (2015) Are Americans of all ages and income levels shortsighted about their finances? Age 25: 34.

Scholz JK, Seshadri A, Khitatrakun S (2006) Are Americans saving "optimally" for retirement? Journal of political economy 114(4): 607-643. 


\section{Appendix 1: Experimental Instructions}

\section{Experiment Instructions}

\section{Participant Number:}

The purpose of the present study is to advance our understanding of how people invest their retirement savings. To do so, we are going to play a game in two stages. The first stage is very simple and consists of answering just one question. The second stage consists of actually playing a game.

\section{Experiment Overview}

In this experiment we will make the analogy between an absentminded driver that gets distracted while driving and isn't sure which exit to take to get home, and an absentminded investor that is not sure whether a risky stock will be a good or bad investment. Both the absentminded driver and the absentminded investor are presented with a safe and a risky option. The safe option for the driver is to take the highway and drive all the way to the end where she can spend the night at a motel. The driver can get to the motel with certainty as there are no exits that she needs to take. Similarly, the investor can choose the safe road to retirement and invest her retirement savings in the safe asset. The risky option for the driver is to take an exit, knowing that she can't get back on the highway if it is the wrong one. If she takes the wrong exit she ends up in a bad neighborhood (associated with a payoff of zero), while if she takes the exit and it turns out to be the correct one, she ends up home (associated with the highest payoff). The analogous of taking the exit for the investor is to invest in the risky stock, not knowing whether it will have a high or low payoff.

\section{The experiment consists of 2 stages, a planning stage and an action stage.}

The planning stage begins by answering a question as of how you PLAN to prepare for retirement. Imagine you must start saving for retirement, in order to provide for yourself during the years when you will not be able to work. Once you have saved some money out of your paychecks, the issue will be how to invest your savings to guarantee yourself a future retirement income. You can plan to invest your retirement in either a moderately safe asset that provides relatively predictable returns, or in a risky asset that has uncertain returns. It is impossible to know in advance whether the risky asset will turn out to be good or bad. The only thing you know about the risky asset is that $50 \%$ of the time it pays a high return and the other $50 \%$ pays nothing, or 0 .

In the action stage, the actual decision of investing your savings in the safe or risky asset will be made. The absentminded driver starts driving on the retirement highway and must choose the optimal strategy: to drive all the way until the end of the highway (spend the night at the motel), or to take the exit when reaching an intersection. Driving to the motel is equivalent to investing in the safe asset while taking the exit is equivalent to investing in the risky asset. At this point there is no turning back and you must face the consequences of your decision. Chance determines the nature of the risky asset and payoffs are revealed. 
Please go ahead and enter the "Participant Number". This is the number written on the sticker on your screen.

\section{Continue by entering the number:}

\section{Stage 1: Planning Stage}

Imagine that you will have to provide for yourself during the years when you will not be able to work. Once you have saved some money out of your paychecks, the issue will be how to invest the money in order to guarantee yourself future retirement income. There are two assets in which to invest your retirement savings. The first asset is a (moderately) safe asset that provides relatively predictable returns. You can think of the safe asset as a balanced index of stocks and bonds in large American companies, such as the companies in the Dow Jones Industrial Average. Investing in the Dow Jones is not likely to provide extraordinarily high returns, but is quite likely to "get the job done." In other words, it is a secure investment with relative low risk, that will ensure your future retirement. The other asset available to invest your retirement savings is a risky asset that has uncertain returns. You can think of the risky asset as investing in some brand new bioscience company stock. There are many new bioscience companies in the market. If you pick the wrong bioscience stock then the risky asset will implode and pay nothing, but if you pick the right bioscience stock then you will end up with very high returns well in excess of the safe asset.

Knowing whether you have picked the right or wrong risky asset will be impossible. In other words, it is impossible to know in advance whether the "new" stock is a scam. The only thing you know about the risky asset is that $50 \%$ of the time it pays a high return of 4 experimental dollars, and the other $50 \%$ pays nothing, or 0 experimental dollars. When the risky asset pays zero you will be left with no income during your years in retirement. You should assume that you will not be able to rely on Social Security. On the other hand, if you decide to invest in the safe asset you will get a certain payoff of 1 experimental dollar. Please keep in mind that you will be playing the game with experimental dollars that will be converted to real money at the end of the experiment. For now just make your decisions based on relative payoffs. For example, a payoff of 4 experimental dollars will be associated with four times more earnings compared to a payoff of 1 experimental dollar.

Keep in mind that this is the PLANNING STAGE, and you will be asked to declare what you SHOULD invest your savings in. In other words, you are declaring what you SHOULD be doing with your retirement savings, not necessarily what you will do. Be mindful that this just a plan, and you can alter your plans later on, in the action stage. You can proceed now to answer the question on your screen. BUT DO NOT CLICK NEXT BEFORE YOU ARE TOLD TO DO SO.

Q: In what asset SHOULD you invest your savings?
A:
a) Safe asset
b) Risky asset

No go on by explaining the reason behind selecting your strategy. DO NOT CLICK NEXT BEFORE YOU ARE TOLD TO DO SO. 


\section{Stage 2: Action Stage}

There will be two basic elements on the screen you will see in a while:

- Retirement Highway

- Flashing Exit Signs

Exit signs will flash on your computer screen to try to represent your fictional movement along the retirement road. Your task will be to try to count the rapidly flashing Exit signs in order to identify which exit you are at. Correctly identifying the exit is akin to knowing whether the risky asset is good or bad. However correctly identifying the exit will only reveal the true nature of the risky asset, it will not change it (If the risky asset is bad it will continue being bad regardless of you counting correctly).

To give you an idea as of how the highway will look like, please go ahead, enter next, and try to count the flashing signs that will appear in 30 seconds on your screen. Continue by answering, which exit you think you are at by pushing next. The next screen will reveal whether your counting was accurate or not.

In the action stage, the highway has a "critical region" comprising of Exit 16 and Exit 17. After counting the flashing exits you will arrive at the "critical region." There you will have to decide if you want to continue on the highway or take an Exit. If you decide to continue on the highway, you take no risk and you will get a payoff of 1 experimental dollar, corresponding to investing in the safe asset. In other words, imagine as if you decided to invest your retirement in the balanced index of Treasury bonds and stocks of large American companies. If you decide to take the Exit then you will either get a payoff of zero experimental dollars, which is akin to having picked the wrong bioscience stock, or you will get a payoff of 4 experimental dollars, which is akin to having guessed correctly and picked the right bioscience stock.

Only by correctly counting the flashing signs, you can identify which exits you are at, exit 16 or 17. You will only be allowed to exit at Exit 16 or 17. If you happen to exit at Exit 16, the new bioscience stock pays $\$ 0$ experimental dollars. If you happen to exit at Exit 17, the new bioscience stock pays $\$ 4$ experimental dollars. Chance, which will be implemented by a coin toss, will determine if you will see 16 or 17 flashing signs, ie whether the new bioscience stock is the good or the bad payoff.

\section{Coin Toss:}

The Role of Chance in determining at what Exit you will be allowed to Exit This procedure determines if you see 16 or 17 flashing exit signs.

Please toss the coin on your desk and enter on the computer screen either $T$ for "tails" or H for "heads."

The "ACTUAL" action stage will begin next. When you click on next you will start your way along to retirement and the flashing signs will appear in 30 seconds. You have to ensure that you will be able to count the flashing signs correctly.

Do not continue until you are being told to do so.

Please enter the number ----- and then click "next".

Please go ahead and answer the following questions on paper.

Questions on Beliefs about HERE (PAPER-based)

Question: What's your best guess that you have counted the flashing exit signs correctly and that you know where you are on the highway? Options:

1. probability of having counted correctly $=1$ (or 100\%)

2. probability of having counted correctly $=0.9$ (or $90 \%)$ 
3. probability of having counted correctly $=0.8$ (or $80 \%)$

4. probability of having counted correctly $=0.7$ (or 70\%)

5. probability of having counted correctly $=0.6$ ( or $60 \%)$

6. probability of having counted correctly $=0.5$ (or $50 \%)$

7. probability of having counted correctly $=0.4$ (or 40\%)

8. probability of having counted correctly $=0.3$ (or 30\%)

9. probability of having counted correctly $=0.2$ (or 20\%)

10. probability of having counted correctly $=0.1$ (or 10\%)

11. probability of having counted correctly $=0$ (or $0 \%)$

On the next screen you will need to decide whether to exit or not.

Deciding whether to exit or not

Expected Value calculation

Given your guess about the probability of having counted Exits correctly, the expected value of exiting the road is:

Prob (correct count) $* 4+$ Prob (incorrect count) $* 0=X>=<1$

At this point you have to compare the alternatives of staying on the road and exiting the road.

Please enter the number ----- and then click "next".

To declare whether you will exit at this point of the game or not, please check the respective box on the computer screen and answer this question:

- Would you like to take this exit now?

i. Yes

ii. No.

Please go ahead and check whether you would like to exit or not.

PLEASE CLICK ON "NEXT" answer the following questions:

1. Why did you choose what you chose now?

2. In which exit do you think you are at?

Do not continue before you are told to do so.

\section{Compensation}

You will now be paid in cash for your participation. You will receive the amount that you have earned based upon your decisions. Experimental dollars are converted into actual dollars at a rate of 1 Experimental dollar $=\$ 4$

To be compensated you need to fill out your subject payment receipt. Please do not proceed until one of the research team members checks that you have entered the correct numbers on your subject receipt. You will find the subject receipt in the documents next to your keyboard.

\section{Survey}

Please click on "Survey" and fill out the questionnaire.

\section{Actual payment procedure}

After you complete the survey bring the receipt to the experimenters. You will be paid individually and anonymously and no one else, other than the experimenters, will know how much you received. 


\title{
How to Survive with Various Sets of Ethical Values
}

\author{
By Eduardo V. López*
}

The repetition of governance fiascos made it necessary to reassess the fundamentals of what have up till now been considered to be undisputable knowledge. As outdated governance practices are incapable to cope with the challenge presented by the struggle between business and society ethics, the sources of deviance need to be identified to adopt new governance approaches able to drive simultaneously business success and social responsibility. This paper highlights the existence of various sets of ethical values that people pick for different contexts, and that interact with other factors such as personal interests, allegiances, and opportunity. This process is depicted by the ethics cube. The shuffling of this cube disturbs professional ethics by presenting characteristics such as selfishness, idealism, and pragmatism into the picture. The outline of two new concepts: The Small Sins Allowed (a level below which adherence to ethical standards is not anticipated), and the Line of Impunity (the judgment that privileges are permitted for upper ranks), help to understand the mechanics of shifting ethical values. (JEL G30, G41, Z13)

Keywords: Ethics Cube, Line of Impunity, Small Sins allowed, Various Sets of Ethical Values.

\section{Introduction}

It is generally accepted that parental examples, religious teaching, early socialization at school and other get-together settings (sports, street, clubs, parties, etc.), along with the legal system, are constituents of universal and local beliefs that shape individual ethics. Linking the ethical attitude of the individual with the standards of a group has always been thought-provoking because group ethics requires conformity with the shared values of the majority. As different groups might have dissimilar ethical standards, moral relativism admits that it is incorrect to assume that the same ethical framework applies to all of them. The presence of cultural alterations and varied perceptions of moral intensity (Jones 1991) lead to a subjective field where several ethical mentalities have dissimilar tolerance for irregular behaviors. When Friedman (1970: 32) presented the idea of rules of the game, saying that "there is one and only one social responsibility of business... to increase its profits", business ethics differentiated itself from their player's individual ethics. Supporting this particular group's ethics, even when it might imply deviant or anomic behaviors, was driven in some cases by the need of belongingness and in other instances compelled by personal ambitions, still when the logic of this economic conception undermined the values embraced by the society at large.

\footnotetext{
*Assistant Professor of Management, Belmont University, USA.
} 
Ethical issues in business may be associated to values, rights, operations, deliverables, society, and government. Some shared views discuss unsafe product and workplace, infringement of labor regulations, discrimination, unfair treatment of minorities and women, harassment, environmental issues, product quality, theft, fraud, bribery, embezzlement, absenteeism, conflict of interests, unethical decision making, withdrawal, vandalism, sabotage, taking unfair advantages, buying influence, privacy, security of company records, appropriation of other's ideas, deceptive sales practices, rule violation, misguiding advertisement, corporate social responsibility, ideology, attitudes, and stakeholder management.

Corporate anomie and deviance are associated with characteristics such as double standards, absence of accountability, privilege to bend the rules, a feeling of being above others, and the rationalization that everybody else does it. With perceptions affected by circumstantial variables, economic and group values tend to relax the logic of morality such that some social strata join nonconformist conducts, increasing the tolerance level toward rule violations and allowing for devious behaviors to be disregarded. Brooks (2012: A23) noted that "the value of success substituted the value of virtue. As striving aggressively for success is encouraged by our customs, many people are compelled by determination to succeed at all cost, even by sacrificing ethics". Accent on outcomes make public accept as true that, without examination of principles, success is never wrong, while failure always is.

Renz (2007: 45) warned about the presence of "a gap in an integrative and complete institutionalization of the ethical discourse" when ethical issues are not discussed, analyzed, and meditated upon, when the experiences are not shared, and when the ethical considerations of policy development are not explained. Bandura et al. (1996: 365) sustained that "people do not ordinarily engage in reprehensible conduct until they have justified to themselves the rightness of their actions". Sykes and Matza (1957: 22) explained that the means used to do that are known as moral neutralization techniques (denial of responsibility, denial of victim, denial of injury, condemnation of condemners, and appeal to a higher loyalty). Consequently, any governance system must encourage a culture where shots at neutralization are not consented, generating an inner communication atmosphere that permits employees to speak up when meeting moral challenges, as muteness is a partner of neutralization.

As ethics designates actions that are right or wrong in unambiguous contexts and circumstances, it was detected that individuals could have as least two different brains or "sets of ethical values." Related to their individual ethics, Ariely (2009: 99) alleged that "even the most brilliant and rational person, in the heat of passion, seems to be absolutely and completely divorced from the person he thought he was". In the case of group ethics, individuals could have a professional brain and a social brain to apply discretionary according to the situation. Ludlow (2013: 2) postulated that "the mid-level managers... in the context of their jobs, had a separate moral code altogether". Ferrell et al. (2019: 138) highlighted the difference between moral philosophy and business ethics, sustaining that while the first is an individual person-specific choice of principles and values, the second comprises decisions made by groups performing duties aimed to meet business 
objectives in accordance to what the organization defined as correct or incorrect activities that relate to its corporate operations. Facing diverse settings, individuals may have even more than two brains. Lopez (2016: 366) found evidence of subgroups across organizational ranks.

\section{Methodology}

This study is framed by a set of beliefs, assumptions, and values that define its research paradigm elements as follows:

Ontologically it is attached to subjectivism, as it views reality as socially constructed, created from perceptions and collective interactions.

Epistemologically it is aligned with constructivism, adopting a relativistic stance by supporting the existence of multiple realities. Reality is assumed as individually constructed.

Induction is the research approach in which its methodology is founded, as the analysis of the data, considering the context of the events, piloted to the formulation of the theory in such a way that the knowledge claims contained in the conclusions were not inferred in the premises. It was used an adaptation of the Sekaran's (2003) research process for applied and basic research.

The investigation entailed two phases; in the first one (qualitative) two focus groups helped on the development of the hypotheses, while in the second one (quantitative) a survey was used to test the hypotheses using participants from professional and academic networks. This multimethod approach followed the premises mentioned by Sobh and Perry (2006) that recommend the building of the conceptual framework using one method and its substantiation by means of a different technique.

\section{Findings}

\section{The Small Sins Allowed and the Line of Impunity}

In an attempt to explain the roots of corporate anomie and deviance, Lopez (2016: 233) has defined two new constructs. The first one, Small Sins Allowed (SSA), represents "a subjective mental model that establishes the level of certain behaviors above which adherence to ethical standards is expected. It can also be thought of as the ethical tolerance level that splits any dimension into two domains; above this level there are ethical standards to comply with and abide by, whereas below it there are no ethical concerns. This level represents a limit to the freedom of deviating deliberately from customary ethical behaviors and normally applicable rules and practices. No evil in the sense of morally objectionable behavior such as immorality, iniquity, malevolence, or viciousness is perceived below this level, where actions may be perceived by some as insignificant, minimized, understated, or belonging to the domain of permissiveness". 
Behaviors that fall under the SSA are excused of any moral connotation, laying between compliance and laxity as socially tolerated. Aligned with this concept, Ariely (2009: 292) said that "on one hand, we want to look in the mirror and feel good about ourselves... On the other hand, we're selfish, and we want to benefit from cheating...our flexible psychology allows us to act on both of them when we cheat just by a bit". Bitektine (2008: 76) mentioned the concept of a certain threshold or boundary when referring to social norms. The presence of some critical value of conformance with the expectations was then named "legitimacy threshold", which was recognized as the borderline between the socially accepted and the socially rejected behaviors. SSA instead differentiates between the fields of permissiveness and compliance. Where permissiveness does not imply socially accepted behaviors, but socially tolerated. Levine's (2005) "broken windows theory" is associated with the potential consequences of SSA suggesting that any small indication that something is amiss and not being taking care of sends signals about a lack of order, leading to lawlessness, and anarchy.

As individual attitudes and actions are related to the characteristics of its positions within an organization, a second construct, the Line of Impunity (LoI), "refers to the idea that certain ranks or positions in the social hierarchy entitle prerogatives or advantages, and that the power granted at those levels transcends the limits of control or law enforcement (such as in a tyranny). Overcoming the Line of Impunity consequently implies a rise in the ethical tolerance level (SSA), and hence a detachment from the customary ethical behaviors still demanded for lower ranks".

This concept is connected to the balance between risks and privileges. There are plenty of references related in one way or another to this concept, staring with Hofstede's (1984: 83) "power distance". Privileges and discrimination due to social rank were mentioned by Washington and Zajac (2005: 282), and Weber (1978: 305). The power of the elite was mentioned by Cohan, as the struggle for power, prestige and money characterized by ambition, elitism, talent, racial prejudice, impunity and perception of entitlement, where those engaged stayed unwilling or unable to realize their failures. The LoI represents a threshold that opens the door to foster manipulation, as there is perceived that different rules apply at higher echelons. Then, appealing to the field of politics serves to justify a disregard for the morality realm, as it is generally alleged that business decisions are built on strategy rather than on ethics. Even Porter (2012: B1), supports that corporate officials are rewarded for maximizing proceeds, not to behave ethically.

Academics like Brass (2002: 141) supported that power is an attribute of the position. Nevertheless, Nohria and Eccles (1992: 4) as well as Pryke (2005: 927) found a link between those positions and the actions, attitudes, and behaviors of its incumbents, which reaffirms Trevino's (1986: 603) assertion that both individual and situational variables have a role when dealing with ethical dilemmas. Fraedrich (1992: 14) sustained that individual's status within an organization could generate opportunities for unethical behaviors. In addition, it was observed a tendency in subordinates to pamper into self-deception by adopting the values, beliefs, attitudes, and behaviors of their superiors (Turnbull 1999: 129), or to accommodate their personal values to attain company goals (Carroll 1978). While 
opposing the LoI on moral grounds, Drucker (1986: 254) recognized its existence claiming that nobody should acquire exemption from ordinary rules due to their work or job. Academics like Stark (1993) recognized that a different kind of ethics is expected above certain hierarchy levels. Hiley (1987) found a link between power and values in organizational life. In his view, early behavioral studies as well as classical political theory are inadequate for understanding the concept of corporate power.

Solomon (1997) suggested that as a result of their grades, effort, and merit, a privileged class has appeared, being raised into power. Their success in corporate business made these people embrace a logic of social distance and inequality, standing as an out-of-touch manipulative and corrupt elite. Hayes (2012) argued that meritocracy has failed to fulfill its potential and that the social contract between the elites and ordinary citizens is wrecked. Brooks (2012) reaffirmed these concepts by asserting that the most capable elites have a leadership deficiency and they lack awareness of their social role, as the value of success has dethroned the value of virtue.

The Management Index (Bertelmann 2009) contains two dimensions, executive capacity and executive accountability, which in many cases seems to work in opposite directions. As one grows the other fades away. In his testimony before the U.S. Senate Committee on Banking, Housing, and Urban Affairs, Don Phillips (2004) -Managing Director of Morningstar, Inc.- stated that "the recent scandals make it abundantly clear that too many people in this industry is willing to forsake their responsibility in exchange for short-term personal profit. Sadly, these were not the acts of a few, low-level employees, but instead were violations of trust that took place at the highest levels, including company founders, CEOs, portfolio managers, and several current or former members of the Investment Company Institute's Board of Governors".

Levine (2005) referred to the propensity of some corporations to believe that they are so positive, so huge, so unbeatable, so much part of the modern civilization that they are not subject to the same examination by the public that makes any other company accountable. According to Davis et al. (2007) there is a general consensus among researchers and business analysts that the rising levels of executive rewards, along with the difficulties associated with monitoring top management activities, is creating an ethical dilemma. In view of the very few prosecutions of individuals resulted from the multiple fraud cases of the last times, Kelleher (2012: B1) speculated that the scarcity of criminal charges may cheer executives to test the legal boundaries. The absence of fear of punishment for ethical violations was described by Ross and Benson (1995: 350) as a cultural variable. Whilst Solomon (1997) talked about a sense of inequality and social distance embraced by corrupt and manipulative elites, Hayes (2012) blamed the meritocratic system mentioning that the social contract has been broken. Durham (2010) stated that many people are compelled by determination to succeed at all cost, often leading to unethical decisions. Stanford (2004) highlighted the existence of power abusers who frequently rule with unrestricted autonomy, as well as incidents of personal avarice among top executives, finding a positive correlation between the managerial level of authority and the potential for 
opportunistic actions, which reinforce the impression that unleashed conducts occur above the LoI. In this sense, Tiger Woods' extramarital affair provided a good example. Woods (2010) commented "I knew my actions were wrong, but I convinced myself the normal rules didn't apply... Money and fame made me believe I was entitled".

\section{Various Sets of Ethical Values and the Ethics Cube}

In order to depict how the various sets of ethical values operate, it was necessary to find a concept focused exclusively on the moral issue, independent of the traits of the moral agent or the organizational context. In this sense, Jones' (1991: 372) "moral intensity" captures the extent of issue-related moral imperative in a situation, including magnitude of consequences, social consensus, probability of effect, temporal immediacy, proximity, and concentration of effect.

The components of each set of ethical values are associated with the level of moral intensity assigned to certain factors. Figure 1 illustrates the case of four sets of ethical values. The horizontal axis represents the factors (desire, tolerance, ambition, apathy, irritation, resentment, and arrogance), the vertical axis specifies the levels of moral intensity. An analysis of the four sets of ethical values depicted in Figure 1 shows the differences among them. The highlights between individual ethics and social group ethics are that desire is constrained by the social group, while arrogance is boosted. Tolerance towards self and other's flaws and apathy increase in the social context. Moving to the professional ethics, desire and ambition, as well as irritation and resentment prevail, while there is also an increase in tolerance and arrogance. Finally, when considering the rank ethics, desire, ambition, irritation, and arrogance peak, while tolerance also increase, and apathy falls drastically. Overall, it is observed how these factors are pondered by each set of ethical values.

Along with the various sets of individual and group ethical values, other variables enter into the process of recognizing an ethical issue and acting upon it. Among them, personal interests, loyalties, and opportunity.

Personal interests denote private goals, feelings, and needs. From trivial to intricate, they comprise simplicities that can be obtained with no effort to aggressively pursued ambitions. Whatever biological or induced, associated with sensorial stimuli or with dreams, sometimes they have the muscle to bend, modify, and even replace ethical values. Ariely (2009: 293) expressed that "managing to see reality from a self-serving perspective is not an exclusive moral flaw, limited only to "bad people". It's a common human foible and is part of being human". 
Figure 1. Various Sets of Ethical Values

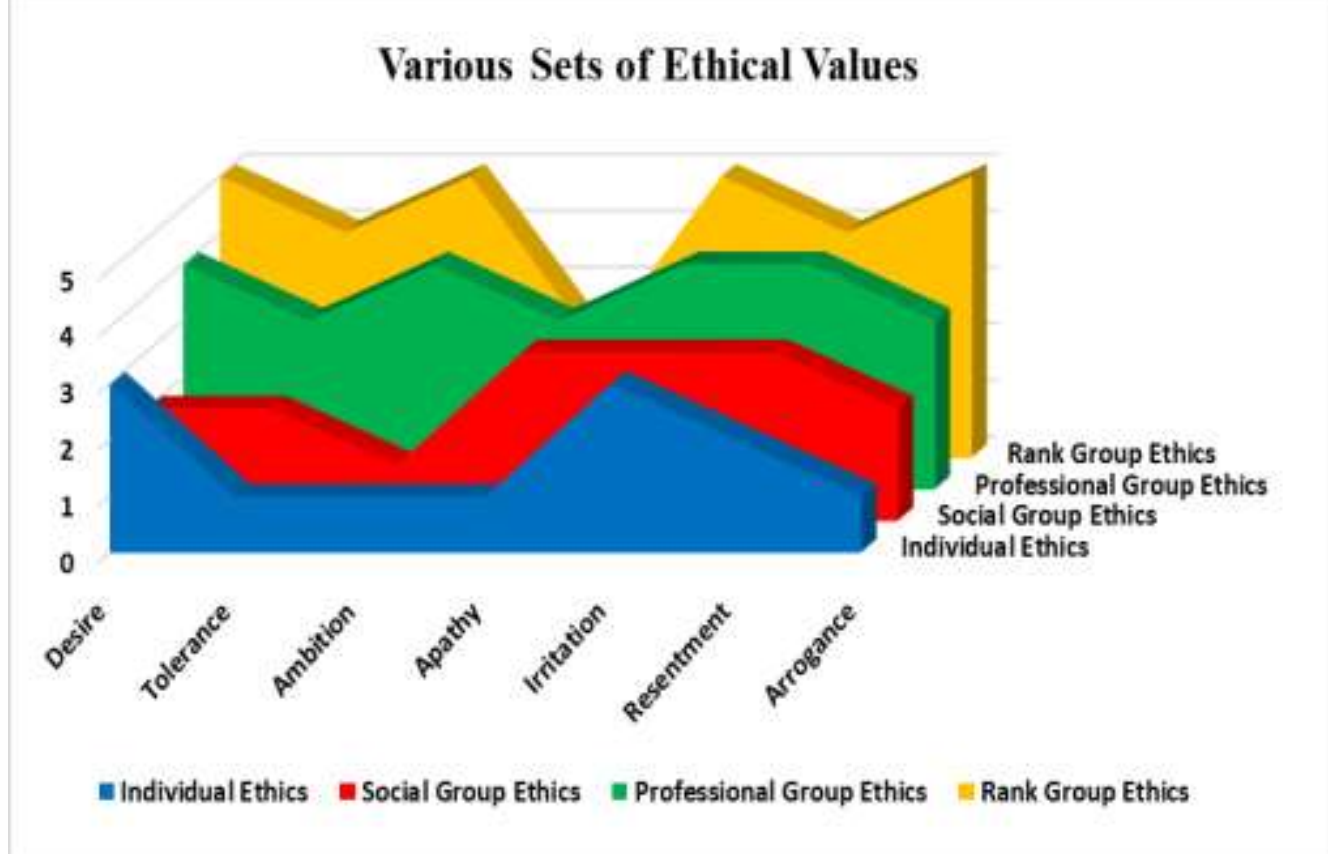

Source: Author.

Loyalties are strong feelings of allegiance, faithfulness, obedience, adherence, or devotion to an individual, a group, a cause, a country, or a faith. They are strengthened by social pressure and tough to modify. They could manifest in the form of herding (assuming other people's behavior), or differential association (attitudes favorable to the contravention of rules). Sometimes loyalties take precedence over ethical values and personal interests as they enjoy a higher level of devotedness.

Occasionally, people could undermine their values as the result of having the opportunity to take an advantage. In these cases, even truthful people could cheat. Trevino (1986: 608) warned that a lower moral judgment can be anticipated from managers in real job-related circumstances, than in reply to hypothetical predicaments. Ariely (2009: 202) said that "individuals are honest only to the extent that suit them".

Putting together the various sets of ethical values and the variables aforementioned, it is possible to build a tridimensional model capable to symbolize these components as well as its interactions. For instance, we could imagine a cube (like the Rubik's cube) where each face represents one of them. In such a way, one face symbolizes the attributes of the individual ethics, a second face denotes characteristics of social groups' ethics, as subsequent faces do with professional group ethics, personal interests, loyalties, and opportunity. In this way, for example, the professional group ethics face could display traits of efficiency, quality, cost consciousness, leadership, direction, risk propensity, and scrupulousness; while the opportunity face could display tendency to take advantage, unpredictability, unorthodox and hazardous courses of action, etc. 
In this theoretical state, each face displays solely its own attributes (imagine one color per face as in Figure 2). Nevertheless, as soon as ethical dilemmas surface, the cube becomes ruffled. In this condition, attributes of diverse faces are assorted irregularly, such that the faces lost their homogeneity. In this way, attributes of a particular set of ethical values (let's say professional ethics) are replaced by other traits that don't belong to it (Figure 3). It can be said that the shuffling process is stimulated by the SSA and the LoI (Lopez and Medina 2016).

Figure 2. Theoretical Ethical Cube

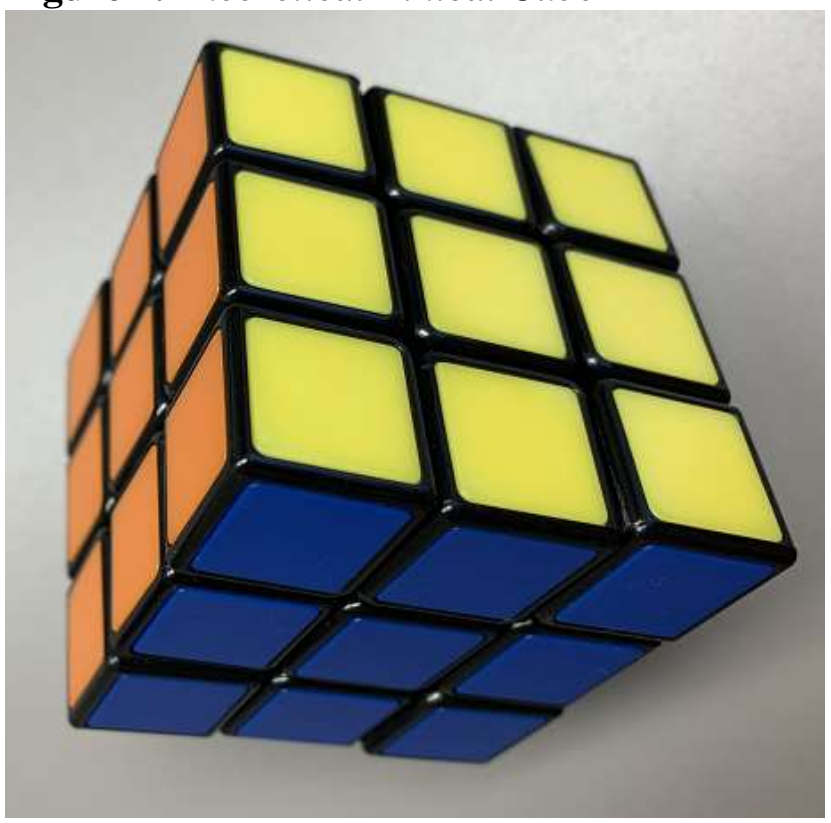

Source: Author

Figure 3. Shuffled Ethical Cube

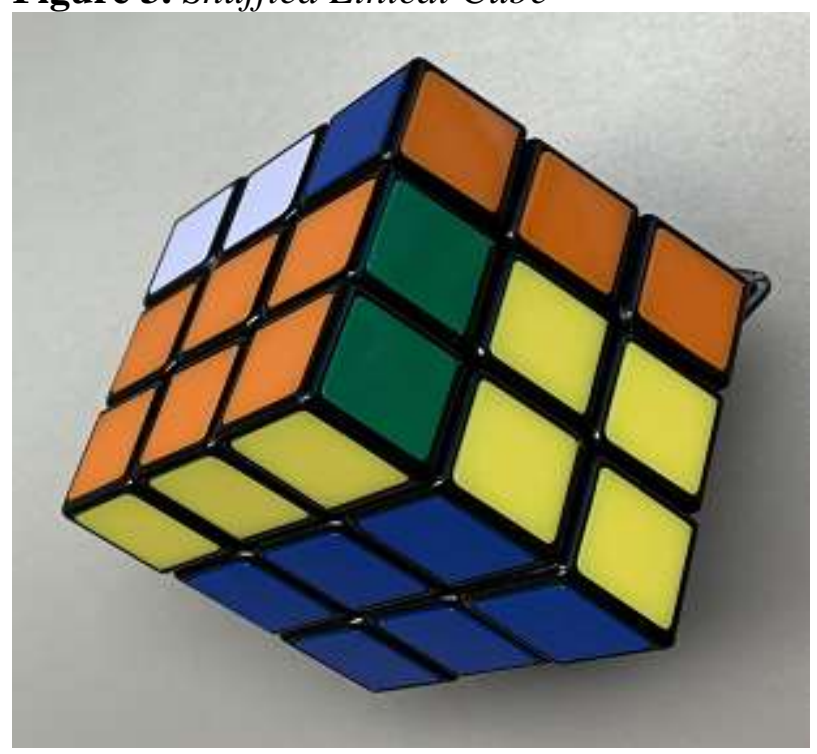

Source: Author 
As the Ethical Cube can be assumed to be a geometrical depiction of the governance system, it is worth reflecting about the contribution of the SSA and the LoI in this representation.

Three evidences should be considered:

1. An increase in either the size or the number of the SSA impacts negatively the quality of the governance system and vice versa.

2. When the LoI has been trespassed, the negative impact of the SSA upsurges. As a consequence, it can be said that the LoI affects the relationship between SSA and the governance system.

3. The context mediates in the way the SSA and the LoI affect the governance system. Reciprocally, the strength of the governance system reduces the incidence of the SSA, the chances of trespassing the LoI, impacting the context.

When there is a repetition of SSA, the professional group ethical posture is damaged as the confrontation approach towards unethical situations is worn out, and the monitoring and control attitude decays. Even the business objectives become blurred, ultimately reducing the chances of attaining them. The recurrence of SSA has a spiral effect that makes them grow over time, in such a way that something not tolerated at the early stages develops to be eventually tolerated. The SSA can be viewed as the ability to rotate the Ethics Cube's squares vertically.

The change in mentality that the perception of the LoI generates in the corporate ranks, facilitates the adoption of lax standards. Executives and managers that feel entitlement as legitimate are most likely lured into noncompliant conducts, which certainly involves a raise in the threshold associated with the SSA. The LoI can be viewed as the ability to rotate the Ethics Cube's squares horizontally. Additionally, the looseness or tightness of the Ethics Cube can be associated with context-related factors like anomie, cultural differences, scarceness-abundance, work environment, pressure and greed.

\section{Conclusions}

It was found that the SSA affects all the sets of ethical values, while the LoI affects principally the rank group ethics and in a lower degree the professional group ethics.

Governance systems change over time according to the prevailing ethical standards of the society. Whilst governance frames the permissible ethical behaviors, it is grounded on the ethical principles and expectations of the society in such a way that the relationship between ethical activities and governance is reciprocal and associated with the context where those activities take place. The expected ethical conducts appropriate for a profession, industry, or corporation, are the building blocks of the governance systems, which in turn will observe the outcomes of those sets of ethical values to avoid misconduct. Public perceptions, attitudes, and sentiments have changed. Consequently, achieving business 
objectives involves an alignment with the principal public beliefs. As such, trustworthiness is a fundamental element of the strategic management process. Conforming to societal ideals is the imperative that legitimizes business, as the ability to accomplish the social drive influences success. As social expectations are not merely associated with legal compliance but also with a correct attitude, accomplishing goals encompasses an alignment with community sentiments. Visions utterly molded in financial terms that relegates ethics will not last; they ought to go beyond boosting returns, sanctioning higher values.

Acknowledging that people operate with more than one set of ethical values, that they can be affected by situational factors, and that the presence of SSA and the LoI make it difficult to keep the ethical cube unshuffled, could be the first step toward defining a new and stronger business governance model, capable to resist deviant tendencies and to maintain an alignment with the social expectations. Working on the prevention and minimization of SSA and the LoI should be the paramount objective of a progressive governance that aims to keep all faces of the ethical cube pristine.

Looking into the future of ethics and governance, some aspirational directions of further analysis include a research into the dynamics of the components of the different sets of ethical values. An ideal development could be the depiction of a new and more sophisticated model that comprises all the variables that control the interactions among its parts.

\section{Acknowledgments}

My thanks to Dean Patrick Raines and Assistant Dean Stan York (Massey College of Business) at Belmont University for their continuous support of faculty scholarly advancement.

\section{References}

Ariely D (2009) Predictably Irrational. New York: Harper Collins.

Bandura A, Barbaranelli C, Caprara G, Pastorelli C (1996) Mechanisms of moral disengagement in the exercise of moral agency. Journal of Personality and Social Psychology 71(2): 365 .

Bertelmann (2009) Sustainable Governance Indicators: Policy Performance and Executive Capacity in the OECD. Gutersloh, Germany: Bertelmann Stiftung.

Bitektine A (2008) Legitimacy-based entry deterrence in inte-population competition. Corporate Reputation Review 11(1): 73-93.

Brass D (2002) Intraorganizational Power and Dependence. In JA Baum (ed) The Blackwell Companion to Organizations, 138-157. Malden: Blackwell Publications.

Brooks D (2012) Why Our Elites Stink? The New York Times: A23, (13 ${ }^{\text {th }}$ July 2012). Available at: https://www.nytimes.com/2012/07/13/opinion/brooks-why-our-elitesstink.html.

Carroll A (1978) Linking business ethics to behaviors in organizations. SAM Advanced Management Journal 43(3): 4-11.

Cohan WD (2014) The Price of Silence. New York: Scribner. 
Davis JL, Tyge Paine G, McMahan GC (2007) A few bad apples? scandalous behavior of mutual fund managers. Journal of Business Ethics 76(3): 319-334.

Drucker P (1986) Management: Tasks, Responsibilities, Practices. New York: Harper Collins Publishers.

Durham G (2010) Ethics: It Starts with you. Available at: http://www.pmi.org/About-Us/ Ethics/Ethics-It-Starts-With-You.aspx.

Ferrell OC, Fraederich J, Ferrell L (2019) Business Ethics: Ethical Decision Making and Cases, $\left(12^{\text {th }} \mathrm{ed}\right)$. Boston, MA: Cengage.

Fraedrich J (1992) Signs and signals of unethical behavior. Business Forum 17(2): 13-17.

Friedman M (1970) The Social Responsibility of Business is to Increase its Profits. The New York Times Sunday Magazine: 32-33.

Hayes C (2012) Twilight of the Elites: America after Meritocracy. New York: Crown Publishers.

Hiley D (1987) Power and values in corporate life. Journal of Business Ethics 6(5): 343353.

Hofstede G (1984) Cultural dimensions in management and planning. Asia Pacific Journal of Management 1(2): 81-99.

Jones TM (1991) Ethical decision making by individuals in organizations: an issuecontingent model. The Academy of Management Review 16(2): 366-395.

Kelleher D (2012) Corporate Fraud Cases Often Spare Individuals (8 August 2012). New York Times: B1.

Levine M (2005) Broken Windows, Broken Business: How the Smallest Remedies Reap the Biggest Rewards. New York: Business Plus.

Lopez E (2016) Influence of Ethical Behaviors in Corporate Governance. Saarbrucken, Germany: Lambert Academic Publishing.

Lopez E, Medina A (2016) Ethics and Governance in Project Management. Boca Raton, FL: CRC Press.

Ludlow P (2013) The Banality of Systemic Evil. The New York Times: 2.

Nohria N, Eccles RG (1992) Networks and Organizations. Boston: Harvard Business School Press.

Phillips D (2004). Testimony before the U.S. (25 February 2004). Senate Committee on Banking, Housing, and Urban Affairs.

Porter E (2012). The Spreading Scourge of Corporate Corruption (10 July 2012). The New York Times: B1.

Pryke S (2005) Towards a socila network theory of project governance. Construction Management and Economics 23(9): 927-939.

Renz P (2007) Project Governance: Implementing Corporate Governance and Business Ethics in Nonprofit Organizations. New York: Physica-Verlag.

Ross DL, Benson JA (1995). Cultural change in ethical redemption: a corporate case study. The Journal of Business Communications 32(4): 345-362.

Sekaran U (2003) Research Methods for Business: A Skill Building Approach, 4th ed. Hoboken, NJ: Wiley \& Sons.

Sobh R, Perry C (2006) Research design and data analysis in realism research. European Journal of Management 40(11-12): 1194-1209.

Solomon R (1997) It's Good Business. Lanham: Rowman \& Littlefield Publishers.

Stanford J (2004) Curing the ethical malaise in corporate America: organizational structure as the antidote. SAM Advanced Management Journal 69(3): 14-21.

Stark A (1993) What's the matter with business ethics? Harvard Business Review 71(3): $38-46$.

Sykes G, Matza D (1957) Techniques of neutralization: a theory of delinquency. American Sociological Review 22(6): 664-670. 
Trevino L (1986) Ethical decision making in organizations: a person-situation interactionist model. The Academy of Management Review 11(3): 601-617.

Turnbull S (1999) Emmotional labor in corporate change programmes. Human Resource Development International 2(2): 125-146.

Washington M, Zajac EJ (2005) Status evolution and competition: theory and evidence. Academy of Management Journal 48(2): 282-296.

Weber M (1978) Economy and Society: An Outline of Interpretive Sociology. Berkeley, CA: University of California Press.

Woods T (2010) Tiger Woods Admits Thought Entitled. New York Daily News - Entertainment. Available at: http:-thought//www.nydailynews.com/entertainment/gossip/tige r-woods-admits-thought-entitled-doesnt-deserve-forgiveness-article-1.197884\#ixzz2 Vol9pbTa. 


\title{
Social Welfare Consequences of the Radius of Employment Decency
}

\author{
By Thomas Dickson Ndamsa*, Gladys Njang ${ }^{\dagger} \&$ Francis Menjo Baye ${ }^{*}$
}

The private sector in Cameroon employs close to $90 \%$ of the labour force, and about $80 \%$ of those employed in this sector are in a situation of precarious employment. This paper investigated the private sector social welfare shares and impacts of employment decency among other regressed-income sources in Cameroon. Specifically, it (1) investigated the role of decent employment in shaping private sector inequality; (2) evaluated the share of decent employment in total social welfare of private sector households; and (3) examined the effect of growth in the mean value of decent employment on private sector social welfare. It employed the Cameroon Household Consumption Survey (CHCS III) conducted in 2007 by the Government's Institute of Statistics. Findings indicated that decent employments, human capital, and financial capital endowments have inequality-reducing effects. Our analysis further noted that good working conditions (decent employment), education and training facilities (human capital) as well as access to micro-credit (financial capital) accrue relatively more to the rich or privileged households than the poor or underprivileged households in the private sector. We found that a decision-maker who is absolutely equity seeking may lay more emphasis on micro-credit access, education and training programmes, and better working conditions, in that order, to obtain commendable social welfare outcomes. In addition, results indicated that if the decision-maker mediates 50:50 between efficiency and equity, then human capital endowments are ranked first followed by decent employment endowments in terms of social welfare enhancement. This order was maintained for more efficiency seeking policymakers. These findings indicated that policy measures focused on driving private sector working conditions, education and training facilities as well as improve micro-credit access should consider their relative disparities between the rich and the poor private sector households in order to better tap their inequality-reducing effects. (JEL D60, E24, D63)

Keywords: Decent Employment, Efficiency, Equity, Generalised Social Welfare Function and Private Sector.

\section{Introduction}

The past decade has witnessed a growing interest in the impact of development on poverty. This era is marked by burgeoning research interests and debates on the extent to which economic growth benefit the poor (Ravallion, 1998 and 2001,

\footnotetext{
*Senior Lecturer, University of Bamenda, Cameroon.

${ }^{\dagger}$ Assistant Lecturer, University of Bamenda, Cameroon.

"Professor, University of Yaounde II, Cameroon.
} 
Ravallion and Datt 2000, 2002, Quah 2001, Ravallion and Chen 2003). One school of the debate maintains that the potential benefits of economic growth to the poor are undermined or offset by the inadequate redistributive policies and by increases in inequality that accompany economic growth. Worthy of note, the UN (2015) posited that a continued lack of decent job opportunities will erode the potentials of the society to share in economic growth. This paper supports the UN (2015) by providing empirical evidence on the extent to which an increase in the situation of decent jobs can enhance social welfare in the private sector of employment. Another school argues that despite increased inequality in the liberal economic policies, open markets raise incomes of everyone in the society, including the poor, which proportionally reduce the incidence of poverty. However, we do not also have to forget that if open markets fail to consider people's social, economic and especially the fundamental employment rights of workers it may lead to deprivation. In effect, in the midst of globalization, the concern of policymakers should not be on which school is right or wrong, but rather on the ability to mediate between these prominent policy goals; income objectives (efficiency) and redistributive objectives (equity).

Poverty remains a major issue for developing countries, especially in SubSaharan Africa (SSA). For instance, Aoun (2004) intimated that poverty is an outsized and increasing problem in the world and he further underlined that most developing countries suffer from poverty. According to the World Bank (2000), SSA is one of the poorest regions in the world. The problem of widespread poverty in SSA is rooted in the economic downturn of the late 1980s. While jobs were at the core of economic policy even before the economic crisis, there was growing concern that many of the jobs being created were "vulnerable jobs", insecure in nature, marked by unstable pay and lack of representation. It is increasingly clear that employment is not always a guarantee to avoid poverty. A recent ILO (International Labour Organization) report estimates that roughly 500 million people (that is, $18 \%$ of the work force) in low income countries are 'working poor', living with an annual income below the poverty line (ILO 2007). Although these numbers have fallen, this decline has been driven essentially by development in China, South Asia, and middle-income countries. Despite the important gains during the second half of the 1990s, nearly 4 out of every 10 Cameroonians in 2001 were 'working poor', living with an annual income below the poverty line of FCFA 185,490 (F stands for franc and CFA for Communaute Financière d'Afrique ${ }^{1}$ ), roughly equivalent to US $\$ 1$ per person, per day, or FCFA 19,000 per month (Government of Cameroon, 2003). According to the Government of Cameroon (2007), the monetary poverty threshold in 2007 stood at 269,443 francs CFA per adult equivalent per year and the poverty situation between 2001 and 2007 remained almost the same; passing from 40\% to 39.9\%. Between 2007 and 2014, poverty witnessed a slight decrease in headcount (by 2.4 points) but this reduction failed to meet the target of the current government's policy document (Growth and Employment Strategy Paper - GESP) to reduce poverty to 35\% in 2015.

\footnotetext{
${ }^{1}$ It is the currency used in Cameroon and in some central African countries.
} 
According to the World Follow-up Report of $2008^{2}$, halfway towards achieving the MDGs, the progress achieved in the world is not satisfactory, particularly in Africa. In Cameroon, poverty reduction is a burning concern of the government, worrisomely Cameroon did not meet the 2015 millennium target of reducing poverty by half; as monetary poverty incidence only reduced marginally between 2001 and 2014 (Government of Cameroon 2014). One attractive characteristic of income poverty in Cameroon is its sector disparity. According to the Government of Cameroon (2007), only $10.2 \%$ of public sector workers are working poor; living below a monthly income of about $22,454 \mathrm{CFA}^{3}$ francs compared to $44 \%$ in the private sector. More organised and off farm sectors appear to be routes out of poverty. This is because only $9.5 \%$ of workers in formal private employment are working poor compared to $46.8 \%$ in informal employment. Equally, $20.4 \%$ of those in nonfarm private sectors are working poor as opposed to $59 \%$ in farming activities.

The situation of income distribution in Cameroon depicts a widening gap between the poor and nonpoor, formal and informal workers as well as between workers employed in farm and nonfarm sectors. Formal private sector income inequality remained higher than informal sector inequality in 2007. Per capita income inequality among formal private sector households stood at $38.7 \%$ compared to $35.3 \%$ in the informal sector. The same scenario is observed for farm and nonfarm private employment sectors, where nonfarm sector inequality stood at $34.3 \%$ in 2007 as opposed to $30.4 \%$ in the farm sector (Government of Cameroon 2007). These observed disparities suggest the need to accompany or blend income growth policies with appropriate redistributive policies to ensure the fruits of growth benefit all sectors in the economy. This is also indication that not only GDP growth, but also other factors like income distribution patterns associated with socio-demographic factors should be considered to address welfare concerns of the poor and nonpoor. Such factors like decent employment, human capital, financial capital just to mention a few may help enhance total social welfare represented in terms of efficiency (household mean income) and equity (household income distribution). This way, this paper is conducted to address the measurement of social welfare received by private sector households on the basis of mean income and income distribution, using the generalised social welfare decomposition framework. The paper innovatively decomposes social welfare as a weighted sum of individual welfare of various regressed-income components or endowments.

Given that the growing concern of most development policymakers is to identify key variables-cum policies that can boost income growth and enhance equity, thus improving social welfare, the main research question here is: What are the social welfare impacts of decent employment and other regressed-income sources? Specifically, this paper attempts to provide answers to the following questions:

\footnotetext{
${ }^{2}$ World Development Indicators: Report on the progress of the achievement of the Millennium Development Goals by region.

${ }^{3}$ The annual poverty line was estimated at 269,443 CFA francs per adult equivalent per year (giving 22,454 CFA francs per adult equivalent per month).
} 
- How does decent employment shape private sector income inequality?

- What is the share of decent employment and other regressed-income components in total social welfare of private sector households?

- What are the impacts of an increase in the mean value of decent employment and other regressed-income components on total social welfare of private sector households?

The main objective of this paper is to evaluate the private sector social welfare impacts of employment decency and other regressed-income sources. The specific objectives are:

- To investigate the role of decent employment and other regressed-income components in shaping private sector inequality;

- To evaluate the share of decent employment and other regressed-income components in explaining total social welfare of private sector households;

- To examine the private sector social welfare impacts of an increase in the mean value of decent employment and other regressed-income components on;

- To provide targeted policy measures that tackle income growth and equity simultaneously.

These objectives may help inform policymakers better on regressed variablescum-policies which can impact both income inequality and poverty. Confirming this policy objective, Kakwani et al. (2006) asserts that a policy menu that targets both distributional concerns and poverty reduction worries could lead to the enhancement of both economic growth and equity.

The rest of the paper is organized as follows: Section II reviews the literature that has attempted to blend efficiency and equity in the analysis of social welfare; Section III presents the theoretical framework; Section IV develops the methodology of the study; Section V presents the findings; and Section VI hosts the concluding remarks and policy implications of the paper.

\section{Literature Review}

The concept of social welfare function, as intimated earlier, was first introduced by Bergson (1938). He considered the social welfare function as a real-valued function that ranks conceivable social states from lowest to highest. Samuelson (1949) in turn evaluated the various ways by which social welfare function can be used in welfare economics. Economic literature measures social welfare either cardinally in terms of monetary units (say CFA franc or Dollar) or ordinal in terms of Pareto efficiency. The ordinal approach is made up of the Lorenz Dominance and Generalised Lorenz Dominance approaches whereas the cardinal approach is the measurement of social welfare using the Sen social welfare function (Sen-SWF). The Sen-SWF takes as inputs any variable considered to affect economic welfare (for example life expectancy or per capita income) of 
the population (Sen 1970:33). In this perspective, credit access (Pitt and Khandker 2002, Khandker 2005) and employment/job quality (Andolfatto and Gomme 1998, ILO 2014, European Commission 2018) stand out as important inputs into the Sen-SWF. Cardinal measures, unlike ordinal measures, are not aggregated from individual utility functions.

The ordinal approaches hinge on Atkinson theorem (Atkinson 1970) which holds that the Lorenz Dominance is a necessary and sufficient condition to identify welfare superiority in the dominating distribution, for a policymaker who is income-seeking and inequality-averse. For this theorem, the mean of the dominating distribution should be the same or higher than that of the dominated distribution. In specific terms, social welfare is higher in distribution B than distribution $\mathrm{A}$ if the following conditions are verified: (i) the Lorenz Curve of distribution $\mathrm{B}$ dominates that of distribution $\mathrm{A}$; (ii) the distributions have the same mean income or the mean income in $\mathrm{B}$ is greater than that in $\mathrm{A}$; and (iii) the policymaker is income-seeking and inequality-averse (that is, SWF has positive first derivative and negative second derivative with respect to individual incomes).

Baluch and Razi (2007) as Mukhopadhaya (2003) has applied the ordinal approach in Pakistan and Singapore respectively. Baluch and Razi (2007) observed that while social welfare in the society increased over-time, their comparisons were ambiguous because Lorenz Curves were intersecting. In such situations, cardinal measures are more appropriate. Nonetheless, Mukhopadhaya (2003) suggested that in such a case it is possible to find out different concave utility functions that can rank two social situations differently.

Critics, championed by Shorrocks (1983), attacked on the premise that it permitted comparison only when distributions have the same mean and produced ambiguous results when Lorenz Curves intersect. In an attempt to resolve these insufficiencies of the Lorenz Dominance criterion, Shorrocks (1983) extended Atkinson's formulation by introducing the concept of Generalized Lorenz Dominance Approach. This approach was estimated by scaling the ordinary Lorenz curve up by the mean income. He indicated that even if ordinal Lorenz Curves of two distributions intersect, the condition of generalised Lorenz Dominance could still be satisfied by testing for higher order of dominance.

However, it was observed that Lorenz Dominance and generalised Lorenz Dominance criteria of welfare comparison provides only partial ordering of social welfare considering only the inequality aspect (Baluch and Razi 2007). Moreover, according to Baluch and Razi (2007), these criteria ignore the economic efficiency/ growth aspect of social welfare considerations. In addition, Mukhopadhaya (2001c) and Baye (2011) underscore that the generalised Lorenz Dominance has profound efficiency bias. After the demerits of the generalised Lorenz Dominance approach, the search is for an approach that will consider both equality and efficiency considerations of social welfare. Fortunately, the expectations of the literature found refuge in Sen (1974).

Sen (1974) in an attempt to address the insufficiencies of the Lorenz Dominance criteria introduced the Sen-SWF which judges trends in total welfare and trends in its components (equality and efficiency). The Sen-SWF, a cardinal SWF with complete ordering, can be employed to assign numerical values of 
all possible social situations in the income distribution space. Baluch and Razi (2007) have also applied the Sen-type SWF on data from Pakistan. They observed that an increase in mean income of $0.5 \%$ and income inequality of 0.16 resulted to a $16.1 \%$ increase in welfare of rural areas as opposed to urban areas where a lower growth rate of $1.1 \%$ and higher income inequality of 0.48 led to a fall in welfare by $5.1 \%$ between 2001 and 2002 .

However, some endeavours have questioned the sole reliability on the Pareto criterion of Sen-SWF. Mukhopadhaya (2001b) has questioned the philosophy of Paretian principle as a desirable property of the SWF. He further demonstrated that it is possible to generalise the widely used Sen-SWF, which can be non-Paretian under special circumstances and to allow mediation between efficiency and equity considerations. Mukhopadhaya (2001b) has applied the method (generalised SenSWF) using Australian data to decompose total welfare into different factor components of income (Earned Income, Unearned Income and Government Benefit). Baye (2011) has also employed it on Cameroon data to decompose trends in social welfare across regions (rural, semi-urban and urban).

Some literature has focused on investigating whether increases in global social welfare are accompanied by increases in global population size (Parfit 1984, Burns and Hart 2000 and Cockburn et al. 2014). The work of Cockburn et al. (2014) employed the critical-level generalized utilitarianism (CLGU) approach to investigate if global social welfare has improved in the last decades because of the substantial increase in global population. Their study underlined that global social welfare can be deemed to have increased between 1990 and 2005 if it is judged that lives with per capita yearly consumption of more than $\$ 1,248$ necessarily increase social welfare. They posited that the same conclusion can be made for Sub-Saharan Africa if and only if the same judgement can be made for lives with a level of per capita yearly consumption above $\$ 147$.

It is evident that most attempts in the literature limit analysis of social welfare on income/expenditure and completely ignore the determinants of income. This paper adopts a new analytical perspective that uses the information contained in income generating equations to account for total social welfare in a given population. The analytical perspective derived here has advantages of its own. Because it relies on a regression framework, it expresses the level of total social welfare as a function of the income determinants that are used in the regression of income.

\section{Theoretical Framework}

The concern of most development policymakers is to design policy intervenetions that can revamp growth (income growth) and reduce income inequality; this is tantamount to increasing efficiency and equity. Efficiency and equity, components of the SWF, can be tracked by a non-utilitarian form of the Bergson (1938)-Samuelson (1949) SWF as follows:

$W=W(Y, \theta)$ 
Where $\mathrm{W}$ is total social welfare, $\mathrm{Y}$ is total income representing efficiency and $\theta=\theta\left(x_{1}, x_{2}, x_{3}, \ldots ., x_{n}\right)$ stands for a measure representing inequality. For this SWF (equation 1), an increase in efficiency and inequality will increase and decrease social welfare (W), respectively. With a reading of this function, it is clear that many SWFs will verify the above conditions. In an attempt to render the welfare function in equation (1) more specific, Sen (1974 and 1979) using a nonutilitarian approach ${ }^{4}$ introduced axiomatically the following SWF:

$W=\mu(1-G)$

Where $\mu$ is the mean income of the population and $\mathrm{G}$ is the Gini inequality coefficient of the income distribution ${ }^{5}$. This function indicates that an increase in mean level of income will lead to a higher level of social welfare and an increase in income inequality will reduce social welfare. It can be shown that the Sen-SWF also obeys the Paretian principle. For the Sen-SWF, the rate of substitution between mean income (efficiency) and income inequality at a constant welfare level is written as follows:

$\frac{\partial G}{\partial \mu}=\frac{1-G}{\mu}$

From equations (2) and (3), the Sen-SWF is more sensitive to mean income than to inequality. Given that both $G$ and $u$ are determined by the income profile of the society and cannot be influenced by the policymaker or decision-maker at different levels of growth or income distribution, this SWF is not flexible. The marginal welfare change with respect to mean income, in this case, is $(1-G)$ which is a constant. In this perspective, for any inter-sector comparison, this SWF will always be biased in favour of more advanced economic sectors with higher per capita incomes and relatively low inequality. Equally, in the case of an international comparison, this SWF will always be unfair or biased in favour of developed countries with relatively high per capita incomes and relatively low inequality.

Conscious of these shortcomings of the Sen-SWF, Mukhopadhaya (2001a) proposed a general and flexible SWF for policy mediation by incorporating a trade-off parameter, $\beta$, between efficiency and equity. This way, we have:

$W=\mu^{\beta}(1-G) \quad \forall 0 \leq \beta \leq 1$

Equation (4) is non-Paretian if $\beta$ is less than 1 (since when $\beta=1$, the modified SWF becomes the Sen SWF, which is Paretian). With equation (6.4), social welfare will decrease if the benefits of a growth process only go to the

\footnotetext{
${ }^{4}$ Note that all utilitarian SWFs are Paretian.

${ }^{5}$ Sen (1976) shows that this index, calculated from the income distribution, 'is a sub-relation of social preference relation defined in the distribution of commodities'. Alternatively, Yitzhaki (1979, 1982) showed that this index could be based on relative deprivation. Sheshinski (1972) also derived this index from the Gini coefficient.
} 
richest person in the society (for $\beta<1$ ). When $\beta=0$, the SWF becomes a function of inequality $(\mathrm{G})$ regardless of the level of efficiency of the population (Mukhopadhaya 2001b).

With this modified SWF, the rate of substitution between inequality and efficiency at a constant welfare level is given by:

$$
\frac{\partial G}{\partial \mu}=\left(\frac{1-G}{\mu}\right) \beta
$$

With variable values of $\beta$ the decision-maker now has the choice of $\beta$ depending on whether she is more income-seeking than being inequality averse. Thus, the SWF is now flexible with respect to the trade-off between efficiency and equity. If the decision-maker considers efficiency to be more important than equality, she will choose a higher value of $\beta$ (close to one). In the contrary, if she is more inequality averse than income-seeking, she will go for a lower value of $\beta$ (close to zero).

This SWF may be criticized on the basis of its unfairness in favour of the poor in the population. For instance, if the income of the poorest person increases irrespective of the values of $\beta$ and $\mathrm{G}$, social welfare must increase. In this perspective, this SWF has some Rawlsian flavour; according to which an increase in the richest person's (sector's) income does not change social welfare. Fortunately enough, in our modified SWF, with $\beta<1$, an increase in the income of the richest person (or sector) causes social welfare to decrease. Thus, the class of SWF (with $\beta<1$ ) is non-Rawlsian and also non-Paretian.

Kaldor-Hicks efficiency criterion takes a rather deviated stands stressing on the compensation of losers. It supposes that a decision can be deemed to be more efficient if it produces a net gain to the society and enables any potential losers to be compensated from the net gain secured. Their position tailors somewhat with Pareto efficiency, where this compensation can occur through voluntary agreements between losers and those who gain. This theory is strongly criticised for blowing economic welfare/economic utility above other moral considerations.

\section{Methodology and Data used}

\section{Decomposition of Social Welfare (W) by Regressed-Income Components}

Our new analytical perspective to social welfare consists to use information contained in an income-generating equation to decompose social welfare. We propose in this paper to baptise this approach 'regression-base perspective to social welfare ${ }^{6}$ The regressed-income components or endowments retained here are decent employment, human capital, financial capital, and household demographics. These regressed-income components will be further discussed

\footnotetext{
${ }^{6}$ This approach to social welfare that springs from a regression analysis is first of its kind; it has seen light thanks to this paper. The appellation 'regression-based perspective to social welfare' is born in this paper.
} 
below. We hinge on the framework proposed in Mukhopadhaya (2001b) to implement this analytical perspective.

According to Rao (1967), the Gini coefficient $(G)$ of income inequality can be decomposed by components of income as follows:

$$
G=\sum_{m=1}^{M} S_{m} C_{m}
$$

Where:

$S_{m}=\frac{\mu_{m}}{\mu}$ stands for the factor share of the regressed-income component;

$C_{m}$ is the concentration coefficient of the regressed-income component $m$; and

$M$ is the total number of regressed-income components.

The concentration coefficient of the regressed-income component is calculated using the same formula as the Gini coefficient; the ranking will remain the same as in the case of the Gini coefficient ${ }^{7}$. The deviation of the Gini coefficient from the concentration coefficient, $C_{m}-G$, represents the direction of inequality augmenting or reducing effect of the regressed-income component $\mathrm{m}$. Essentially, if certain regressed-income components accrue relatively more to the poor households than the rich in the private sector (for example programmes like free education for all that favour the poor) the concentration coefficient will be negative. Conversely, if the regressed-income factor accrues more to the rich households (say investment income or loans) the concentration coefficient would be positive and will exceed the value of the Gini coefficient. This way, if the concentration coefficient of any regressed-income component is higher (lower) than the overall Gini, the component has an inequality augmenting (reducing) effect. Thus, an extra CFA franc directed to the component will increase (decrease) overall inequality.

According to Mukhopadhaya (2001b), total social welfare can be represented as a weighted sum of individual welfare of various regressed-income components as follows:

$W=\sum_{m=1}^{M} a_{m} W_{m}$

Where $W_{m}$ is the welfare of the $m^{\text {th }}$ regressed-income component and $a_{m}$ is the weight attached to the individual component's welfare.

The generalised SWF can be represented as the weighted sum of individual component's welfare following the steps below. From equations (6) and (7), total social welfare, $\mathrm{W}$, is given by the sum of the product between the weights attached

\footnotetext{
${ }^{7}$ When a specific factor income is arranged in ascending order of total income and the proportion of factor incomes are plotted against the proportions of income units, we get the concentration curve. One minus twice the area of the concentration curve is the concentration index. Unlike Lorenz curve, the concentration curve may lie above the $45^{\circ}$ diagonal and in that case the concentration index will be negative. The value of the coefficient lies between $(-1,1)$ and, most importantly, it satisfies the Pigou-Dalton condition of transfer.
} 
to the $M$ regressed-income components and the welfare of these components. Thus, we have:

$$
\begin{aligned}
W & =\mu^{\beta}(1-G) \\
& =\mu^{\beta}\left(1-\sum_{m=1}^{M} \frac{\mu_{m}}{\mu} C_{m}\right) \\
& =\mu^{\beta}-\sum_{m=1}^{M} \frac{\mu_{m}}{\mu^{1-\beta}} C_{m} \\
& =\sum_{m=1}^{M} \frac{\mu_{m}}{\mu} \mu^{\beta}-\sum_{m=1}^{M} \frac{\mu_{m}}{\mu^{1-\beta}} C_{m} \quad\left(\text { as } \sum_{m=1}^{M} \frac{\mu_{m}}{\mu}=1\right) \\
& =\sum_{m=1}^{M} \frac{\mu_{m}}{\mu^{1-\beta}}\left(1-C_{m}\right) \\
& =\sum_{m}\left[\left(\frac{\mu_{m}}{\mu}\right)^{1-\beta}\right]\left[\mu_{m}^{\beta}\left(1-C_{m}\right)\right] \\
& =\sum_{m} a_{m} W_{m} \quad(8)
\end{aligned}
$$

Where $a_{m}=\left(\frac{\mu_{m}}{\mu}\right)^{1-\beta}$ is the weight attached to the regressed-income component or endowment $m$ and $W_{m}=\mu_{m}^{\beta}\left(1-C_{m}\right)$ is the welfare that accrues to that regressed-income component.

Thus, the relative welfare due to this component is written as follows:

$\frac{a_{m} W_{m}}{W}=\frac{\left[\left(\frac{\mu_{m}}{\mu}\right)^{1-\beta}\right]\left[\mu_{m}^{\beta}\left(1-C_{m}\right)\right]}{\mu^{\beta}(1-G)}=\left(\frac{\mu_{m}}{\mu}\right)\left(\frac{1-C_{m}}{1-G}\right)$

When we are interested in measuring the relative contribution of a component to total social welfare (W), the question of trade-off between efficiency and equity does not arise; reason why $\beta$ does not appear in equation (9). In equation (9), the last term in parenthesis on the right hand side, $\frac{1-C_{m}}{1-G}$, has an attractive economic interpretation and can be called 'relative equity of component $m$ '. If the value of the relative equity of component $m$ is greater (less) than 1 (one), the component will have an inequality reducing (augmenting) effect. Worthy of note, the relative welfare share accruing to a regressed-income component depends on the relative mean income $\left(\frac{\mu_{m}}{\mu}\right)$ and the relative equity of the component (see equation 9).

The effect of growth (that is, growth in the mean value) in a component on the total social welfare of the population is an important policy question. It is answerable here by determining the elasticity of total social welfare with respect to a change in the mean amount or value of the component as in equation (10) below:

$$
\begin{aligned}
\epsilon_{m}^{W} & =\frac{\partial W / W}{\partial \mu_{m} / \mu_{m}}=\left(\frac{\partial W}{\partial \mu_{m}}\right)\left(\frac{\mu_{m}}{W}\right) \\
& =\left(\frac{\mu_{m}}{\mu}\right)\left(\frac{1-C_{m}}{1-G}\right)+\left(\frac{\mu_{m}}{\mu}\right)(\beta-1)
\end{aligned}
$$

Equation (10) is the elasticity of total social welfare, W, with respect to a change in the mean amount of component $m$. This elasticity attempts to paint a 
scenario where this change is distributed proportionately among all private sector individuals so that no change occurs in terms of inequality. Importantly, this elasticity equals the relative share of the component when $\beta=1$ (this is simply because the second term on the right hand side vanishes for $\beta=1$ ). When $\beta<1$, the elasticity is less than the relative share; since the second term on the right hand side becomes negative. If the factor share of the component is high, the second term of equation (10) will be large and will only reduce the elasticity more. Essentially, it is also true that if the factor share of the component is small the reducing effect will be small.

These elasticities have important policy guides; in comparing the elasticities of the different components, a policymaker or decision-maker may use her judgment for an equitable policy mix. With this procedure, we will be able to assess the effects of growth in decent employment (or the effects of an additional CFA franc directed to boost decent employment) on total social welfare. Equally, we will provide the decision-maker with sound knowledge on the effects of growth in human capital endowment, improvement in credit access, as well as better family planning schemes on total social welfare of private sector households in Cameroon. In this context, policy targeting to improve social welfare may prioritise components for which both the relative share of welfare and the elasticity with respect to the mean amount are high.

\section{Combining Income Components}

Given the following linear regression, with no constant $^{8}$ (as per Control Function Regression ${ }^{9}$ in appendix - Table A4):

$$
\begin{aligned}
& y_{i}=\beta_{1} x_{i, 1}+\beta_{2} x_{i, 2}+---+\beta_{m} x_{i, m}+\varepsilon_{i} \\
& m=1,2, \ldots \ldots, M \text { and } i=1,2, \ldots \ldots, n
\end{aligned}
$$

Where, $\mathrm{Y}_{\mathrm{i}}$ is per capita monthly income of household $i ; \beta_{0}, \beta_{1}, \ldots, \beta_{m}$ are parameters to be estimated; $x_{i}(i=1,2, \ldots, n)$ the set of independent variables; and $\varepsilon$ is the error term.

It is possible from the regression results to generate the estimated income flows attributable to the various explanatory variables. These estimated income flows are obtained from $\hat{y}^{m}=X \hat{\beta}_{m}$. It then follows that total income is the sum of these income flows plus the residual:

\footnotetext{
${ }^{8}$ Given that the constant is not an income source per se, this regression was done without the constant term.

${ }^{9}$ The results internalize for potential endogeneity of employment decency and unobserved heterogeneity bias which standard Ordinary Least Squares may suffer from.
} 


$$
y_{i}=\sum_{m=1}^{M+1} \hat{y}_{i}^{m} \quad \text { where } \hat{y}_{i}^{m}= \begin{cases}\hat{\beta}_{m} x_{i}^{m} & \text { for } \mathrm{m}=1 \ldots \ldots . \mathrm{M} \\ \hat{\varepsilon}_{i} & \text { for } \mathrm{m}=\mathrm{M}+1\end{cases}
$$

The regressed-income source ${ }^{10}$ ' 1 ', $C_{1}$, is obtained as follows:

$$
C_{1}=y_{i}-\sum_{m \neq 1}^{M} \hat{y}_{i}^{m}
$$

Which can also be written:

$$
C_{1}=y_{i}-\left[\sum_{m \neq 1}^{M-1} \hat{y}_{i}^{m}-\hat{\varepsilon}_{i}\right]
$$

The other regressed-income sources $\left(C_{2}, C_{3}, \ldots \ldots, C_{M}, C_{M+1}\right)$ are obtainable in the same manner. Thus we have:

$$
\begin{gathered}
y=\hat{y}+\varepsilon \\
\text { Where } \hat{y}=C_{1}+C_{2}+C_{3}+\ldots \ldots+C_{M} \text { and } \varepsilon=C_{M+1}
\end{gathered}
$$

These regressed-income sources can now be combined in groups of regressedincome components according to the needs of the study. For instance, $C_{1}+C_{2}$ could form a component, $C_{3}+C_{4}$ another component and so on. The regressedincome components or endowments retained in our study are decent employment, human capital, financial capital, household demographics as per Table 1 below.

\section{Data Used}

The main data used here is the Cameroon household consumption survey (CHCS III) conducted in 2007 by the Government's Institute of Statistics. The variables used in this paper are solely inspired from the control function regression analysis placed at the appendix. However, in the analysis of social welfare here, we considered a decent employment indicator; whose primary variables/categories and its construction are displayed in the appendix as well. After combination of income sources, we obtained the following components:

\footnotetext{
${ }^{10}$ The use of the term 'regressed-income source/component' is inspired from the works of Wan (2002) and Morduch and Sicular (2002), but this appellation is unique in this paper; it refers to income sources/components generated from a regression model.
} 
Table 1. Combined Income Components

\begin{tabular}{|l|l|}
\hline Combined Income Components & Income Sources \\
\hline Decent employment endowment & Decent employment indicator \\
\hline Human capital endowment & $\begin{array}{l}\text { Experience, experience square; years of schooling; } \\
\text { and head of enterprise. }\end{array}$ \\
\hline Financial capital endowment & Access to micro-credit \\
\hline Household demographics & $\begin{array}{l}\text { Children below five years old; currently married; } \\
\text { male gender type; and urban residency }\end{array}$ \\
\hline Indirect decent employment endowments & $\begin{array}{l}\text { Predicted residual of decency and the interaction } \\
\text { term (interaction between predicted residual of } \\
\text { decency and decency indicator) }\end{array}$ \\
\hline Other income sources & $\begin{array}{l}\text { Residual term (sources not captured in the } \\
\text { structural equation) }\end{array}$ \\
\hline
\end{tabular}

Source: Authors.

\section{Empirical Results}

\section{Descriptive Statistics}

The descriptive statistics of the combined income components or endowments of the dependent variable (per capita household monthly income) are submitted in Table 2.

From Table 2, it is evident that in the private sector, human capital endowments have the highest share of the dependent variable, followed by decent employment endowments and household demographics, in the light of their means. However, financial capital endowments and other income endowments, not captured in our regression, are also potent when it comes to private sector household income. The indirect decent employment endowments have a lessening effect on the dependent variable.

Table 2. Descriptive Statistics of Combined Income Components

\begin{tabular}{|c|c|c|c|}
\hline Variables & Number of Observations & Mean & Standard Deviation \\
\hline \multicolumn{4}{|c|}{ Combined Income Components } \\
\hline $\begin{array}{l}\text { Decent employment } \\
\text { endowments }\end{array}$ & 9219 & 8368.495 & 11945.15 \\
\hline $\begin{array}{l}\text { Human capital } \\
\text { endowments }\end{array}$ & 9219 & 10719.13 & 4493.137 \\
\hline $\begin{array}{l}\text { Financial capital } \\
\text { endowments }\end{array}$ & 9219 & 414.958 & 641.0229 \\
\hline Household demographics & 9219 & 2176.465 & 4785.521 \\
\hline $\begin{array}{l}\text { Indirect decent } \\
\text { employment endowments }\end{array}$ & 9219 & -596.530 & 8185.521 \\
\hline Other income sources & 9219 & 427.312 & 17452.79 \\
\hline Total income & 9219 & 21509.83 & 20357.37 \\
\hline
\end{tabular}

Source: Computed by author from CHCS III Survey Data. 
Regression-based Analytical Perspective of the Generalised Class of Sen-SWF

Decomposition of the Generalised Class of Sen-SWF by Regressed-Income Components

Table 3 submits the necessary statistics to serve in the decomposition of total private sector welfare by regressed-income components or endowments. The first and second columns present the mean of each regressed-income component and its share in private sector total mean income and the last column hosts their concentration coefficients. The share of human capital endowments in total mean income is highest at about $49.8 \%$, followed by that decent employment endowment (38.9\%) and household demographics $(10.1 \%)$. The shares of the other endowments in total mean income are marginal and can come in the following order: other income sources (2.0\%); financial capital endowment (1.9\%); and indirect decent employment endowment (-2.7\%).

The Gini coefficient of total private sector household per capita income is estimated at 0.38 (Table 3 ). The values of the concentration coefficients of decent employment, human capital, and financial capital endowments are less than the overall Gini coefficient, illustrating their inequality-reducing effects. However, it should be noted that good working conditions (decent employment), higher education and training facilities (human capital) as well as access to micro-credit (financial capital) accrue relative more to the rich or privileged households than the poor or underprivileged in the private sector; reason why the values of their concentration coefficients though less than the Gini are positive. This is indication that though they have inequality-reducing effects, policy measures driven in their directions should consider their relative disparities between the rich and the poor private sector households in order to better tap these effects (inequality-reducing effects). These policy measures should ensure a level playing ground with equal opportunities.

In a nutshell, the values of the concentration coefficients of household demographics and indirect decent employment are in excess of the Gini coefficient, indicating their inequality-augmenting effects. Concerning household demographics, this is implication that family planning measures (like birth control to target the number of young children in households) and geographic considerations (zone of residence) be made part and parcel of policy arrangements interested to affect inequality. For indirect decent employment, the very high value of its concentration coefficient indicates that the power to bargain better or good working conditions and the ability to manage household shocks (like unemployment and birth) accrue overwhelmingly to the rich households in the private sector. 
Table 3. Factor Shares of Income Components and Concentration Coefficients

\begin{tabular}{|l|c|c|c|}
\hline Components & $\begin{array}{c}\text { Mean Value } \\
\boldsymbol{\mu}_{\boldsymbol{m}}\end{array}$ & $\begin{array}{c}\text { Factor Shares } \\
\boldsymbol{\mu}_{\boldsymbol{m}}\end{array}$ & $\begin{array}{c}\text { Concentration } \\
\text { Coefficients }\end{array}$ \\
\hline Decent employment endowment & 8368.50 & 0.389 & $\boldsymbol{C}_{\boldsymbol{m}}$ \\
\hline Human capital endowment & 10719.13 & 0.498 & 0.250 \\
\hline & & $(0.009)$ & $(0.012)$ \\
\hline Financial capital endowment & 414.96 & 0.019 & 0.091 \\
\hline & & $(0.001)$ & $(0.006)$ \\
\hline Household demographics & 2176.47 & 0.101 & 0.035 \\
\hline & & $(0.007)$ & $(0.069)$ \\
\hline Indirect Decent employment & -596.53 & -0.027 & 0.933 \\
\hline endowment & & $(0.009)$ & $(0.244)$ \\
\hline Other income sources & 427.31 & 0.020 & 0.324 \\
\hline & & $(0.014)$ & $(7.087)$ \\
\hline Overall private sector & 21509.83 & 1.000 & $0.380^{*}$ \\
\hline
\end{tabular}

Source: Calculated by author from CHCS III Survey Data using DASP 2.1 (DASP: Distributive Analysis STATA Package).

Note: *this is the Gini coefficient and standard errors are in parentheses.

Table 4 presents social welfare generated by regressed-income components, that is, social welfare attributable to each regressed-income endowment across the parameter $\beta \in[0,1]$. An equity seeking decision-maker will prefer $\beta=0$ which side-lines the effects of mean incomes on social welfare and only focuses on equity. In this perspective, financial capital endowment is classified first followed closely by human capital and decent employment endowments in terms of social welfare. Thus, this decision-maker who is absolutely equity seeking may lay more emphasis on micro-credit access, education and training programmes, and better working conditions to obtain commendable social welfare outcomes. However, in a situation of limited resources, we may advise an absolute equity seeking decision-maker to give priority to financial capital, human capital and decent employment endowments in that order.

In a nutshell, the values of the concentration coefficients of household demographics and indirect decent employment are in excess of the Gini coefficient, indicating their inequality-augmenting effects. Concerning household demographics, this is implication that family planning measures (like birth control to target the number of young children in households) and geographic considerations (zone of residence) be made part and parcel of policy arrangements interested to affect inequality. For indirect decent employment, the very high value of its concentration coefficient indicates that the power to bargain better or good working conditions and the ability to manage household shocks (like unemployment and birth) accrue overwhelmingly to the rich households in the private sector. 
If the decision-maker mediates 50:50 between efficiency and equity ( $\beta=0.5$ ), then human capital endowments are ranked first in terms of social welfare, with a numerical value in excess of total social welfare and it is followed by decent employment endowments. In this case, financial capital endowments rank fourth after household demographics in the third position. Thus, a decision-maker who gives the same degree of importance to efficiency and equity considerations in the quest to improve social welfare may be encouraged to prioritise policy measures that boost human capital and improve working conditions of household heads. This observation also holds for values of the parameter $\beta>0.5(\beta=0.75$ and 1$)$. Thus, an efficiency seeking policymaker may choose interventions to improve human capital and working conditions.

Table 4. Decomposition of the Generalized Social Welfare Function by Regressed Income Components

\begin{tabular}{|l|c|c|c|c|}
\hline & $\boldsymbol{W}_{m}(\boldsymbol{\beta}=0)$ & $\boldsymbol{W}_{m}(\boldsymbol{\beta}=0.5)$ & $\boldsymbol{W}_{m}(\boldsymbol{\beta}=0.75)$ & $\boldsymbol{W}_{m}(\boldsymbol{\beta}=1)$ \\
\hline $\begin{array}{l}\text { Decent } \\
\text { employment } \\
\text { endowment }\end{array}$ & 0.75 & 68.61 & 656.22 & 6276.38 \\
\hline $\begin{array}{l}\text { Human capital } \\
\text { endowment }\end{array}$ & 0.909 & 94.11 & 957.60 & 9743.69 \\
\hline $\begin{array}{l}\text { Financial capital } \\
\text { endowment }\end{array}$ & 0.965 & 19.66 & 88.72 & 400.44 \\
\hline $\begin{array}{l}\text { Household } \\
\text { demographics }\end{array}$ & 0.433 & 20.20 & 137.98 & 942.41 \\
\hline $\begin{array}{l}\text { Indirect decent } \\
\text { employment } \\
\text { endowment }\end{array}$ & 0.067 & - & -39.97 \\
\hline $\begin{array}{l}\text { Other income } \\
\text { sources }\end{array}$ & 0.676 & 13.97 & 63.53 & 288.86 \\
\hline Total social welfare & 0.62 & 90.93 & 1101.21 & 13336.09 \\
\hline
\end{tabular}

Source: Calculated from CHCS III Survey Data using DASP 2.1 Software for Distributive Analysis. $W_{m}$ is the welfare share of endowment $m$.

Importantly, when $\beta=1$, we have the Sen SWF, which blows the efficiency consideration over the equity consideration. With these findings, we can observe that changes in $\beta>0$ are not sensitive to the ranking of regressed incomecomponents (Table 4). This observation is indicative of the trading of equity for efficiency as the parameter, $\beta$, is brought in. This way, efficiency considerations are more vital than equity considerations in determining social welfare. Nonetheless, other income sources, not captured in our regression, are also potent in generating social welfare and indirect decent employment endowments have diluting effects on private sector social welfare when $\beta=1$. 
Table 5. Contributions of Regressed-Income Endowments to Social Welfare and its Components

\begin{tabular}{|l|c|c|c|}
\hline & $\begin{array}{c}\text { Factor } \\
\text { share } \\
\left(\frac{\boldsymbol{\mu}_{m}}{\boldsymbol{\mu}}\right)\end{array}$ & $\begin{array}{c}\text { Relative equity } \\
\left(\frac{\mathbf{1}-\boldsymbol{C}_{\boldsymbol{m}}}{\mathbf{1}-\boldsymbol{G}}\right)\end{array}$ & $\begin{array}{c}\text { Relative share of social } \\
\text { welfare }\left(\frac{\boldsymbol{a}_{m} \boldsymbol{W}_{m}}{\boldsymbol{W}}\right)\end{array}$ \\
\hline Decent employment endowment & 0.389 & 1.210 & 0.470 \\
\hline Human capital endowment & 0.498 & 1.466 & 0.730 \\
\hline Financial capital endowment & 0.019 & 1.556 & 0.029 \\
\hline Household demographics & 0.101 & 0.698 & 0.070 \\
\hline $\begin{array}{l}\text { Indirect decent employment } \\
\text { endowment }\end{array}$ & -0.027 & 0.108 & -0.003 \\
\hline Other income endowments & 0.019 & 1.090 & 0.021 \\
\hline
\end{tabular}

Source: Calculated from Table 3 using Microsoft Excel.

\section{$\underline{\text { Relative Contributions of Regressed-Income Components to Social Welfare }}$}

Table 5 hosts the relative share of income, the relative equity, and the relative share of social welfare for each regressed-income component. The values of the relative equity of decent employment, human capital, financial capital endowments, and other income sources are greater than one, further indicating that these components or endowments have inequality-reducing effects. This implies that if an extra CFA franc goes to boost decent employment, and if proportionately distributed, inequality will reduce. Worthy to note is also the observation that household demographics and indirect decent employment endowments are inequality-augmenting; since the values of their relative equities fall below unity. These observations further confirm the analysis done so far.

In Table 5, the relative share of human capital endowments to overall private sector social welfare is outstanding, followed by that of decent employment and household demographics. Human capital alone accounts for about $73.0 \%$ and decent employment about $47 \%$. Household demographics make about $7.0 \%$, financial capital about $2.9 \%$, other income sources about $2.1 \%$ while indirect decent employment dilutes overall social welfare by about $0.3 \%$. These relative welfare shares are also interpreted as the elasticities of social welfare with respect to equity $\left(1-C_{m}\right)$, maintaining the mean value of the component unchanged (Mukhopadhaya 2001a). Thus, policy efforts that focus on the twin goal of improving equality and boosting overall welfare among private sector household heads or workers are advised to prioritise human capital and decent employment endowments in their policy menu.

Elasticities of Social Welfare with respect to Growth in Regressed-Income $\underline{\text { Components }}$

Table 6 addresses the elasticity of social welfare with respect to a change in the mean value of each income component for different values of $\beta$. These elasticities identify quantitatively the expected change in total welfare for a $1 \%$ 
increase in the mean amount of a given regressed-income endowment (apportioned proportionately among all private sector individuals so that no change occurs in terms of inequality). In Table 6 , this elasticity is highest with human capital endowment across the different values of the parameter, $\beta$. The elasticity of welfare with respect to decent employment endowment ranked second after human capital for an equity and efficiency $(\beta=0.75)$ seeking policymaker. This means that if an extra CFA franc goes to boost working conditions and is distributed proportionately to all private sector workers or household heads, social welfare will increase considerably.

Table 6. Elasticity of Social Welfare with respect to a Change in the Mean Value of each Regressed-Income Endowment

\begin{tabular}{|l|c|c|c|}
\hline & $\boldsymbol{\epsilon}_{\boldsymbol{\mu}_{m}}^{W}(\boldsymbol{\beta}=\mathbf{0 . 5})$ & $\boldsymbol{\epsilon}_{\boldsymbol{\mu}_{m}}^{\boldsymbol{W}}(\boldsymbol{\beta}=\mathbf{0 . 7 5})$ & $\boldsymbol{\epsilon}_{\boldsymbol{\mu}_{m}}^{\boldsymbol{W}}(\boldsymbol{\beta}=\mathbf{0 . 9})$ \\
\hline Decent employment endowment & 0.276 & 0.373 & 0.432 \\
\hline Human capital endowments & 0.481 & 0.606 & 0.680 \\
\hline Financial capital endowment & 0.020 & 0.025 & 0.028 \\
\hline Household demographics & 0.020 & 0.045 & 0.060 \\
\hline $\begin{array}{l}\text { Indirect decent employment } \\
\text { endowments }\end{array}$ & 0.011 & 0.004 & 0.000 \\
\hline Other income endowments & 0.011 & 0.016 & 0.019 \\
\hline
\end{tabular}

Source: Calculated from Tables 3 and 5 using Microsoft Excel. $\epsilon_{\mu_{m}}^{W}$ is the elasticity of social welfare $(W)$ with respect to a change in the mean value of an endowment or a component $\left(\mu_{m}\right)$.

The numerical values of these elasticities are non-negligible for financial capital endowments and household demographics, but very low with indirect decent employment endowment for all values of $\beta$. Thus, a decision-maker who is either midway between efficiency and equity $(\beta=0.5)$ or more efficiency seeking than inequality averse $(\beta=0.75$ and 0.9$)$ in the quest to improve social welfare, may be advised to prioritise human capital and direct decent employment endowments in a situation of tight budgetary resources. The prominent elasticities of welfare registered with human capital and direct decent employment endowments are attributable more to total income share than to relative equity. This is because their rankings in terms of elasticity mimic that in terms of income share and not relative equity. This finding further substantiates our first hypothesis of study. In terms of income share, human capital ranks first and direct decent employment comes second; obeying their elasticity rankings, whereas in terms of relative equity, they come in the second (human capital) and third (direct decent employment) positions after financial capital endowment (Table 6). Thus, if target endowments or components were needed for policy purpose, they will be human capital and direct decent employment. 


\section{Concluding Remarks and Policy Implications}

The paper conducted the analysis of social welfare received by private sector households on the basis of mean income and income distribution. The paper proposed a new analytical perspective of social welfare that decomposed it as a weighted sum of individual welfare of various regressed-income components or endowments. This way, the paper employed the information contained in an income generating equation to account for total social welfare in the private sector in Cameroon. For this purpose, it combined the regressed-income sources into the following endowments or components: decent employment, human capital, financial capital, household demographics, and indirect decent employment endowments. This paper attempted to evaluate the share of each regressed-income component in social welfare and tease-out the effect of growth in each regressedincome component on total social welfare of private sector households.

The share of human capital endowments in total mean income was highest, followed by that of decent employment endowment and household demographics. Decent employments, human capital, and financial capital endowments were found to have inequality-reducing effects, as their concentration coefficients fell well below the overall Gini coefficient. Our analysis further noted that good working conditions (decent employment), education and training facilities (human capital) as well as access to micro-credit (financial capital) accrue relatively more to the rich or privileged households than the poor or underprivileged households in the private sector $^{11}$; reason why the values of their concentration coefficients though less than the Gini were positive. This finding indicated that policy measures focused on driving private sector working conditions, education and training facilities as well as improve micro-credit access should consider their relative disparities between the rich and the poor private sector households in order to better tap their inequality-reducing effects. On the contrary, the values of the concentration coefficients of household demographics and indirect decent employment were in excess of the Gini coefficient, indicating their inequalityaugmenting effects. This result implied that family planning measures (like birth control to target the number of young children in households) and geographical considerations (zone of residence) are made an essential part of policy arrangements geared at addressing inequality. This finding underlined also that institutions (ministerial delegations of labour, trade unions, international labour organisation just to mention a few) should mobilise more efforts to ensure workers are protected and working conditions are made better.

We found that for an equity seeking decision-maker who prefers $\beta=0$, financial capital endowment was classified first followed closely by human capital and decent employment endowments in terms of welfare. This result implied that a decision-maker who is absolutely equity seeking may be encouraged to lay more emphasis on micro-credit access, education and training programmes as well as

\footnotetext{
${ }^{11}$ According to the Government of Cameroon (2007), out of the total number who obtained credit in $2007,84.4 \%$ were from rich households and $15.6 \%$ from poor households. It also underlined that better working conditions (stable remuneration, contract employment etc.) are more widespread among the rich than the poor households.
} 
better working conditions to obtain commendable welfare outcomes. For a decision-maker who is midway between efficiency and equity $(\beta=0.5)$, human capital endowments was ranked first in terms of social welfare, with a numerical value in excess of total welfare, and was followed by decent employment endowments. This finding implied that a decision-maker who gives the same degree of importance to efficiency and equity considerations in the quest to improve social welfare should be encouraged to prioritise policy measures that boost human capital and improve working conditions of private sector household. This observation and policy implication hold for decision-makers who are more efficiency seeking than equity $(\beta=0.75$ and 1$)$.

In terms of relative social welfare share, human capital endowments registered the highest share to overall private sector social welfare, followed by that of decent employment and household demographics. The elasticity of welfare with respect to human capital was highest across the different values of the parameter, $\beta$. That of welfare with respect to decent employment ranked second after human capital. This finding indicated that if an extra CFA franc goes to boost working conditions and is distributed proportionately to all private sector workers, social welfare would increase considerably. The numerical values of these elasticities were also considerable with household demographics, but lower with financial capital endowments for all values of $\beta$. This result further implied the importance of human capital and good working conditions in determining social welfare. The prominent elasticities of social welfare registered with human capital and decent employment were found to be attributable more to total income share than to relative equity.

\section{References}

Andolfatto D, Gomme P (1998) Unemployment and Economic Welfare. Economic Review 1998: Q3. Available at: http://clevelandfed.org/research/review/.

Aoun A (2004) Poverty Alleviation in the Developing Economies: the Leading Issues. NEW MEDII N 1: 2004

Asselin L M (2002) Composite Indicator of Multidimensional Poverty. CECI: June 2002.

Atkinson AB (1970) On the Measurement of Inequality. Journal of Economic Theory 2(3): 244-263.

Baluch MUH, Razi S (2007) Social Welfare Measure in Pakistan an Ordinal and Cardinal Approach. Pakistan Economic and Social Review 45(1): 55-88.

Baye MF (2011) A Gini-Based generalised Decomposition Analysis of Social Welfare Trends in Cameroon. African Journal of Economic Policy 18(1): 1-32.

Benzécri JP (1979) Sur le Calcul des Taux d'Inertie dans l'Analyse d'un Questionnaire. Les Cahiers de l'Analyse des Données 4: 377-378.

Bergson A (1938) A Reformulation of certain aspects of Welfare Economics, Quarterly Journal of Economics 52(2): 310-34.

Burns J, Hart (2000) Bentham, Jeremy. A Comment on the Commentaries and a Fragment on Government. In J Burns (ed) The Works of Jeremy Bentham. USA: Charlottesville, Virginia. 
Cockburn J, Duclos J and Zabsonré A (2014) Is Global Social Welfare Increasing? A Critical-Level Enquiry, Centre de recherche sur les risques les enjeux économiques et les politiques publiques, www.crrep.ca.

European Commission (2018) Employment and Social Developments in Europe. Directorate- General for Employment Social Affairs and Inclusion. Annual Review 2018.

Government of Cameroon (2003) Poverty Reduction Strategy Paper, August 2003, Republic of Cameroon, Yaoundé.

Government of Cameroon (2007) Enquête Camerounaise Auprès des Ménages, ECAMIII, National Institute of Statistics 2007, Yaoundé.

Government of Cameroon (2014) Enquête Camerounaise Auprès des Ménages, ECAMIV, National Institute of Statistics 2014, Yaoundé.

ILO (2014) Developing with Jobs. World of Work Report 2014. Revised Edition.

ILO (2007) ILO Report on Key indicators of the Labour Market. 5th Edition, International Labour Office, Geneva 2008.

Kakwani N M, Neri and Son H H (2006) Linkages between Growth, Poverty and the Labour Market, paper presented in a keynote address at the 5th General Meeting of the PEP Research Network, June 18-22, 2006, Addis Ababa, Ethiopia.

Kamgnia, Dia B, Wangun SL, Tatsinkou C, Afor J (2008) Benefices acquis et ciblage des pauvres dans les Depenses Publiques de sante et d'éducation au Cameroun. PEP research network, PMMA Working Paper 2008-08.

Khandker SR (2005) Microfinance and Poverty: Evidence Using Panel Data from Bangladesh. World Bank Economic Review 19(2): 263-286.

Ki J B, Faye S, and Faye B (2005) Multidimensional Poverty in Senegal: A NonMonetary Basic Needs Approach. Final Report, PMMA Working Paper-PEP.

Morduch J, Sicular T (2002) Rethinking inequality decomposition with evidence from rural China. Economic Journal 112: 93-106.

Mukhopadhaya P (2001a) A Generalized Social Welfare Function, Its Decomposition and Application, Department of Economics, National University of Singapore, Working Paper 0119. DOI= http://www.fas.nus.edu.sg/ecs/pub/wp/wp0119.pdf.

Mukhopadhaya P (2001b) A Generalised Social Welfare Function and its Disaggregation by Components of Income: The Method and Application, Department of Economics, National University of Singapore, Working Paper 0121. DOI = http://www.fas.nus. edu.sg/ecs/pub/wp/wp0121.pdf.

Mukhopadhaya P (2001c) Efficiency Criteria and the Sen-type Social Welfare Function", Department of Economics, National University of Singapore, Working Paper 0114. DOI= http://www.fas.nus.edu.sg/ecs/pub/wp/wp0114.pdf.

Mukhapadhaya P (2003) The ordinal and cardinal judgment of social welfare change in Singapore, 1982-99. The Developing Economies 61(1): 65-87.

Nenadic O, Greenacre M (2007) Computation of Multiple Correspondence Analysis. With code in R, BBVA Foundation, Madrid.

North D (1990) Institutions, Institutional Change and Economic Performance. Cambridge: University Press.

Pagès N (2003) Hétérogénéité des systèmes d'emploi urbain et vulnérabilité au travail: application aux entreprises et aux petites unités productives en Côte d'Ivoire. 3rd Conference sur l'approche des capacités: d'un développement viable à une liberté durable. Italy: University of Pavia, September 8-10.

Parfit D (1984) Reasons and Persons. Oxford: Oxford University Press.

Pitt MM, Khandke SR (2002) The Impact of Group-Based Credit Programs on Poor Households in Bangladesh: Does the Gender of Participants Matter? Journal of Political Economy 106(5): 958-996. 
Quah D (2001) Some simple arithmetic on how income inequality and economic growth matter", Paper presented at WIDER conference on Growth and Poverty, 25- 26 May 2001, Helsinki.

Rao VM (1967) Two decomposition of concentration ratio. Journal of Royal Statistical Society Series A(132): 428-435.

Ravallion M (1998) Does aggregation hide the harmful effects of inequality on growth? Economics Letters 61: 73-77.

Ravallion M (2001) Growth, Inequality and Poverty: Looking beyond Averages. World Development 29(11): 1803-15.

Ravallion M, Datt G (2000) When growth is pro-poor? Evidence from the diverse experience of Indian states, World Bank Policy Research, Working Paper 2263.

Ravallion M, Datt G (2002) Why Has Economic Growth Been More Pro-Poor in Some States of India than Others? Journal of Development Economics 68(2): 381-400.

Ravallion M and Chen S (2003) Measuring Pro-poor Growth. Economic Letters 78(1): 9399.

Samuelson PA (1949) Foundation of Economic Analysis. Cambridge: Harvard University Press.

Sen AK (1970) Collective Choice and Social Welfare (description), Chapter 3, "Collective Rationality". New York: Oxford University Press.

Sen AK (1974) Informational bases of alternative welfare approaches: aggregation of income distribution. Journal of Public Economics 3(4): 387-403.

Sen AK (1976) Liberty, Unanimity and Rights. Economica 43(171): 217-245.

Sen AK (1979) The welfare basis of real income comparisons: A survey. Journal of Economic Literature 17(1): 1-45.

Sheshinski E (1972) Relation between a social welfare function and the Gini Index of income inequality. Journal of Economic Theory 4(1): 98-100.

Shorrocks AF (1983) Rethinking Income Distributions. Economica 50: 3-17

United Nations (2015) United Nations Sustainable Development Goals, Goals adopted by the United Nations Member States. New York: United Nations.

Wan GH (2002) Regression-Based inequality decomposition: pitfalls and a solution procedure. Helsinki-Finland: UNU-WIDER Discussion paper 2002/101.

World Bank (2000) World Development Report 2000/01: Attacking Poverty. Washington DC.

World Follow-up Report (2008) World Development Indicators: Report on the progress of the achievement of the Millennium Development Goals by region. Washington DC.

Yitzhaki S (1979) Relative deprivation and the Gini coefficient. Quarterly Journal of Economics 93(2): 321-324.

Yitzhaki S (1982) Relative deprivation and the economic welfare. European Economic Review 17(1): 99-113. 


\section{Appendices}

Appendix 1: Multiple Correspondence Analysis (MCA) of Employment Decency

To construct the employment decency indicator, we employ the MCA as developed by Asselin (2002) and used by Ki et al. (2005) and Kamgnia Dia et al. (2008).

Table A1 presents the explained inertia by the factor axes. From Table A1, it follows that the first factor axis that represents almost $29 \%$ of total inertia (quantity of information) ${ }^{12}$ is the one that describes better employment quality of workers.

Table A1. Explained Inertia by the Factor Axis

\begin{tabular}{|l|c|c|c|}
\hline & Principal Inertia & Percentage & Cumulated percentage \\
\hline Factorial axis 1 & 0.57 & 28.5 & 28.5 \\
\hline Factorial axis 2 & 0.23 & 11.3 & 39.8 \\
\hline Total inertia & 2.00 & & \\
\hline
\end{tabular}

Source: Author.

Table A2 hosts the initial indicator variables/categories used for the construction of employment decency (column 1). The scores of the initial indicators coded in 0/1 obtained with the MCA and the contributions of the various categories are presented in Table A2. This table hosts the initial scores on the first axis as well as the squared correlations or squared cosines which represent the quality of representation of each initial indicator.

Table A2. Scores, Contributions and Squared Cosines of MCA on the Initial Indicators of Employment Quality

\begin{tabular}{|l|c|c|c|c|c|}
\hline $\begin{array}{l}\text { Variables/ } \\
\text { categories }\end{array}$ & $\begin{array}{c}\text { Initial } \\
\text { scores on } \\
\text { the First } \\
\text { axis }\end{array}$ & $\begin{array}{c}\text { Squared } \\
\text { correlations }\end{array}$ & Contributions & $\begin{array}{c}\text { Numbers } \\
\text { of } \\
\text { observations }\end{array}$ & Percentage \\
\hline $\begin{array}{l}\text { Employment } \\
\text { contract }\end{array}$ & 2.147 & 0.292 & 4.59 & 1,302 & 11.43 \\
\hline $\begin{array}{l}\text { Open-ended } \\
\text { (written) }\end{array}$ & 1.223 & 0.047 & 0.79 & 749 & 6.58 \\
\hline $\begin{array}{l}\text { Fixed term } \\
\text { (written) }\end{array}$ & -0.104 & 0.009 & 0.13 & 1,024 & 8.99 \\
\hline Verbal agreement & -0.346 & 0.249 & 0.92 & 8,316 & 73.01 \\
\hline No contract & 2.573 & 0.907 & 12.75 & 2,752 & 24.16 \\
\hline Payslip & -0.619 & 0.907 & 3.02 & 8,639 & 75.84 \\
\hline Possess a payslip & & & $\mathbf{1 5 . 3 6}$ & & \\
\hline No payslip & 2.653 & 0.881 & 12.60 & 2,548 & 22.37 \\
\hline Social security & -0.584 & 0.881 & 2.76 & 8,843 & 77.63 \\
\hline Affiliated to NSIF & & & & & \\
\hline $\begin{array}{l}\text { Not affiliated to } \\
\text { NSIF }\end{array}$ & & & & & \\
\hline
\end{tabular}

\footnotetext{
${ }^{12}$ Note that the adjusted inertia approach, proposed by Benzecri (1979), to measure the quantity of information brought by an axis can only be used for an axis, $\alpha$, with principal inertia (eigenvalue) $\lambda_{a} \leq 1 / K$ (Nenadic and Greenacre 2007: 7).
} 


\begin{tabular}{|c|c|c|c|c|c|}
\hline Job satisfaction & & & 7.36 & & \\
\hline $\begin{array}{l}\text { Training matches } \\
\text { job }\end{array}$ & 1.216 & 0.425 & 4.86 & 4,503 & 39.53 \\
\hline $\begin{array}{l}\text { Training does not } \\
\text { match job }\end{array}$ & -0.615 & 0.425 & 2.50 & 6,888 & 60.47 \\
\hline $\begin{array}{l}\text { Under- } \\
\text { employment }\end{array}$ & & & 1.18 & & \\
\hline $\begin{array}{l}\text { Less hours fixed } \\
\text { by employer }\end{array}$ & 1.226 & 0.012 & 0.26 & 224 & 1.97 \\
\hline Indifferent & 0.102 & 0.034 & 0.13 & 9,607 & 84.34 \\
\hline $\begin{array}{l}\text { Less hours due to } \\
\text { economic situation }\end{array}$ & -0.708 & 0.007 & 0.13 & 305 & 2.68 \\
\hline $\begin{array}{l}\text { Less hours due to } \\
\text { health problems } \\
\text { and domestic work }\end{array}$ & -0.779 & 0.044 & 0.66 & 1,255 & 11.02 \\
\hline Remuneration & & & 14.98 & & \\
\hline Fixed salary & 1.697 & 0.336 & 4.86 & 2,378 & 20.88 \\
\hline Daily/hourly pay & 3.115 & 0.406 & 6.57 & 1,080 & 9.48 \\
\hline Indifferent & -0.173 & 0.001 & 0.00 & 157 & 1.38 \\
\hline Piece rate & -0.290 & 0.008 & 0.13 & 319 & 2.80 \\
\hline $\begin{array}{l}\text { Commissions/bene } \\
\text { fits }\end{array}$ & -0.677 & 0.678 & 3.29 & 7,324 & 64.30 \\
\hline $\begin{array}{l}\text { In-kind and no } \\
\text { payment }\end{array}$ & -0.606 & 0.007 & 0.13 & 133 & 1.17 \\
\hline Labour status & & & 8.8 & & \\
\hline $\begin{array}{l}\text { Permanent } \\
\text { regular }\end{array}$ & 0.066 & 0.004 & 0.13 & 7,116 & 62.47 \\
\hline $\begin{array}{l}\text { Permanent } \\
\text { seasonal }\end{array}$ & 2.967 & 0.389 & 6.30 & 1,106 & 9.71 \\
\hline Indifferent & -0.774 & 0.155 & 1.84 & 2,318 & 20.35 \\
\hline $\begin{array}{l}\text { Temporary } \\
\text { undefined/defined }\end{array}$ & -0.212 & 0.021 & 0.53 & 851 & 7.47 \\
\hline $\begin{array}{l}\text { Housing } \\
\text { allowance }\end{array}$ & & & 14.45 & & \\
\hline $\begin{array}{l}\text { Receive housing } \\
\text { allowance }\end{array}$ & 2.834 & 0.828 & 12.22 & 2,171 & 19.06 \\
\hline $\begin{array}{l}\text { Do not Receive } \\
\text { housing allowance }\end{array}$ & -0.513 & 0.828 & 2.23 & 9,22 & 80.94 \\
\hline Paid leaves & & & 15.31 & & \\
\hline $\begin{array}{l}\text { Perceive paid } \\
\text { leaves }\end{array}$ & 2.697 & 0.891 & 12.75 & 2,469 & 21.68 \\
\hline $\begin{array}{l}\text { Do not perceive } \\
\text { paid leaves }\end{array}$ & -0.580 & 0.891 & 2.56 & 8,922 & 78.32 \\
\hline $\begin{array}{l}\text { Union } \\
\text { membership }\end{array}$ & & & 0.26 & & \\
\hline $\begin{array}{l}\text { Member of a trade } \\
\text { union/association }\end{array}$ & 0.194 & 0.019 & 0.13 & 5,351 & 46.98 \\
\hline $\begin{array}{l}\text { Not a member of a } \\
\text { trade union/ } \\
\text { association }\end{array}$ & -0.169 & 0.019 & 0.13 & 6,04 & 53.02 \\
\hline
\end{tabular}

Source: Constructed by author with help of STATA 10 using CHCS III. 
We normalise the indicator predicted from the first axis using:

$$
\widetilde{C}_{l}=\left(C_{i}-r \min (C)\right) /(r \max (C)-r \min (C))^{13}
$$

The normalised indicator $\widetilde{C}_{l}$ classifies workers in terms of increasing employment decency, with values ranging from 0 to 1 .

\section{Appendix 2. Reduced form Estimates of Employment Decency and Income Production Function}

Employment decency intensity: ranges from 0 to 1 for household heads actively employed in the private sector and having a decent job is not a fruit of a random process, implying the problem of potential endogeneity. Again, there can be a non-linear interaction between this endogenous regressor and unobserved variables, implying the problem of heterogeneity bias. This way, standard OLS regression stands to be limited.

Results in Table A4 cleanse the structural equation estimates of potential endogeneity and unobserved heterogeneity biases. Thus, in Table A4, additional regressors arise: the residual of employment decency is generated from the reduce form equation (Table A3b) and included as additional regressor to check for potential endogeneity and the interaction term (interaction of employment decency and its residual) is also generated and included in the structural equation to account for unobserved heterogeneity.

Table A3a: Density of Institutions per Region

\begin{tabular}{|c|c|c|c|c|c|c|c|c|c|}
\hline Adamawa & Centre & East & $\begin{array}{c}\text { Far } \\
\text { North }\end{array}$ & Littoral & North & $\begin{array}{c}\text { North } \\
\text { West }\end{array}$ & West & South & $\begin{array}{c}\text { South } \\
\text { West }\end{array}$ \\
\hline 17 & 51 & 23 & 43 & 30 & 17 & 33 & 36 & 26 & 29 \\
\hline
\end{tabular}

Source: The density of regional institutions is extracted from the Presidential Decree $N^{\circ} 2008 / 376$ of November 2008 based on Administrative Organisation in Cameroon.

\section{Excluded Variables versus Employment Decency}

Table A3b submits the reduced-form estimates of the endogenous variable, employment decency. The density of institutions per region (measured by the number of subdivisions per region, Table A3a) and attachment to traditional believes measured as cluster level mean, are used as instruments to settle the endogeneity of employment decency.

In almost every country today, governments have an unquestionable responsibility in ensuring decent working conditions among individuals. Vulnerability is related to the risks, shocks, and stresses to which a household head is subjected and the state of being defenceless or the lack of means to cope with these risks, shocks, stresses, or demands (Pagés 2003: 9). The sources of these risks, among other things, may include institutions governing resource access and contract enforcement, working conditions, together with labour and commodity

\footnotetext{
${ }^{13}$ Note that $r \max$ and $r$ min simply mean absolute maximum and minimum respectively.
} 
markets as a whole. We argue that the regional spread of administrative institutions and institutional change may help household heads in their efforts to attain decent employment status. Almost every household in Cameroon would be capable of developing better working conditions if the regional institutions implement policies and programmes related to contract enforcement, minimum wages, social security and other decent work facets.

Table A3b: Reduced-form Estimates of Employment Decency

\begin{tabular}{|l|c|c|c|c|}
\hline Employment decency index & Coef. & Std. Err. & $\mathrm{t}$ & $\mathrm{P}>\mathrm{t}$ \\
\hline Density of institutions (per region) & 2.950529 & 0.467525 & 6.31 & 0.000 \\
\hline Attachment to traditional beliefs (cluster level) & -13.4048 & 1.808478 & -7.41 & 0.000 \\
\hline Labour experience & 0.197382 & 0.04417 & 4.47 & 0.000 \\
\hline Labour experience squared & -0.00253 & 0.00058 & -4.36 & 0.000 \\
\hline Years of education & 0.873387 & 0.039978 & 21.85 & 0.000 \\
\hline Seniority in the enterprise & 5.036394 & 0.55433 & 9.09 & 0.000 \\
\hline Access to microcredit (cluster level) & 0.106367 & 1.606801 & 0.07 & 0.947 \\
\hline Number of younger children (cluster level) & -0.27893 & 0.114236 & -2.44 & 0.015 \\
\hline Number of married household heads (cluster level) & -2.92702 & 0.810263 & -3.61 & 0.000 \\
\hline Gender of household head (male =1) & 2.948296 & 0.378777 & 7.78 & 0.000 \\
\hline Location of household head (urban =1) & 6.094944 & 0.350972 & 17.37 & 0.000 \\
\hline Constant & -0.48557 & 1.0395 & -0.47 & 0.640 \\
\hline Number of obs = & 9219 & & & \\
\hline F( 11, 9207) & 195.87 & & & \\
\hline Prob > F = & 0.0000 & & & \\
\hline Adj R-squared = & 0.1887 & & & \\
\hline
\end{tabular}

The government and her regional institutions have, as duty, to encourage a general attitude in the population about the quality of work and favourable working conditions. The formal institutions, found in each sub-division, range from civil and municipal administrations, law and order, to ministerial delegations. Each sub-division in Cameroon is generally endowed with these institutions; the more there are sub-divisions in a region, the higher the institutional coverage in this region. Thus, we consider the number of sub-divisions in a region to capture its institutional coverage.

The density of institutions which represents the institutional coverage in each region is positively and significantly associated with employment decency. This implies that decision making to increase decent employment among private sector workers in Cameroon should also be seen from the angle of institutional strength in regions. Regional institutions (civil and municipal administrations, law and order, ministerial delegations, and trade unions) can play a vital role in encouraging a general attitude among private sector workers about the quality of work and favourable working conditions. This sense of judgment corroborates that which is underlined in North (1990) on the role of institutions. 
The average number of household heads who are attached to traditional believes and doctrines captured as cluster level means, is negative and significant in determining employment decency. This is indication that traditional attachment adversely affects a household head's social and economic interactions, limiting the individual's ability to deal with household and economic shocks like unemployment, birth and illness; exposing the latter to greater chances of accepting a vulnerable job in order to cope with these shocks.

Table A4: Income Production Function - Dependent Variable is log of Household Per Capita Monthly Income

\begin{tabular}{|l|c|c|c|c|}
\hline log of Household Per Capita Monthly Income & Coef. & Std. Err. & $\mathrm{t}$ & $\mathrm{P}>\mathrm{t}$ \\
\hline Employment decency index & 778.0058 & 140.0138 & 5.56 & 0.000 \\
\hline Labour experience & 271.118 & 49.0692 & 5.53 & 0.000 \\
\hline Labour experience squared & -2.37831 & 0.698273 & -3.41 & 0.001 \\
\hline Years of education & 763.8185 & 129.0371 & 5.92 & 0.000 \\
\hline Seniority in the enterprise & 9105.985 & 965.3059 & 9.43 & 0.000 \\
\hline Access to microcredit (cluster level) & 7061.49 & 2028.041 & 3.48 & 0.001 \\
\hline Number of younger children (cluster level) & -2460.62 & 149.986 & -16.41 & 0.000 \\
\hline Number of married household heads (cluster level) & 6929.005 & 957.5722 & 7.24 & 0.000 \\
\hline Gender of household head (male =1) & -1727.62 & 621.924 & -2.78 & 0.005 \\
\hline Location of household head (urban =1) & 7126.559 & 970.365 & 7.34 & 0.000 \\
\hline Predicted decency residual & -400.555 & 141.1234 & -2.84 & 0.005 \\
\hline Interaction of decency and its residual & -3.12306 & 0.565466 & -5.52 & 0.000 \\
\hline Number of obs = & 9219 & & & \\
\hline F( 12, 9207) = & 1440.85 & & & \\
\hline Prob > F = & 0.0000 & & & \\
\hline Adj R-squared = & 0.6521 & & & \\
\hline Source: Computed & & & \\
\hline
\end{tabular}

Source: Computed by author using ECAM III. 



\title{
Managing the Inflation Problem in Nigeria using the Fisco-Monetary Approach
}

\author{
By Michael Segun Ogunmuyiwa*
}

\begin{abstract}
This study examined empirically the impact of monetary and fiscal policy management on the problem of inflation in Nigeria. Monthly data spanning from January 2010 to October 2016 on inflation rate, interest rate, exchange rate, narrow money, broad money, government capital expenditure and government recurrent expenditure were obtained from Central Bank of Nigeria $(C B N)$ statistical bulletin and fitted into the regression model. Autoregressive Distributed Lag (ARDL) was employed after ascertaining the stationarity properties of the series through the Augmented Dickey-Fuller (ADF) test. The results showed that broad money supply (M2) and Capital Expenditure (CE) were significant and are positively related (short and long run) to inflation in Nigeria. Exchange rate was significant and positively related to inflation in the long run. The study also revealed that Nigerian inflationary situation is driven by monetary and fiscal policies in the long run. Narrow money has no significant impact on inflation problem both in the short and long run in Nigeria. The study concluded that monetary and fiscal policies have positive impact on inflation in Nigeria and recommended that monetary and fiscal policies should be harnessed, coordinated and sustained with the help of Central Bank of Nigeria in order to combat the problem of inflation in Nigeria. (JELE62, E51, E31)
\end{abstract}

Keywords: Auto-regression, Fiscal Policy, Inflation, Management, Monetary Policy.

\section{Introduction}

Despite frequently changing the fiscal, monetary and macro-economic policies to manage inflation, several challenges still beset the Nigerian economy. Due to this, Nigeria has not been able to harness her economic potentials for rapid economic development. Inflation has been one of the major problems facing the Nigerian economy because of undue reliance on foreign products thereby making Nigeria an import dependent economy, (Abata et al. 2012). Government has in one way or the other taken the precautionary measures to regulate and manage inflation in order to regulate the economy and to maximize the welfare of the citizens by ensuring that the resources are efficiently allocated among the citizenry. Like any other developing country, Nigeria has adopted three types of public policies to carry out the objectives of income distribution and allocation of resources. These management tools of public policy include: monetary policy, fiscal policy and income policy tools (Nwoko et al. 2016).

\footnotetext{
*Senior Lecturer, Department of Business Administration, Olabisi Onabanjo University, Nigeria.
} 
During inflationary periods opportunity cost of holding money is increased causing inefficient use of real resources in transactions. Therefore, inflation weakens the purchasing power of money and sinks the standard of living of the citizenry (Gbadebo and Mohammed 2015). One of the popular policies used to manage inflation in Nigeria is monetary policy. Therefore, the summation of the economic actions taken by the regulatory authorities' in-charge of regulating or managing the dynamic economic variables that affect changes in the prices of goods and services as well as the value of money is known as monetary policy. In other words, monetary policy is a combination of measures designed to regulate the value, supply and cost of money in an economy in consonance with the level of economic activities (CBN 1992). The ineffectiveness of monetary policy is deepened in an underdeveloped financial market like Nigeria. Despite the application of the monetary policy tools, inflation has continued to pose challenges to the monetary authorities. Some of the reasons include the inability of the monetary authorities to enforce compliance through the monetary channel in the banking and non-banking institutions, and fiscal imbalance characterized with expansionary fiscal policy with deficit budget (Ggor 2011).

Fiscal policy management is another instrument used to curb inflation. Fiscal policy is a measure employed by government to stabilize the economy, specifically by adjusting the levels and allocations of taxes and government expenditures. It is the powerful instrument of stabilization in developing economies in which Nigeria is a typical example. Monetary and fiscal policies play a key role in the promotion of the main government objective of promoting the welfare of its citizens. For a developing economy like Nigeria, it is vital to analyze monetary and fiscal policies transmission effect on inflation because of the need to determine the appropriate channel and the effectiveness of monetary and fiscal policies in managing inflation, among other reasons (CBN 2009).

Prominent among the measures introduced by the Nigerian government are monetary and fiscal policies. Before the deregulation of the economy in 1986, inflation still maintained its single digit level. Sequel to the deregulation of the economy, inflation has been a major macroeconomic problem facing Nigeria. There are several arguments in the literature on the impacts of fiscal and monetary policies in controlling inflation in developed and developing countries. A lot of contrasting opinions on which of the two policies has greater impact or influence in managing inflation exists in the literature. Despite the efficacy of fiscal and monetary policies in other developed economies of the world, the two policies have not sufficiently and adequately yielded any encouraging result in Nigeria.

There is no consensus among economist as to whether government intervention through the use of monetary and fiscal policy will control inflation. This disagreement divided the economy into different schools of thought. Each of them has its view on how variation in monetary and fiscal aggregates could affect inflation and create economic stabilization (Nwoko et al. 2016). In spite of the invaluable significance of economic stabilization policy in the actualization of sustainable development, there seems to be different opinions from several studies on the effect of monetary and fiscal policies on inflation in Nigeria. 
However, previous works on monetary and fiscal policies and inflation problem in Nigeria have been examined by some studies in Nigeria and the direction of their causality has been mixed. Likewise, none of these studies in Nigeria have used monthly data on monetary and fiscal policies variables to ascertain the impact of monetary and fiscal policies on inflation problem in Nigeria. To this end, this study intends to fill this vacuum. The rest of the paper is organized into four sections. Section II is on the literature review while section III focuses on the methodology. Section IV centers on the findings and discussion and section $\mathrm{V}$ is the conclusion and policy recommendations.

\section{Review of Empirical Literature}

The relative impact of fiscal and monetary policies has been studied extensively in many literatures. It has generated large volume of empirical studies with mixed findings. However, the bulk of empirical reviews have not reached a conclusion concerning the relative power of fiscal and monetary policy to affect inflation. Nwoko et al. (2016) examined the extent to which the Central Bank of Nigeria monetary policies could effectively be used to promote economic growth, spanning the period of 1990-2011. The influence of money supply, average price, interest rate and labour force were tested on gross Domestic Product using multiple regression models as the main statistical tool of analysis. The findings from this study indicated that average price and labour force have significant influence on Gross Domestic Product while money supply was not significant. The study recommended that if investment is encouraged, unemployment and lending rate are reduced and economy is stabilized, the central Bank Monetary Policy could be an effective tool.

Abata et al. (2012) assessed how fiscal and monetary policies influenced economic growth and development in Nigeria and showed a mild long-run equilibrium relationship between economic growth and fiscal policy variables in Nigeria. They therefore suggested that for any meaningful progress towards fiscal prudence on the part of government, some powerful pro-stability stakeholders strong enough to challenge government fiscal recklessness will need to emerge. To this end, monetary policy rate and bank lending rates are the most important monetary policy tools that can make or mar the Nigerian real sector. Balami et al. (2016) analyzed the impact of monetary policy on inflation, exchange rate and economic growth. The study used both primary and secondary data. The study reviewed that some Central Bank of Nigeria $(\mathrm{CBN})$ policies has been under criticism because not all monetary policy tools favour all economic agents. The study recommended that there is need for policy makers to act in order to reduce round tripping which is unhealthy to the economy and the monetary policy must be supported by fiscal policy.

Gbadebo and Mohammed (2015) examined the effectiveness of monetary policy as an anti-inflationary measure in Nigeria. The co-integration and error correction methods approach were employed on quarterly time series data spanning from 1980Q1 to 2012Q4 in order to explore the relationship between 
inflation and monetary impulses. The estimated result for the period covered revealed that interest rate, exchange rate, money supply and oil-price are the major causes of inflation in Nigeria. It was also observed that although in the short run increased in income encouraged inflation, proper utilization of the growth would reduce inflation. The study recommended that Nigerian inflationary situation is driven by monetary impulses. Adigwe et al. (2015) studied the impact of monetary policy on the Nigerian economy. The Ordinary Least Square was used to analyze the data between 1980 and 2010. The result revealed that monetary policy represented by money supply exerts a positive impact on GDP growth but negative impact on the rate of inflation. The study recommended that monetary policy should facilitate favourable investment climate through appropriate interest rates, exchange rate and liquidity management mechanism.

Udude (2014) investigated the impact of monetary policy on the growth of the Nigerian economy between the period of 1981-2012 with the objective of finding out the impact of various monetary policy instruments (money supply, interest rate, exchange rate and liquidity ratio) in enhancing economic growth of the country. The study employed Augmented Dickey Fuller Unit Root, Johansen Cointegration Test and Vector Error Correction Mechanism (VECM). The result of the VECM indicated that only exchange rate exerted significant impact on economic growth in Nigeria while other variables did not. The study concluded that monetary policy did not impact significantly on economic growth of Nigeria. ThankGod and Tamarauntari (2014) investigated the effectiveness of monetary policy on economic growth and inflation in Nigeria over the period of 1970 to 2011. The study revealed that in the short run the level of production is more important in controlling inflation but it is monetary policy variables that matter in the long run.

Kareem et al. (2013) studied the impact of fiscal and monetary instruments on economic growth. OLS regression was employed to analyze the variables employed. The results of the findings revealed that there has been fluctuation in the trend of policy variables in Nigeria. It also showed that broad money and recurrent expenditure have positive relationship with RGDP but recurrent expenditure is $5 \%$ significant with broad money having no significant level. Whereas, narrow money, inflation, interest rate and capital expenditure have negative impact on GDP though interest rate is significant at $10 \%$. The study concluded that narrow money, broad money, government recurrent expenditure and capital expenditure were significant variables that affect economic growth in Nigeria. Other relevant studies on the fisco-monetary management of the inflation problem are Nathan (2012) and Musa et al. (2013). Sequel to the above, monetary policy as a stabilizing variable has been applied more often than fiscal instruments in managing the inflation problem in Nigeria.

\section{Methodology}

The data used were mainly from secondary source collected from Central Bank Statistical Bulletin and the econometric method was used to analyze the data. 
Monthly time series data sourced spanned from January 2010 to October 2016 and were gathered on six independent variables. The variables are: Interest Rate, Narrow Money Supply, Broad Money Supply, Exchange Rate, Government Capital Expenditure and Government Recurrent Expenditure while the dependent variable is the inflation rate.

\section{Model Specification and Estimation Procedure}

The model was adapted from Adigwe, Echekoba and Onyeagba (2015) and Gbadebo and Mohammed (2015). The theoretical model estimated is as presented below.

$\mathrm{INF}=f(\mathrm{INT}, \mathrm{M} 1, \mathrm{M} 2, \mathrm{EXR}, \mathrm{RE}, \mathrm{CE})$

Explicitly in behavioural terms equation (1) can be written as:

$\mathrm{INFL}=\lambda_{0}+\lambda_{1} \mathrm{INT}+\lambda_{2} \mathrm{M}_{1}+\lambda_{3} \mathrm{M}_{2}+\lambda_{4} \mathrm{EXR}+\lambda_{5} \mathrm{RE}+\lambda_{6} \mathrm{CE}+\mu_{1}$

In logarithm form with time subscript, equation (3) will be written as:

$\mathrm{LINFL}=\lambda_{0}+\lambda_{1} \mathrm{LINT}+\lambda_{2} \mathrm{LM}_{1}+\lambda_{3} \mathrm{LM}_{2}+\lambda_{4} \mathrm{LEXR}+\lambda_{5} \mathrm{LRE}+\lambda_{6} \mathrm{LCE}+\mu_{\mathrm{t}}$

Where:

$\mu_{\mathrm{t}}=$ Stochastic Error term

$\lambda_{1}, \lambda_{2}, \lambda_{3}, \lambda_{4}, \lambda_{5}$, and $\lambda_{6}$ are parameters.

$\lambda_{0}=$ constant term.

$\mathrm{L}=$ Natural logarithmic form

$\mathrm{INFL}=$ Inflation rate

INT $=$ Interest rate

$\mathrm{M}_{1} \quad=$ Narrow Money Supply

$\mathrm{M}_{2} \quad=$ Broad Money Supply

EXR = Exchange Rate

$\mathrm{RE}=$ Government recurrent expenditure

$\mathrm{CE} \quad=$ Government capital expenditure

In a-priori terms, it is expected that $\lambda_{1}, \lambda_{2}, \lambda_{3}, \lambda_{4}, \lambda_{5}$ and $\lambda_{6}$ to be $>0$.

\section{Analytical Techniques}

The technique adopted in this research is Autoregressive Distributed Lag (ARDL)/Bounds testing approach for testing the long-run co-integrating relationship among the time series variables. The Bounds testing methodology developed by Pesaran and Shin (1999) has some advantages over the conventional co-integration testing approaches because it can be used with a mixture of $\mathrm{I}(0)$ and I(1) data, and again, it involves just a single-equation set-up, making it simple to implement and interpret. For equation (3), the corresponding ECM is as follow: 
$\Delta$ LINFL $_{\mathrm{t}-\mathrm{i}}=\mathrm{a}_{0}+\sum_{\mathrm{i}=\mathbb{0}}^{\mathrm{n}} \mathrm{a}_{1} \Delta \mathrm{LINF}_{\mathrm{t}-\mathrm{i}}+\sum_{\mathrm{i}=\mathbb{0}}^{\mathrm{n}} \mathrm{a}_{2} \Delta \mathrm{LINT}_{\mathrm{t}-\mathrm{i}}+\sum_{\mathrm{i}=\mathbb{0}}^{\mathrm{n}} \mathrm{a}_{3} \Delta \mathrm{LM}_{\mathrm{t}-\mathrm{i}}+\sum_{\mathrm{i}=0}^{\mathrm{n}} \mathrm{a}_{4} \Delta \mathrm{LM} 2_{\mathrm{t}-\mathrm{i}}$ $+\sum_{\mathrm{i}=\mathbb{\mathrm { l }}}^{\mathrm{n}} \mathrm{a}_{5} \Delta \mathrm{LEXR}_{\mathrm{t}-\mathrm{i}}+\sum_{\mathrm{i}=\mathbb{0}}^{\mathrm{n}} \mathrm{a}_{6} \Delta \mathrm{LRE}_{\mathrm{t}-\mathrm{i}}+\sum_{\mathrm{i}=\mathbb{0}}^{\mathrm{l}} \mathrm{a}_{7} \Delta \mathrm{LCE}_{\mathrm{t}-\mathrm{I}}+\mathrm{a}_{8} \Delta \mathrm{LINF}_{\mathrm{t}-\mathrm{i}}+\mathrm{a}_{9} \Delta \mathrm{LINT}_{\mathrm{t}-\mathrm{I}}+$ $\mathrm{a}_{10} \Delta \mathrm{LM1}_{\mathrm{t}-\mathrm{i}}+\mathrm{a}_{11} \Delta \mathrm{LM}_{\mathrm{t}-\mathrm{i}}+\mathrm{a}_{12} \Delta \mathrm{LEXR}_{\mathrm{t}-\mathrm{i}}+\mathrm{a}_{13} \Delta \mathrm{LRE}_{\mathrm{t}-\mathrm{i}}+\mathrm{a}_{14} \Delta \mathrm{LCE}_{\mathrm{t}-\mathrm{i}}+\mathrm{a}_{15} \mathrm{ECM}_{\mathrm{t}-\mathrm{i}}+\mu_{\mathrm{t}}$

In the above equation, it assumed that a lag length of t-i for the ECM equation. The first part of equation (4) with $\mathrm{a}_{1}, \mathrm{a}_{2}, \mathrm{a}_{3}, \mathrm{a}_{4}, \mathrm{a}_{5}, \mathrm{a}_{6}$ and $\mathrm{a}_{7}$ represents the short run dynamics of the model whereas the second part with $a_{8}, a_{9}, a_{10}$, $\mathrm{a}_{11}, \mathrm{a}_{12}, \mathrm{a}_{13}$ and $\mathrm{a}_{14}$ represents the long run equilibrium relationship. The null hypothesis in the equation is $a_{8}=a_{9}=a_{10}=a_{11}=a_{12}=a_{13}=a_{14}=0$ which means the non-existence of the equilibrium relationship.

In order to determine the time series properties of the variables and to avoid the problem of spurious regression, the data was subjected to Augmented Dickey-Fuller (ADF) Unit Root Test (Dickey and Fuller 1979). As a preliminary step in ARDL/Bound testing, the Augmented Dickey Fully Unit root test was employed to confirm the order of integration of the time series variables. This is necessary because the presence of an order of integration higher than I(1) such as I(2) will invalidate the use of Pesaran and Shin (1999) computed Fstatistics which is based on the assumption that the underlying variables must be either $\mathrm{I}(0)$ or $\mathrm{I}(1)$ or mutually integrated.

\section{Results and Discussion}

The descriptive statistics was employed to analyze the trends of monetary, fiscal policies and inflation in Nigeria as analyzed below:

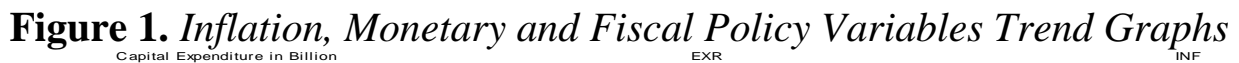
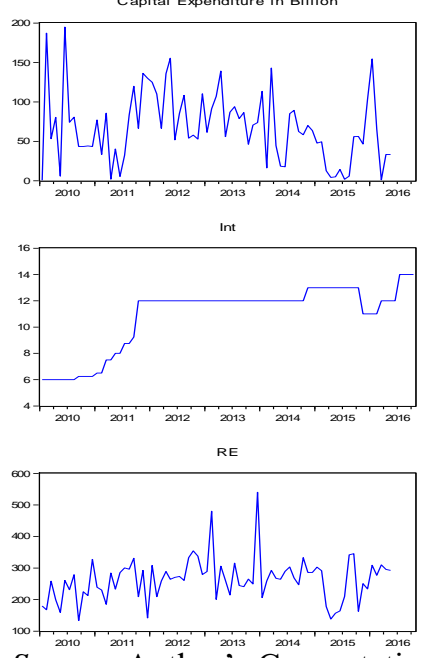

Source: Author's Computation (2017).
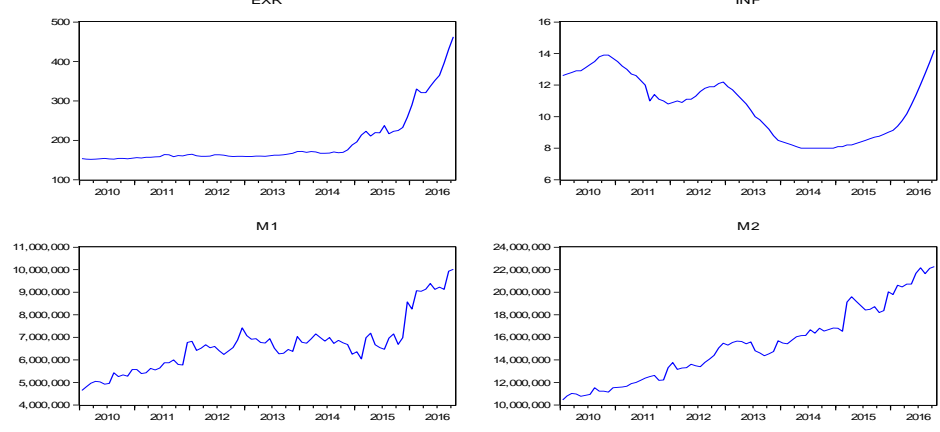

The above charts revealed the trend of inflation rate from January, 2010 to October, 2016. The graph showed that inflation rate was high in 2010 and 
increased to $14 \%$ and dropped in 2011 to $11 \%$ and later increased a little bit in 2012. It showed from the graph that the inflation rate was drastically reduced to low level of $8 \%$ in 2014 but gradually increased to $14 \%$ in 2016.

The trend of interest rate in Nigeria during the period under review showed that interest rate was not stable in 2010 and 2011. It was stable from 2012 to 2014 at $12 \%$. It was high and dropped in 2015 . The trend of exchange rate from January 2010 to October, 2016 revealed that the exchange rate was constant from 2010 to 2014 at the rate of one hundred and fifty naira to a dollar. A sharp increase occurred in 2015 and 2016 which implied that the value of naira to a dollar has increased which might be due to a change in policies and the fall in the price of crude oil in the international market. The graph above on Broad money (M1) indicated that amount of money and liquidity in the economy continued to increase from January 2010 to October, 2016 which might contribute to the inflation rate in the country. Narrow money (M2) showed that there has been continuous increase in the supply of currency with non-bank and demand deposit between the periods under review. Recurrent Expenditure revealed that recurrent expenditure was only increased in 2013. It was not stable and it experienced high and low between 2010 and 2016. Finally, capital expenditure showed that during the period under review was not stable. In 2010 it was increased and decreased in 2011. Since then, capital expenditure has been experienced high and low till 2016.

\section{Augmented Dickey Fuller Test (ADF) Unit Root}

The Augmented Dickey Fuller (ADF) unit root was employed to establish the stationarity of the variables. Also, the ARDL Bound Test was employed to test for the presence of long run relationship among the variables. Thereafter, the Autoregressive Distributed Lag (ARDL) was employed to test the short run and long run equilibrium of the variables

Table 1. Unit Root Results (2010:01-2016:10)

\begin{tabular}{|l|c|c|c|c|c|c|c|}
\hline Variables & \multicolumn{7}{|c|}{ Augmented Dickey Fuller Test } \\
\hline & $\begin{array}{c}\text { Level Form } \\
\text { intercept } \\
\text { no trend } \\
\text { intercept } \\
\text { or } \\
\text { constant }\end{array}$ & $\begin{array}{c}\text { With } \\
\text { intercept } \\
\text { and trend }\end{array}$ & $\begin{array}{c}\text { No intercept } \\
\text { no trend }\end{array}$ & $\begin{array}{c}\text { With } \\
\text { intercept or } \\
\text { constant }\end{array}$ & $\begin{array}{c}\text { With } \\
\text { intercept } \\
\text { and trend }\end{array}$ & \\
\hline LCE & -0.8384 & $-7.6840^{* *}$ & $-8.0429^{* *}$ & $-15.9112^{* *}$ & $-15.7923^{* *}$ & $-15.6558^{* *}$ & $\mathrm{I}(0)$ \\
\hline LEXR & 0.4542 & $4.9531^{* *}$ & 2.1854 & 2.7364 & $-6.2262^{* *}$ & $-7.4289^{* *}$ & $\mathrm{I}(0)$ \\
\hline LINT & 1.8507 & -1.8271 & -1.4166 & $-8.1712^{* *}$ & $-8.5340^{* *}$ & -8.6516 & $\mathrm{I}(1)$ \\
\hline LM1 & 1.7375 & -0.9111 & -2.3777 & $-9.8379^{* *}$ & $-10.1714^{* *}$ & $-10.1279^{* *}$ & $\mathrm{I}(1)$ \\
\hline LM2 & $2.9074^{* *}$ & -0.3625 & -3.5434 & $-8.5496^{* *}$ & $-9.3346^{* *}$ & $-9.2928^{* *}$ & $\mathrm{I}(0)$ \\
\hline LRE & 0.1960 & $-7.5187^{* *}$ & $-7.6046^{* *}$ & $-16.2631^{* *}$ & $-16.1693^{* *}$ & $-16.0698^{* *}$ & $\mathrm{I}(0)$ \\
\hline LINF & $4.9092^{* *}$ & -0.3580 & $-4.2533^{* *}$ & $-3.3430^{* *}$ & $-12.3668^{* *}$ & $-12.2811^{* *}$ & $\mathrm{I}(0)$ \\
\hline
\end{tabular}

Source: Author's Computation (2017).

**Significant at $1 \%$.

Model 1 (with no intercept \& trend) critical value at $1 \%=-2.5961$, $5 \%=1.9452,10 \%=-1.6139$. Model 2 (with constant only) critical value at $1 \%=$ $3.5191,5 \%=-2.900,10 \%=-2.5874$. Model 3: (with intercept and trend) at $1 \%=-$ $4.0834,5 \%=-3.4700,10 \%=-3.1620$. 
The result in Table 1 above showed that Capital Expenditure (CE), Recurrent Expenditure (RE), Exchange Rate (EXR), Broad Money Supply (M2) and inflation (INFL) were stationary at level, i.e., I(0) while Interest Rate (INT) and Narrow Money (M1) were stationary at first difference, i.e., I(1). This can be seen by comparing the observed values (in absolute terms) of the ADF test statistics at $1 \%, 5 \%$, and $10 \%$ levels of significance.

Table 2. 4.2 ARDL Bounds Test (for the Presence of Long Run Relationship)

\begin{tabular}{|l|c|c|}
\hline \multicolumn{3}{|l|}{ ARDL Bounds Test } \\
\hline \multicolumn{3}{|l|}{ Included observations: 71} \\
\hline Null Hypothesis: No long-run relationships exist \\
\hline Test Statistic & Value & $\mathrm{K}$ \\
\hline F-statistic & 8.381768 & 6 \\
\hline \multicolumn{3}{|c|}{ Critical Value Bounds } \\
\hline Significance & I0 Bound & I1 Bound \\
\hline $10 \%$ & 2.53 & 3.59 \\
\hline $5 \%$ & 2.87 & 4 \\
\hline $2.5 \%$ & 3.19 & 4.38 \\
\hline $1 \%$ & 3.6 & 4.9 \\
\hline
\end{tabular}

Source: Author's Computation (2017).

The above result in Table 2 showed that there is long run co-integration among variables since F-statistic is more than the upper bound value. This implies that collectively or jointly the independent variables are significant. Therefore, the study would need to proceed to short run relationship of the variables.

\section{The Error Correction Model Results}

The model in Table 3 above examined the impact of monetary and fiscal policies on inflation in Nigeria. It showed the results of the regression having logged all the independent variables involved. The adjusted $\mathrm{R}^{2}$ revealed that $99.6 \%$ of the total variation in the rate of inflation is occasioned by interest rate, broad money, narrow money, exchange rate, government recurrent expenditure and government capital expenditure. Similarly, there is trend among the variables which implies that an increase in the monetary and fiscal policies variables will increase inflation and vice-versa. The F-statistic is significant at $1 \%$ which is showing a general goodness of fit. The Durbin-Watson (DW) statistic has a value of 2.2748 which is more than the upper bound of DW critical value and it shows that there is serial correlation in the model. 
Table 3. ECM Results of Short Run Estimation using ARDL Approach (2010:012016:10)

\begin{tabular}{|c|c|c|c|c|}
\hline Variable & Coefficient & Standard Error & T-Statistic & Probability \\
\hline $\mathrm{C}$ & 1.573933 & 0.681918 & 2.308098 & 0.0252 \\
\hline DLOG(INT(-2)) & -0.076273 & 0.033455 & $-2.279896 * *$ & 0.0269 \\
\hline DLOG(M1) & 0.016502 & 0.031397 & 0.525595 & 0.6015 \\
\hline DLOG(M2) & 0.089096 & 0.049080 & $1.815322^{*}$ & 0.0755 \\
\hline $\begin{array}{l}\text { DLOG } \\
(\text { EXR }(-1))\end{array}$ & -0.080111 & 0.056028 & -1.429836 & 0.1590 \\
\hline DLOG(CE(-2)) & 0.002989 & 0.001459 & $2.048158^{* *}$ & 0.0458 \\
\hline DLOG(RE(-2)) & 0.012318 & 0.005652 & $2.179541 * *$ & 0.0340 \\
\hline D(@TREND ()$)$ & 0.004619 & 0.000775 & $5.962586^{* * * *}$ & 0.0000 \\
\hline $\operatorname{ECM}(-1)$ & -0.767320 & 0.101190 & $-7.5829 * * *$ & 0.0000 \\
\hline
\end{tabular}

In the above result, the Error Correction Model was used to determine the short run relationship between variables. The threshold for the ECM is that its coefficient must be less than one, negative and it must be significant. These three properties were met in this result because the coefficient of the ECM was -0.767 which was negative and less than one, using probability value of the ECM, it could be concluded that it is highly significant which implied that the other results obtained from the model could be used to establish the short run relationship between inflation and interest rate, narrow money, broad money, exchange rate, recurrent expenditure and capital expenditure. The coefficient also revealed that there was speed of adjustment between the short run and the long run realities of the monthly co-integrating variables.

From the results, narrow money, broad money, capital and recurrent expenditures have positive relationship with inflation while interest rate and exchange rate have negative relationship with inflation in the short run. The coefficient of broad money (M2) was significant at $10 \%$ and rejected the null hypothesis. The coefficient of interest rate (INT(-2)) is -0.076273 implying that a unit increase in interest rate (INT) lagged for two months would bring about $0.0758 \%$ decrease in inflation (INFL) in the short run. In the same vein, capital and recurrent expenditure were significant and have positive relationship to inflation rate in Nigeria. The null hypothesis is rejected since the variables are significant at 5 percent.

However, exchange rate and narrow money are insignificant in the short run and these imply that the variations with these variables cause no significant changes in inflation in the short run. The exchange rate is negatively related while narrow money is positively related. The explanatory variables have inelastic effect on inflation rate in Nigeria and show that a percentage change in them would bring or lead to a less than proportionate change in inflation in Nigeria. The relationship between inflation and broad money, narrow money, capital and recurrent expenditure are positive which is in line with a priori expectation. Interest and exchange rates are negatively related to inflation and it is against a priori expectation. This is similar to Nenbee and Madume (2011) which showed that 
monetary policy tools have mixed impact on inflation in Nigeria. The study, however, differs from that of Asuquo (2012) and ThankGod and Tamarauntari (2014), which revealed that money supply (M2) and interest rate had significant impact on inflation in Nigeria.

\section{Long Run Estimation using ARDL Approach}

Table 4. Long run Estimation using ARDL Approach (2010:01-2016:10)

\begin{tabular}{|l|c|c|c|c|}
\hline Variable & Coefficient & Standard Error & T-Statistic & Probability \\
\hline C & 2.051209 & 0.776543 & $2.641463^{*}$ & 0.0110 \\
\hline L(INT) & 0.018162 & 0.014805 & 1.226757 & 0.2257 \\
\hline LOG(M1) & 0.021506 & 0.040529 & 0.530638 & 0.5980 \\
\hline L(M2) & 0.116113 & 0.066140 & $1.755563^{*}$ & 0.0853 \\
\hline L(EXR) & 0.068243 & 0.029618 & $2.304120^{* *}$ & 0.0254 \\
\hline L(CE) & 0.012489 & 0.004126 & $3.027076^{* * *}$ & 0.0039 \\
\hline L(RE) & -0.002541 & 0.015213 & -0.166996 & 0.8680 \\
\hline @TREND & 0.006020 & 0.000445 & $13.513605^{* * *}$ & 0.0000 \\
\hline \multicolumn{4}{|l}{ Adjusted R ${ }^{2}=0.9963$ D.W. $=2.27$ F-st $=953.7$} \\
\hline
\end{tabular}

Source: Author's Computation, 2017.

***Significant at $1 \% * *$ Significant at $5 \% *$ Significant at $10 \%$.

The result in Table 4 showed the positive value of 2.05 as constant and regression intercept, the independent variables in the study positively affects the dependent variable at constant in the long run and thus conforms to a-priori expectation. Also, capital expenditure is significant at $1 \%$, exchange rate is significant at $5 \%$ and broad money is significant at $10 \%$. Whereas, interest rate, narrow money and recurrent expenditure are not significant and showed that the variations with these variables caused no significant changes in inflation in the long run. The capital expenditure, exchange rate and broad money have highly significant long run equilibrium relationship with inflation problem in Nigeria. A significant level at $1 \%$ level shows a relatively high significance level as compared to the significance at $5 \%$ and $10 \%$ level.

The estimated coefficients show a highly significant positive long term relationship between capital expenditure, exchange rate and broad money supply and inflation rate in Nigeria. A unit change in exchange rate would lead to $0.07 \%$ change in inflation. This shows that exchange rate could have long term effect on inflation in Nigeria. Also, a unit change in broad money supply would lead to $0.12 \%$ increase in inflation. This revealed that money supply in circulation would increase inflation in the long run. The two monetary variables revealed in this study that monetary policy has positive and significant influence on inflation in Nigeria. However, interest rate and narrow money are positively related to inflation though is insignificant in the long run in relation to inflation.

The result conforms to the a-priori expectation which states that interest rate, narrow money, broad money, exchange rate, capital expenditure and interest rate are greater than zero. Only recurrent expenditure is against the a priori expectation which is negatively related in the long run to inflation and is insignificant. 
Summarily, the study shows evidence of long run relationship among the variables. This is in confinement with the findings of Osuala and Jones (2014). Also, the result is in consonance with the study of Gbadebo and Mohammed (2015) in their study titled "Monetary Policy and Inflation Control in Nigeria which concluded that exchange rate and money supply have much long run impact on inflation.

Table 5. Post-Estimation Results (2010:01-2016:10)

\begin{tabular}{|l|c|c|}
\hline Test & Model & Decision \\
\hline ARCH-LM & 0.0357 & \\
(Heteroscedasticity) & $(0.8501)$ & Accept $\mathrm{H}_{0}$ \\
\hline Jarque-Bera & $\begin{array}{c}4.27 \\
(0.147)\end{array}$ & Accept $\mathrm{H}_{0}$ \\
(Normality test) & $\begin{array}{c}4.42 \\
(0.1096)\end{array}$ & Accept $\mathrm{H}_{0}$ \\
\hline $\begin{array}{l}\text { Breusch Godfrey LM } \\
\text { (Serial correlation) }\end{array}$ & $\begin{array}{l}2.9324 \\
(0.931)\end{array}$ & Accept $\mathrm{H}_{0}$ \\
\hline Ramsey Reset & & \\
(Linearity test) & & \\
\hline
\end{tabular}

Source: Author's Computation (2017).

Table 5 shows that the estimated models satisfied all the assumptions of the OLS Regression Model and the estimates obtained were reliable, suitable for forecasting and predictions. The results also indicated that there is no evidence of heteroscedasticity since the errors has constant variance, therefore null hypothesis of homoscedasticity was accepted at $5 \%$ level of significance. The error series was also normally distributed, i.e., well behaved as shown by the Jarque-Berra test. The null hypothesis was accepted because the probability value was greater than $5 \%$ level of significance. Breusch-Godfrey LM test was also adopted to determine if the error series was auto-correlated and the null hypothesis of "no autocorrelation was accepted" since the probability value was greater than $5 \%$ level of significance. Similarly, Ramsey Reset was used to test for the linearity of the model and therefore, the $\mathrm{H}_{0}$ was accepted and showed that the model was linear.

\section{Discussion of Findings}

This study investigated the impact of monetary and fiscal policies on inflation in Nigeria. The results showed that capital expenditure, recurrent expenditure, exchange rate and broad money supply were stationary at levels, I $(0)$ while interest rate and narrow money were stationary at the first difference, I(1). The study has been able to find out that there have been fluctuations in the trend of policy variables in Nigeria (i.e., interest rate, exchange rate, narrow money, broad money, government expenditure and capital expenditure). This implied that an increase in the monetary and fiscal policies variables would increase inflation and vice-versa. The study examined the short run and long run relationship between inflation and fiscal and monetary variables. It was observed that broad money supply (M2) and capital expenditure (CE) were significant and positively related both in the short and long run to inflation in Nigeria. Exchange rate was significant and positively 
related to inflation in the long run but not significant and was negatively related in the short run. Interest rate was significant and negatively related in the short run but not significant in the long-run but positively related to inflation. Narrow money was not significant in the short and long run albeit it has a positive relationship with inflation. Finally, recurrent expenditure was significant and positively related in the short run but not significant and has negative relationship to inflation in the long run.

\section{Conclusions and Policy Recommendations}

In the study, the short run and long run relationships between monetary and fiscal variables with inflation rate were examined in Nigeria. The empirical findings showed that the relationship between inflation and most of the macroeconomic variables were statistically significant. Broad money and capital expenditure were positively related and significant in the short and long run to inflation in Nigeria. The study resolved that there is evidence of long run relationship among variables and revealed that monetary and fiscal policies have long term effect on inflation in Nigeria during the period under review. Therefore, the study concludes that monetary and fiscal policies have significant relationship with inflation problem in Nigeria. This leads to rejecting the null hypothesis of this study which states that there is no significant relationship between monetary and fiscal policies and inflation problem in Nigeria. This study's conclusion is similar to the submission of Gbadebo and Mohammed (2015) which concluded that monetary variables have significant impact on inflation control in Nigeria. The study negates the study of Adigwe et al. (2015) which states that broad money has insignificant influence on inflation in Nigeria. From the findings of this study, it is recommended that:

i. Monetary and fiscal policies should be harnessed, coordinated and sustained with the help of Central Bank of Nigeria in order to enhance the welfare of the citizenry.

ii. The monetary authority should device improved measures of managing the monetary policy in order to achieve price stability. The gap between monetary policy formulation and implementation should be bridged. The non-significance of some of the monetary policy and fiscal policy instruments in the long run is an evidence of a gap between formulation and implementation in Nigeria. Therefore, the implementation mechanism of monetary policy should be checked for effective control of inflation in Nigeria.

iii. Contractionary monetary policy should be implemented to constraint excess money in circulation to achieve low inflationary rate. In addition, monetary policy instruments should be applied properly and timely to put inflation at a permissible level.

iv. Nigerian government should endeavour to ensure exchange stability in order to control inflation in Nigeria. Over reliance on foreign products should be 
discouraged by stimulating the productive capacity of the economy particularly in the agricultural sector to increase aggregate supply of food products which has the tendency to reduce inflation rate in the country drastically.

\section{References}

Abata MA, Kehinde JS, Bolarinwa SA (2012) Fiscal, monetary policy and economic growth in Nigeria: A theoretical exploration, International Journal of Academic Research in Economics and Management Sciences 1(5): 75-88.

Adigwe PK, Echekoba FN, Onyeagba JBC (2015) Monetary policy and economic growth in Nigeria: A critical evaluation. IOSR Journal of Business and Management 17(2): 110-119.

Asuquo A (2012) Inflation accounting and control through monetary policy measures in Nigeria: Multi-regression analysis (1973-2010). IOSR Journal of Business and Management 1(2): 53-62.

Balami DA, Ahmed FF, Yusuf AB (2016) Impact of monetary policy in Nigeria on inflation, exchange rate and economic growth. International Journal of Economic and Business Management 2(5): 67-82.

CBN (1992) Monetary Policy Department. Central Bank of Nigeria Statistical Bulletin for several issues. Available at:http//www.cenbank.org/.

Central Bank of Nigeria (CBN) (2009) Annual Economic Report, Central Bank of Nigeria, Abuja. Available at: http//www.cenbank.org/.

Dickey DA, Fuller WA (1979) 'Distribution of the Estimators for Autoregressive Time Series with a Unit Root'. Journal of the American Statistical Association 74: 427431.

Gbadebo AD, Mohammed N (2015) Monetary policy and inflation control in Nigeria. Journal of Economics and Sustainable Development 6(8): 108-116.

Ggor ML (2011) The global monetary shocks and inflation in developing Economy. International Journal of Economic Management 41(26): 186-217.

Kareem RO, Afolabi AJ, Raheem KA, Bashir NO (2013) Analysis of fiscal and monetary policies on economic growth: Evidence from Nigerian democracy. Current research Journal of Economic Theory 5(1): 11-19.

Musa Y, Asare BK, Gulumbe SU (2013) Effect of monetary-fiscal policies interaction on price and output growth in Nigeria. CBN Journal of Applied Statistics 4(1): 55-73.

Nathan PA (2012) The impact of fiscal policy on the Nigerian economy. International Review of Social Sciences and Humanities 4(1): 142-150.

Nenbee SG, Madume PN (2011) Econometric analysis of the impact of fiscal policy variables on Nigeria's economic growth (1970-2009). International Journal of Economic Development, Research and Investment 2(1): 171-183.

Nwoko NM, Ihemeje JC, Anumadu E (2016) The impact of monetary policy on the economic growth of Nigeria. African Research Review: An International Multidisciplinary Journal, Ethiopia 10(3): 192-206.

Osuala AE, Jones E (2014) Empirical analysis of the impact of fiscal policy on economic growth in Nigeria. International Journal of Economic and Finance 16(6): 203-211.

Pesaran MH, Shin Y (1999) "An Autoregressive Distributed Lag Modelling Approach to Cointegration Analysis." In S. Strom (ed) Econometrics and Economic Theory in the 20th Century: The Ragnar Frisch Centennial Symposium. Cambridge University Press. 
ThankGod OA, Tamarauntari MK (2014) Monetary policy effectiveness, output growth and inflation in Nigeria. International Journal of Economics, Finance and Management 3(6): 301-307.

Udude CC (2014) Monetary policy and economic growth of Nigeria. Journal of Policy and Development Studies 9(1): 234-246. 